Illinois State University

ISU ReD: Research and eData

Theses and Dissertations

$11-9-2015$

\title{
Influence of Dietetic Internship Directors' Involvement with Research on the Research Curriculum in Dietetic Internship Programs
}

Amanda Margaret Bergschneider Newell

Illinois State University, anewell@bradley.edu

Follow this and additional works at: https://ir.library.illinoisstate.edu/etd

Part of the Educational Administration and Supervision Commons

\section{Recommended Citation}

Newell, Amanda Margaret Bergschneider, "Influence of Dietetic Internship Directors' Involvement with Research on the Research Curriculum in Dietetic Internship Programs" (2015). Theses and Dissertations. 533.

https://ir.library.illinoisstate.edu/etd/533

This Dissertation is brought to you for free and open access by ISU ReD: Research and eData. It has been accepted for inclusion in Theses and Dissertations by an authorized administrator of ISU ReD: Research and eData. For more information, please contact ISUReD@ilstu.edu. 


\title{
INFLUENCE OF DIETETIC INTERNSHIP DIRECTORS' INVOLVEMENT WITH RESEARCH ON THE RESEARCH CURRICULUM IN DIETETIC INTERNSHIP PROGRAMS
}

\author{
Amanda Margaret Bergschneider Newell
}

\section{Pages}

Research is considered to be at the foundation of the profession of dietetics. It is a required component of the dietetic curriculum and is especially important as a part of the dietetic internship (DI) process. However, there are increasing concerns that dietitians and dietetic educators are not actively involved with research. This disconnect is concerning; therefore, it was the catalyst for the present study. Though many factors likely contribute to this issue, a novel area of inquiry is the influence of the research experiences of DI Directors on the DI curriculum. The theory of experiential learning was utilized as the overarching framework of this study because the experiences DI Directors have with research likely influence the manner in which they manage the research curriculum within their DI programs. Specifically, the purpose of this study was to examine the relationship of the research involvement of DI Directors and their interpretation and implementation of a required research competency (CRD 1.5) for DI programs. 
This study utilized a cross-sectional, survey design, which consisted of DI Directors who manage ACEND-accredited DI programs $(\mathrm{n}=96)$. The present study was the first to exclusively survey this target population and topic. The findings demonstrated that participants lack research involvement, as evidenced by the majority of participants being classified into the lowest level of research involvement based upon the research continuum. Research involvement was most related to education/training, professional experience, and research experience. These findings are consistent with previous studies of other dietetic educators. Additionally, the data indicated that the research involvement of DI Directors influences both their interpretation and implementation of competency CRD 1.5. Discriminant analysis revealed that the predictors of level of research involvement differentiated significantly among the categories within interpretation and implementation of competency CRD 1.5. These results support the importance of experiential learning because they show that the research involvement of the participants in this study influenced their interpretation and implementation of CRD 1.5. The findings of this study could be used by DI Directors and other dietetic educators to inform curricular decisions that bridge the research-competency gap between curriculum and practice within dietetics.

KEYWORDS: Dietetics, Dietetic Internship Directors, Research, Research Continuum, Research Competency 


\section{INFLUENCE OF DIETETIC INTERNSHIP DIRECTORS' INVOLVEMENT WITH RESEARCH ON THE RESEARCH CURRICULUM IN DIETETIC INTERNSHIP PROGRAMS}

AMANDA MARGARET BERGSCHNEIDER NEWELL

A Dissertation Submitted in Partial Fulfillment of the Requirements for the Degree of DOCTOR OF PHILOSOPHY

Department of Educational Administration and Foundations

ILLINOIS STATE UNIVERSITY 
(C) 2016 Amanda Margaret Bergschneider Newell 


\section{INFLUENCE OF DIETETIC INTERNSHIP DIRECTORS' INVOLVEMENT WITH RESEARCH ON THE RESEARCH CURRICULUM IN DIETETIC INTERNSHIP PROGRAMS}

AMANDA MARGARET BERGSCHNEIDER NEWELL

COMMITTEE MEMBERS:

Wendy G. Troxel, Chair

Lydia Kyei-Blankson

Phyllis A. McCluskey-Titus

Julie Raeder Schumacher 


\section{ACKNOWLEDGMENTS}

I am blessed to have so many wonderful people in my life. I do not have the space to thank every person who has touched my life while I have been working on my doctorate. However, I would like to publicly thank several groups and individuals who have been instrumental to this endeavor. First, I would like to thank the faculty and staff of the EAF Department for welcoming me into the world of Higher Education Administration. I came to this program with little experience in this area, but I am leaving with a great understanding of our educational system. In addition to the faculty and staff, I would also like to thank my cohort classmates for all their comradery and support throughout our doctoral program. I truly appreciate your willingness to share your experiences during class; I learned so much from each of you. Thanks, and I wish you all the best of luck with your future endeavors!

A special thanks to my committee members who provided me with guidance, while allowing me to follow my interests. Thanks to Dr. Lydia Kyei-Blankson for being my methodologist. I truly admire your expertise! Thank you so much for all of your help and for being so prompt! Thanks to Dr. Phyllis McCluskey-Titus, who also served on my doctoral exam committee. I feel fortunate to have worked with you in many capacities during this program. I appreciate your ability to view concepts from many perspectives, and I know that your feedback made my work stronger and more robust. Thanks so much! Thanks to Dr. Julie Schumacher, who served as my content expert. I cannot thank you enough for your wonderful insight. I know you are busy and I appreciate you 
taking on this task. Thank you! I look forward to continuing our work together in the future. Lastly, I would like to thank Dr. Wendy Troxel, who served as my chair. I adored you from my first class with you and my admiration of you has only grown. You have the rare ability to challenge and inspire students, all while making us laugh. I aspire to be like you as an instructor and research mentor! I have enjoyed working so closely with you over the past few years, and I look forward to working on new projects together in the future. Thank you for everything; I truly appreciate it!

Thanks to all of the DI Directors who participated in my study. I appreciate that you were willing to take time out of your busy schedule to help me with my research. I would also like to thank my current and past colleagues at Bradley University, particularly those in the FCS Department, who have been my cheerleaders throughout this entire process. I appreciate all of the support! I cannot imagine working with a better group of people.

Finally, I must thank my family. I am eternally grateful for my parents, Joseph and Barbara Bergschneider, who have instilled in me the value of education and lifelong learning. It is their love, support, and encouragement that have provided me with the opportunities to fulfill my dreams in the academic arena as well as personally and professionally. Thank you for being such positive influences in all of our lives. By your examples, I know that with hard work and determination, anything is possible. From the bottom of my heart, thanks for everything! I love you both! A big thanks to my amazing siblings, Paul, Emily, Catherine, and Susan as well as the rest of my growing family. You each have touched my life in so many ways and you have all been so gracious when 
I have had to miss family events over the past few years. I am truly blessed to have you all in my life!

A special thanks certainly goes to my husband, Shaun, who has been most affected by my educational pursuits. Your unwavering support has been instrumental for me throughout my educational journey. You always stepped up when I was busy, and I cannot thank you enough for all of your help. I truly could not have done this without you! I am blessed to have you in my life. From the bottom of my heart, thank you, thank you, thank you! Last, but certainly not least, thanks to our wonderful son, Elliott, who was perfectly happy listening to me read my work to him, rather than baby books! You have brought much needed balance into my life. I love being your mom! I pray that I am able to foster your interests in life and provide you with the same love, support, and encouragement my parents have for me. Thanks so much, Shaun and Elliott! I love you both so much and I look forward to what the future holds for our family!

A. M. B. N. 


\section{CONTENTS}

Page

ACKNOWLEDGMENTS

CONTENTS

iv

TABLES viii

FIGURES $\quad$ X

CHAPTER

I. INTRODUCTION TO THE STUDY 1

Overview 1

Statement of the Problem 6

$\begin{array}{ll}\text { Purpose and Scope of the Study } & 7\end{array}$

Research Questions $\quad 8$

Theoretical Framework $\quad 8$

Significance of the Study $\quad 11$

$\begin{array}{ll}\text { Important Terms } & 12\end{array}$

Assumptions 15

Limitations $\quad 15$

Delimitations $\quad 15$

$\begin{array}{ll}\text { Summary } & 16\end{array}$

II. REVIEW OF RELATED LITERATURE 17

$\begin{array}{ll}\text { Introduction } & 17\end{array}$

$\begin{array}{ll}\text { Problem Statement } & 17\end{array}$

$\begin{array}{ll}\text { Professional Level } & 18\end{array}$

Historical Perspective $\quad 20$

Role of Research within Dietetics $\quad 22$

Research and Research Competence Defined 23

Summary 24

$\begin{array}{ll}\text { Educational Level } & 25\end{array}$ 
Accreditation

Competency-Based Education

Competence model

Experiential Learning

Issues within Dietetic Education

Inappropriate definitions of experience

Failure to provide holistic experiences

Program directors lack experience

Summary

Individual Level

Research Involvement Continuum Model

Research Involvement of Dietitians

Measurement of research involvement

Research Competence of Dietitians

60

Individuals Prefer Collaborations

64

DI Directors

65

Summary

Summary

III. METHODOLOGY AND PROCEDURES

Introduction

Problem Statement

Purpose of the Study

Research Questions

Participants

Ethical Considerations

Instruments

Section 1

Section 2

Section 3

Procedures 
$\begin{array}{ll}\text { Data Analysis } & 78\end{array}$

Research Question $1 \quad 78$

$\begin{array}{ll}\text { Research Question 2 } & 79\end{array}$

Research Question 3 $\quad 79$

Research Question $4 \quad 80$

Research Question $5 \quad 81$

Research Question $6 \quad 82$

$\begin{array}{ll}\text { Summary } & 83\end{array}$

IV. RESULTS AND ANALYSIS $\quad 84$

$\begin{array}{ll}\text { Introduction } & 84\end{array}$

$\begin{array}{ll}\text { Participant Profile } & 84\end{array}$

$\begin{array}{ll}\text { Results } & 90\end{array}$

Research Question $1 \quad 90$

Research Question $2 \quad 96$

Research Question $3 \quad 108$

Research Question 4

Research Question 5 122

$\begin{array}{ll}\text { Summary } & 126\end{array}$

V. SUMMARY, DISCUSSIONS, IMPLICATIONS, $\begin{array}{ll}\text { AND RECOMMENDATIONS } & 128\end{array}$

Introduction $\quad 128$

Purpose and Scope of the Study 128

Participants 129

Research Design and Methodology 130

Summary and Discussion of the Findings 131

Research Question 1

Research Question 2

Research Question $3 \quad 137$

Research Question $4 \quad 139$

Research Question 5

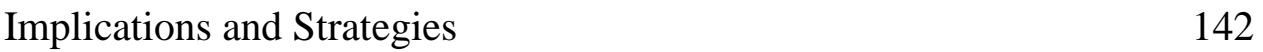

Research Question $6 \quad 142$

Research-competency gap 143

$\begin{array}{ll}\text { Strategies } & 146\end{array}$ 


\section{REFERENCES}




\section{TABLES}

Table

1. Participant Demographic Characteristics

2. Participant Educational Characteristics

3. Participant Research Experience

4. Institutional Characteristics

5. Corresponding Questions to Each Level on the RIQ

6. Frequencies and Means for RIQ Level 1 Items

7. Frequencies and Means for RIQ Level 2 Items

8. Frequencies and Means for RIQ Level 3 Items

9. Frequencies and Means for RIQ Level 4 Items

10. Descriptive Statistics for Summed RIQ Scores for Levels 1, 2, 3, 4, and Overall

11. Criteria for Assigning Participants to Research Involvement Continuum Level

12. Frequency of Participants into the Four Levels of the Research Involvement Continuum

13. Descriptive Statistics for RIQ by Participant Demographics

14. Descriptive Statistics by RIQ by Participant Education/Training and Professional Experience

15. Descriptive Statistics for RIQ by Participant Research Experience

16. Descriptive Statistics for RIQ by Institutional Characteristics 
17. Mean Research Involvement Score for Statistically Significant Variables in Education/Training and Professional Experience Categories per Research Involvement Level

18. Mean Research Involvement Score for Statistically Significant Variables in Research Experience Category per Research Involvement Level

19. Results from ANOVA for Overall RIQ and Sociodemographic, Education/Training, Professional Experience, Research Experience, and Employment Setting

20. Regression Analysis with One Variable for Education/Training, Professional Experience, and Research Experience as Predictors for Overall RIQ

21. Regression Analysis with Two Variables Each for Education/Training, Professional Experience, and Research Experience as Predictors for Overall RIQ

22. Frequency of Participant Interpretation of Competency CRD 1.5

23. Comparisons of Interpretation of Competency CRD 1.5

24. Frequencies of Experiences Aligned with Competency CRD 1.5

25. Criteria Utilized to Classify Implementation of Competency CRD 1.5 into Complete, Partial, or Failed Match

26. Breakdown of Participant Implementation of Competency CRD 1.5

27. Number of Implementation Options Selected by Participants

28. Comparisons of Implementation of Competency CRD 1.5

29. Standardized Coefficients and Correlations of Research Involvement Predictor Variables for Interpretation of Competency CRD 1.5

30. Breakdown of Modification of Participant Implementation of Competency CRD 1.5

31. Standardized Coefficients and Correlations of Research Involvement Predictor Variables for Implementation of Competency CRD 1.5 


\section{FIGURES}

Figure $\quad$ Page

1. Depiction of Research as the Foundation of the Dietetics Profession (Manore \& Myers, 2003, p. 111)

2. Cycle Perpetuating the Lack of Research Competence within Dietetics

3. Proposed Cycle to Help Close the Research-Competency Gap within Dietetics 


\section{CHAPTER I}

\section{INTRODUCTION TO THE STUDY}

\section{Overview}

Research has played an integral role in dietetics, as the profession was founded on the principles of science and inquiry (Cassell, 1990). The emphasis on research continues today through the research philosophy of the Academy of Nutrition and Dietetics, the largest organization for food and nutrition professionals. The research philosophy states that "dietetic professionals are responsible to incorporate research into all areas of practice" (Academy of Nutrition and Dietetics, 2016a, para. 3). In addition to helping the profession and community by advancing knowledge, research can also enhance the knowledge and skills of dietitians (Whelan \& Markless, 2012), because involvement in research has been shown to help improve transferrable skills, such as critical thinking, time management, and self-directed learning (Desbrow, Leveritt, Palmer, \& Hughes, 2014). Accordingly, the Accreditation Council for Education in Nutrition and Dietetics (ACEND) has identified research as a core competency for registered dietitians, and it is included into the ACEND-required curriculum of dietetic internship (DI) programs (Accreditation Council for Education in Nutrition and Dietetics, 2016c).

Since research is at the foundation of dietetics, it seems as though dietetic students, dietetic educators, and dietetic professionals should be competent researchers; 
however, many studies have demonstrated that this is not necessarily the case (ByhamGray, Gilbride, Dixon, \& Stage, 2006; Dougherty, Burrowes, \& Hand, 2015; Eck et al., 1998; Gardner, Rall, \& Peterson, 2002; Guyer, Roht, Probart, \& Bobroff, 1993; Schiller, 1988; Schiller, Rudge, \& Ballinger, 1988; Slawson, Clemens, \& Bol, 2000; Wylie-Rosett, Wheeler, Krueger, \& Halford, 1990). Specifically, dietitians and dietetic educators have been shown to lack the knowledge and skills needed to conduct research (Byham-Gray et al., 2006; Chrencik, Xu, Neal, \& Steiber, 2008; Dougherty et al., 2015; Gardner et al., 2002; Guyer et al., 1993; Schiller et al., 1988; Slawson et al., 2000). Additionally, a lack of confidence in research skills has been reported among dietetic professionals (Guyer et al., 1993; Wylie-Rosett et al., 1990). Thus, there is a clear disconnect between the expectations and reality of the research skills of dietetic professionals. Though there are many factors that might contribute to this gap, one important area of inquiry that has not been investigated is the influence of dietetic internship directors (DI Directors) on the research curriculum within DI programs.

DI Directors are key stakeholders to this issue because these individuals are "responsible for assuring that all ACEND accreditation standards, policies and procedures will be met" (Accreditation Council for Education in Nutrition and Dietetics, 2016c, p. 34). Of course, this does not have to be done in isolation, as it "can be achieved by managing or overseeing other individuals assigned to complete ACEND-required tasks" (Accreditation Council for Education in Nutrition and Dietetics, 2016c, p. 34). ACEND supports the utilization of both internal and external constituents; however, the DI Director is ultimately responsible for the program. In fact, the DI Director "must have the authority, responsibility and sufficient time allocated to manage [their program]" 
(Accreditation Council for Education in Nutrition and Dietetics, 2016c, p. 34). Thus, DI Directors are critical to the success of DI programs.

It should be noted that DI programs are different than traditional internships. First of all, DIs can be housed in a variety of settings, such as governmental agencies, hospitals, industry, universities, and university-based hospitals, but they must comply with ACEND. Furthermore, DIs are highly competitive, post-baccalaureate programs that meet all requirements of ACEND, including the minimum of 1200 hours of supervised practice (Accreditation Council for Education in Nutrition and Dietetics, 2015). Individuals who aspire to become dietitians must complete the supervised practice in order to sit for the required, national registration exam (Accreditation Council for Education in Nutrition and Dietetics, 2015). Although the supervised practice can be met through a few different means, such as a Coordinated Program in Dietetics or an Individualized Supervised Practice Pathway, the DI is the most common, which is why it is the focus of this paper.

As with any accrediting body, ACEND has specific requirements to help ensure adequately prepared students. An essential component of the DI curriculum is ACENDs Core Knowledge and Competencies, which are categorized into four separate domains (Accreditation Council for Education in Nutrition and Dietetics, 2016c). The first domain relates to research, which is the crux of the present study. There are five competencies within this domain, but one competency, CRD 1.5, is specific to the ability to conduct research (Accreditation Council for Education in Nutrition and Dietetics, 2016c), and it is the only competency that is utilized in this study. Specifically, this competency states that students must be able to "conduct projects using appropriate 
research methods, ethical procedures and data analysis" (Accreditation Council for Education in Nutrition and Dietetics, 2016c, p. 54).

As previously discussed, the DI Director is responsible for complying with all ACEND requirements, which includes the alignment of meaningful learning experiences to each competency. Though the DI Director may receive input from other constituents, the DI Director is the gatekeeper of the curricular plan. The DI curriculum must be designed to ensure the competencies are met within the DI program, which utilize experiential learning in the form of supervised practice.

The theory of experiential learning proposes that educators should serve as a guide to ensure the experience is purposeful and structured (Dewey, 1938; Joplin, 1981; Kolb, 1984; Mazurkewicz, Harder, \& Roberts, 2012), and this is one of the many roles of DI Directors. Experiences that are aligned with competency CRD 1.5 must be meaningful and contribute to learning. The inclusion of intentional and purposeful experiences in research has been shown to have positive benefits for dietetic students (Hays \& Peterson, 2003; Peterson, Hays-Kimmons, \& Cole, 2008; Rebovich, Wodarski, Hurley, Rasor-Greenhalgh, \& Stombaugh, 1994; Steiber \& Barkoukis, 2006; Whelan, Thomas, \& Madden, 2007b). On the other hand, the omission of these purposeful and meaningful experiences might make it seem like learning is occurring when it is not. For example, many educators assume that exposure to an experience equates to learning (Gates \& Sandoval, 1998; Gilboy, Harris, \& Lazarow, 2010; Knoblock-Hahn, Scharff, \& Elliott, 2010). Studies have shown that dietetic educators report that exposure is adequate to meet specific competencies in research (Fitz \& Winkler, 1989), public policy (Gilboy et al., 2010), and cultural competence (Knoblock-Hahn et al., 2010). Though 
these are not all research-based competencies, taken together, these studies suggest that there is a trend that dietetic educators utilize inappropriate learning methods or inappropriate experiences to meet competencies.

As previously mentioned, DI Directors play a pivotal role in aligning experiences with competency CRD 1.5, which is the competency that is the focus of the present study. According to the theory of experiential learning, learners must experience something before they can truly learn about it (Dewey, 1938; Joplin, 1981; Kolb, 1984). Using this theory as an underlying framework, it is expected that the experiences DI Directors have with research influences their approach in providing research experiences to their interns, which is the premise of the present study.

The literature is clear that dietetic educational programs are required to include research as a competency, yet dietitians and dietetic educators are not necessarily competent in this skill. Of course, the specific competencies have changed over the years, but the principle that research is at the foundation of dietetics has remained. The lack of research involvement among dietetic professionals is concerning (Dougherty et al., 2015). This study aims to help close the gap between the research competence at the educational level and the research competence at the professional level by assessing the influence of DI Directors. DI Directors are a novel population for inquiry into this topic because little is known about their influence on competency CRD 1.5. The dietetic profession touts research, but it is imperative to know what potentially influences competency CRD 1.5 in DI programs. 


\section{Statement of the Problem}

The Academy of Nutrition and Dietetics advocates the importance of research for the profession of dietetics; however, the lack of research involvement among dietitians and dietetic educators has been well-established (Byham-Gray et al., 2006; Eck et al., 1998; Gardner et al., 2002; Guyer et al., 1993; Schiller, 1988; Schiller et al., 1988; Slawson et al., 2000; Whelan \& Markless, 2012). Research plays many roles within dietetics, including creating a foundation of evidence-based knowledge, improving patient care, saving money, enhancing the skills of dietitians (Whelan \& Markless, 2012), as well as helping with insurance reimbursement issues (Dougherty et al., 2015; Kicklighter, Cluskey, Hunter, Nyland, \& Spear, 2013). Dietitians have been shown to have an interest in research (Anchondo, Campbell, \& Zoellner, 2014; Byham-Gray et al., 2006; Dougherty et al., 2015; Whelan, Madden, \& Thomas, 2007a), but an interest in research does not translate into research competence. Dietitians may know that research is needed, but they must be equipped with the knowledge, skills, and environment to take part in the process. Studies have shown that dietitians lack the knowledge and skills (Byham-Gray et al., 2006; Chrencik et al., 2008; Dougherty et al., 2015; Gardner et al., 2002; Guyer et al., 1993; Schiller et al., 1988; Slawson et al., 2000), confidence (Guyer et al., 1993; Wylie-Rosett et al., 1990), and support (Anchondo et al., 2014; Dougherty et al., 2015; Eck et al., 1998; Gardner et al., 2002; Schiller et al., 1988; Slawson et al., 2000) to conduct research, even though research is described as being at the core of dietetics. Competence in research is a required part of the DI curriculum, which should be centered upon the principles of experiential learning in the form of supervised practice, as these terms are synonymous per ACEND (Accreditation Council for 
Education in Nutrition and Dietetics, 2016c).

DI programs must provide research experiences to dietetic interns to ensure they meet competency CRD 1.5. However, the types of experiences that lead to competence are at the discretion of the individual programs. DI Directors are responsible for aligning experiences with all ACEND-required competencies. Therefore, the experience and involvement DI Directors have with research will likely influence their approach to meeting competency CRD 1.5. This can serve to strengthen or hinder the research capabilities of future dietitians.

Previous research has investigated factors that influence the research involvement of dietitians (Byham-Gray et al., 2006; Whelan \& Markless, 2012), but none have looked exclusively at DI Directors. The present study sought to explore the influence the research involvement of DI Directors has on their interpretation and implementation of competency CRD 1.5 for DI programs. Clearly, there is gap between the dietetic professions' desire for research skills and the actual research competence of dietitians. Furthermore, there is a gap in the literature on the impact of the DI Directors' influence on competency CRD 1.5. The present study aimed to extend previous studies on the lack of research involvement of dietitians by narrowing in on the influence of the DI Directors. Dietetic educators will be able to use this information to make curricular decisions that better align with the overall goals of the profession and to provide experiences that will actually promote research competence.

\section{Purpose and Scope of the Study}

The purpose of this study was to examine the relationship of the research involvement of DI Directors and their interpretation and implementation of competency 
CRD 1.5 for DI programs. This study sought to investigate the influence of DI Directors' experience with research and how it affects the manner in which they manage their DI program as it relates to competency CRD 1.5, using experiential learning as the overarching framework.

\section{Research Questions}

The following research questions were used in this study.

1. Where do DI Directors fall on the research involvement continuum as defined by the Research Involvement Questionnaire?

2. What types of factors influence DI Directors' involvement with research?

3. How do DI Directors interpret competency CRD 1.5?

4. What types of learning experiences are DIs using to fulfill competency CRD $1.5 ?$

5. What is the relationship of the research involvement of DI Directors and their interpretation and implementation of competency CRD 1.5?

6. What are the curricular/professional implications for utilizing experiential learning for competency CRD 1.5 in DI programs and how might this affect the profession as a whole?

\section{Theoretical Framework}

Merriam (2009) describes a theoretical framework as "the underlying structure, the scaffolding or frame of your study" (p. 66). The framework is the lens through which the entire study should be viewed, including design, implementation, and analysis. In a quantitative study, theory should be used deductively (Creswell, 2009); thus, the theoretical framework for this study was identified prior to data collection. 
The present study was conducted using experiential learning as the theoretical framework. Experiential learning is an educational theory that emphasizes the importance of experience in the learning process (Dewey, 1938; Kolb, 1984). In fact, according to Kolb (1984), learning is defined as "the process whereby knowledge is created through the transformation of experience" (p. 38). Thus, learning cannot occur without experience, though experience can occur without learning (Dewey, 1938; Joplin, 1981; Kolb, 1984; Mazurkewicz et al., 2012; Roberts, 2006).

Experiential learning can occur in many mediums, but the two that are seemingly the most common are practicums and internships (Eyler, 2009). Both of these experiences are directed and supervised by faculty or staff and they include an active learning component, which are all essential features of experiential learning. DI programs are not structured like typical internships, as they are competitive, postbaccalaureate programs, similar to a medical residency. However, the emphasis on experiential learning is evident within the accreditation standards set by ACEND. The goal is for students to gain greater levels of knowledge and skills than can be accomplished strictly in the undergraduate didactic program in dietetics. Entry-level dietitians reported that they learned more during the DI than during the undergraduate didactic portion of their education (Barr, Walters, \& Hagan, 2002). Though it is important to understand the perception students have about their educational preparation, it may not truly reflect reality. Regardless of student perception, it is well-documented that students do learn from their experiences (Dewey, 1938; Furman \& Sibthorp, 2013; Green \& Halloway, 2006; Kolb, 1984; Mazurkewicz et al., 2012), but the experiences must be meaningful, and educators play a vital role in this process. 
Although experiential learning can be transformational, it must be carefully constructed (Dewey, 1938; Kolb, 1984). Learning does not simply occur from exposure to various experiences. In fact, a classic quote by Dewey highlights this concept. He argues that the "belief that all genuine education comes about through experience does not mean that all experiences are genuinely or equally educative" (Dewey, 1938, p. 25). Many educators fail to align the experiences with the principles of experiential learning theory (Clark, Threeton, \& Ewing, 2010). The curriculum must be purposeful and directed by educators (Mazurkewicz et al., 2012). It is not sufficient for students to simply participate in an experience (Dewey, 1938; Kolb, 1984).

By using experiential learning as a framework, this study sought to examine the influence of DI Directors' experience with research and how it affects the manner in which they manage their DI program as it relates to competency CRD 1.5. A persistent issue within the dietetic profession is that despite efforts to improve the research skills of dietitians, studies indicate that dietitians lack the knowledge (Byham-Gray et al., 2006; Gardner et al., 2002; Slawson et al., 2000) and skills (Byham-Gray et al., 2006; Eck et al., 1998; Guyer et al., 1993) to conduct research. Dietetic education has not changed much since 1928 (Skipper \& Lewis, 2005); therefore, DI Directors may not have gained ample experience in research. However, they are expected to ensure meaningful experiences for their dietetic interns. This disconnect might serve to perpetuate the cycle of dietitians lacking research knowledge and skills even though research is supposed to be embedded throughout education and practice. This might contribute to a deficient research curriculum in DI programs, which could create dietetic interns and, eventually dietitians who lack these same skills. DIs are designed to include experiential learning, but the 
extent to which this occurs for research projects is not known. The purpose of this study was to examine the influence of DI Directors' experience with research and how it affects the manner in which they manage their DI program as it relates to competency CRD 1.5, using experiential learning as a framework.

\section{Significance of the Study}

Research has been described as the "backbone" of the dietetics profession (Sims \& Simko, 1988; Smitherman \& Wyse, 1987). Therefore, it is embedded into dietetic education, specifically into the curriculum of DI programs, which have an emphasis on experiential learning. However, studies have shown that dietitians and dietetic educators have displayed a lack of knowledge and skills needed to conduct research (Byham-Gray et al., 2006; Chrencik et al., 2008; Gardner et al., 2002; Guyer et al., 1993; Schiller et al., 1988; Slawson et al., 2000) as well as a lack of confidence in their research competence (Guyer et al., 1993; Wylie-Rosett et al., 1990). This disconnect is concerning and warrants further investigation.

The present study aims to provide information that can be used to bridge the research-competency gap between curriculum and practice by investigating the influence the DI Directors' involvement with research has on the manner in which DI Directors interpret and implement competency CRD 1.5. To date, no studies have targeted the effect of the DI Directors' involvement with research on the research component of DI programs. The results of this study could be used by DI Directors and other dietetic educators to inform curricular decisions that may improve the link between research competency within DIs and research competency in the professional setting. Better alignment of this competency could serve to strengthen the dietetic profession. 


\section{Important Terms}

This study uses terms that have a specific meaning for dietetic professionals. In an attempt to clarify these terms, the definitions for each are presented in alphabetical order.

Academy of Nutrition and Dietetics (formerly the American Dietetic Association) is the largest professional organization for food and nutrition professionals. Approximately $70 \%$ of the 75,000 members are registered dietitians (Academy of Nutrition and Dietetics, 2016c).

Accreditation Council for Education in Nutrition and Dietetics (ACEND) (formerly the Commission on Accreditation for Dietetic Education) is the Academy of Nutrition and Dietetics' accrediting body for all dietetic education programs. ACEND is recognized by the United States Department of Education and is a member of the Association of Specialized and Professional Accreditors.

ACEND-required research competencies refers to the five competencies (CRD 1.1-CRD 1.5) that fall under domain one, which is classified as "scientific and evidence base of practice" of ACENDs required curriculum (Accreditation Council for Education in Nutrition and Dietetics, 2016c, p. 54). Competence in research must consist of activities that include "all components of the scientific method" (Accreditation Council for Education in Nutrition and Dietetics, 2016c, p. 54).

Commission on Dietetic Registration $(C D R)$ is the Academy of Nutrition and Dietetics' credentialing agency.

Competency is a "set of specific knowledge, skills and values; behaviors expected of a practitioner; and the minimum level of performance requiring speed and accuracy 
consistent with providing optimal service or care to patients or clients" (Accreditation Council for Education in Nutrition and Dietetics, 2016c, p. 74).

Competency CRD 1.5 refers to one of the required competencies for DI programs. It is considered a core competency for registered dietitians and it states that students must be able to "conduct projects using appropriate research methods, ethical procedures and data analysis" (Accreditation Council for Education in Nutrition and Dietetics, 2016c, p. 54).

Dietetic education programs refer to only those programs that meet the accreditation standards set by ACEND and those programs that fulfill the requirements for an individual to become a registered dietitian. These include didactic programs in dietetics, coordinated programs, and DI programs.

Dietetic educators are individuals who manage or assist with the development and implementation of ACEND-accredited dietetic education programs. These include program directors, faculty, and preceptors.

Dietetic internship (DI) is an "education program that provides at least 1200 hours of required supervised practice experiences to meet ACEND's competency requirements to become a registered dietitian" (Accreditation Council for Education in Nutrition and Dietetics, 2016c, p. 79). Upon successful completion of the internship, students are eligible to sit for the national registration exam.

Dietetic internship director (DI Director) is the individual who manages an ACEND-accredited DI and is responsible for ensuring all ACEND standards, policies, and procedures are met. 
Dietitians are professionals who have successfully completed the ACENDrequired dietetic education, have passed the national registration exam, and are credentialed by the Commission on Dietetic Registration. Other terms for a dietitian are registered dietitian $(\mathrm{RD})$ and registered dietitian/nutritionist (RDN).

Experiential learning is an "approach to learning that relies on students obtaining knowledge and skills through first hand observation, experience and experimentation" (Accreditation Council for Education in Nutrition and Dietetics, 2016c, p. 77).

Research is considered "a type of scholarship that systematically tests a hypothesis or theory in order to discover facts or reach conclusions" (Accreditation Council for Education in Nutrition and Dietetics, 2016c, p. 82).

Research involvement refers to the level at which participants' rate themselves on the research continuum. The four levels of the research continuum include practice, collaboration, participation, and leadership (Wylie-Rosett et al., 1990). The validated, research involvement questionnaire (RIQ) (Whelan, Copeland, Oladitan, Murrells, \& Gandy, 2013) was used to determine the involvement of the participants. Operationally, the research involvement of the participants refers to the total score on the RIQ.

Supervised-practice experience is defined as "planned learning experiences in which students/interns perform tasks over a defined period of time to integrate knowledge, skills and values in real-life situations to contribute to acquisition and mastery of practitioner competencies" (Accreditation Council for Education in Nutrition and Dietetics, 2016c, p. 83). DI programs are required to have a minimum of 1200 hours of supervised practice. 


\section{Assumptions}

Several assumptions were made throughout the development and implementation of this study. It was assumed that all participants represented the general population of DI Directors. It was also assumed that the DI Directors provided authentic answers to every question on the survey. Additionally, there was an underlying assumption that the survey questions were appropriate to generate data to effectively answer the research questions.

\section{Limitations}

An inherent limitation in survey research is the response rate. All DI Directors in the United States were contacted to participate in the study, but the professional obligation to participate in the study may not have been adequate to obtain a high response rate. Further, data were only collected from DI Directors and not other individuals who might also be involved with competency CRD 1.5. DI Directors are required to provide evidence of program assessment to ACEND, including the manner in which competencies are attained; thus, it was expected that these individuals had the ability to provide accurate information.

\section{Delimitations}

Delimitations of this study affected the generalizability of the results. The crosssectional design utilized in this study only gathered data at one point in time. Participants of the study might have had a greater interest in research, which might have influenced the data. The purpose of this study was to assess DI programs and not other programs that can lead to the dietetic registration exam, such as a coordinated program and individualized supervised practice pathways. Finally, the study was delimited to the 
concepts of interpretation and implementation as measured by the tool developed for the present study.

\section{Summary}

Research has been identified as a core competency for dietitians (Accreditation Council for Education in Nutrition and Dietetics, 2016c), but there is a substantial body of literature suggesting that dietitians and dietetic educators lack the necessary knowledge and skills to conduct research (Byham-Gray et al., 2006; Eck et al., 1998; Gardner et al., 2002; Guyer et al., 1993; Schiller, 1988; Schiller et al., 1988; Slawson et al., 2000; Wylie-Rosett et al., 1990). This indicates a trend that there is a mismatch regarding research competence between the educational level and the professional level. DI Directors are responsible for aligning experiences with competency CRD 1.5; therefore, they have significant influence on promoting or hindering research competence in dietetic interns, who are the future of the dietetic profession. Little research has been done with DI Directors, and no published studies to date have assessed the influence of their research involvement and experience with research on the manner in which they interpret and implement competency CRD 1.5. This study sought to fill this void in the literature. Accordingly, the next chapter will feature a review of the literature on this topic. 


\section{CHAPTER II}

\section{REVIEW OF RELATED LITERATURE}

\section{Introduction}

This chapter highlights the literature that was used as the foundation of this study. The literature revealed three areas that must be discussed in order to understand the importance of assessing the influence of DI Directors' experience with research and its potential to affect the manner in which they manage their DI program as it relates to competency CRD 1.5. Specifically, the literature review presents the literature on this topic at the professional level, educational level, and individual level.

\section{Problem Statement}

Research has been described as the foundation of the dietetics profession (Cassell, 1990), and it has been identified as a core competency for dietitians (Accreditation Council for Education in Nutrition and Dietetics, 2016c). Evidence suggests that many dietetic educators and dietitians lack the knowledge and skills necessary to conduct research (Byham-Gray et al., 2006; Eck et al., 1998; Gardner et al., 2002; Guyer et al., 1993; Schiller, 1988; Schiller et al., 1988; Slawson et al., 2000; Whelan \& Markless, 2012; Wylie-Rosett et al., 1990). Theoretically, competencies are beneficial, but having competencies within the dietetic curriculum does not always ensure competence within dietetic students (Fitz \& Winkler, 1989; Gilboy et al., 2010; Knoblock-Hahn et al., 2010). The curriculum must be carefully planned, which is the responsibility of the DI Director. Naturally, these individuals play a vital role in the research paradigm of the dietetic 
profession, but no study has investigated the role of DI Directors on this phenomenon. It is clear that there is a disconnect among the research competence at the professional level, educational level, and individual level and this study aims to help fill the void in the literature on this topic.

\section{Professional Level}

The Academy of Nutrition and Dietetics is projecting an excess demand of dietetic professionals through at least 2020 (Hooker, Williams, Papneja, Sen, \& Hogan, 2012). The most growth is expected to be in clinical nutrition (78\%), food and nutrition management (35\%), and community nutrition (34\%); while the least expected growth is anticipated to be consultation and business (28\%) and education and research (24\%) (Hooker et al., 2012). These projections are aligned with the percent of dietitians working in each area with clinical (56\%), food and nutrition management (12\%), community (11\%), consultation and business (8\%), and education and research (7\%) (Ward, 2012). Taken together, the data might seem to suggest that education and research are less important areas of dietetics, but it should be noted that these areas are critical to the success of the profession (Hand, 2014). Research has been described as the backbone (Sims \& Simko, 1988) and foundation (Cassell, 1990) of the profession of dietetics. As such, it is a part of the dietetic curriculum per the requirements of ACEND (Accreditation Council for Education in Nutrition and Dietetics, 2016b; Accreditation Council for Education in Nutrition and Dietetics, 2016c).

The link between the profession and research cannot be underscored. Figure 1 depicts the research model for dietetics, as originally created by the American Dietetic Association, which is now the Academy of Nutrition and Dietetics (Manore \& Myers, 
2003). Research is shown at the core of the profession, as all branches of dietetics are to utilize the principles of research. Dietetics "requires a broad theoretical and applied research base because it is the integration of several disciplines" (Gilbride \& ByhamGray, 2008, p. 441). The following section will discuss the historical perspective of research within the profession of dietetics.

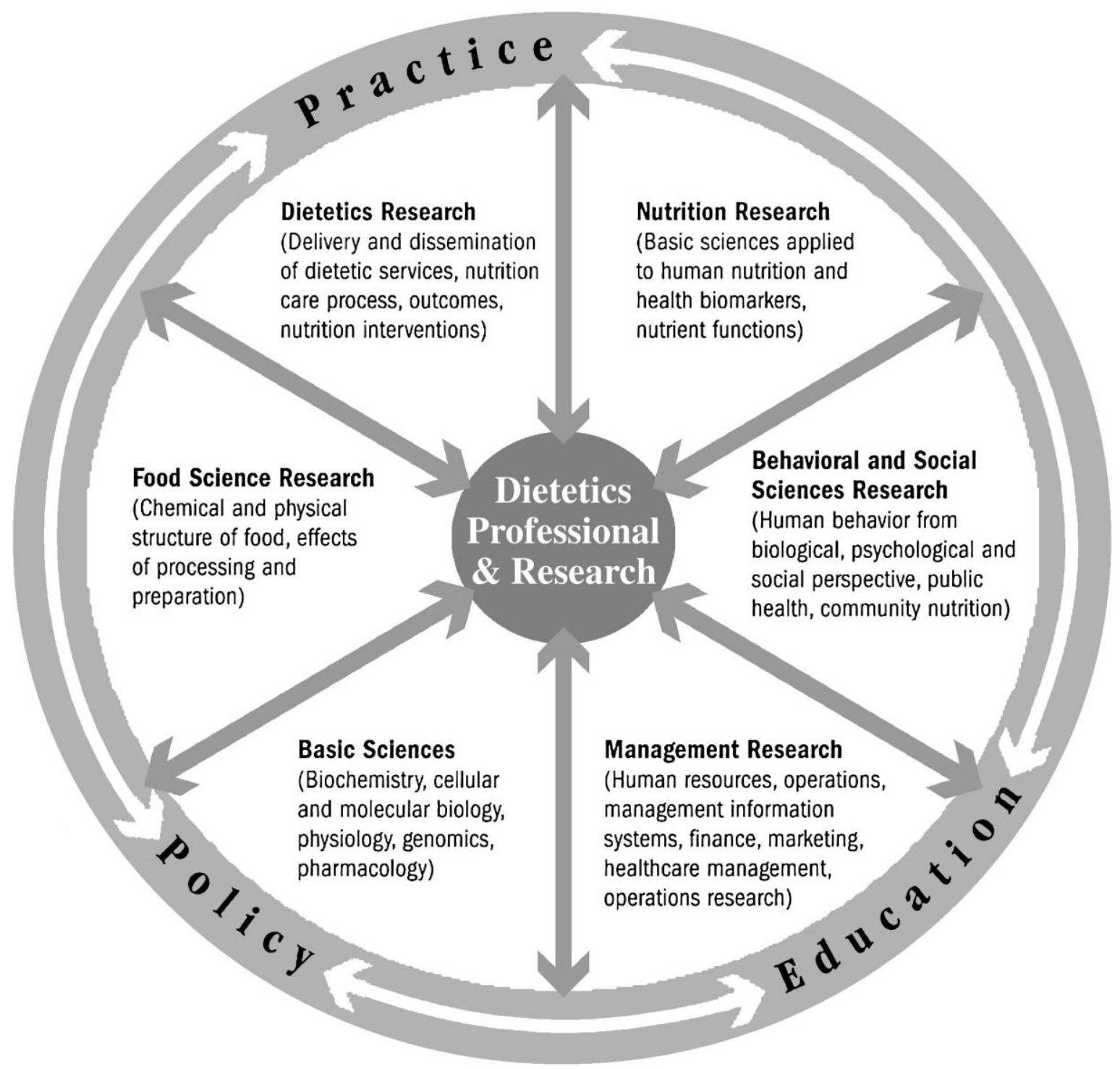

Figure 1. Depiction of Research as the Foundation of the Dietetics Profession (Manore \& Myers, 2003, p. 111). Used with permission. 


\section{Historical Perspective}

Though the profession of dietetics was born with the notion of research at the forefront, it took many years for this concept to be embedded into education and practice. In 1910, Florence Corbett, who was a pioneer within the profession, noted the importance of having science as the foundation for dietetic practice and training (Corbett, 1910). The first edition of the Journal of the American Dietetic Association was published in 1925, and it encouraged dietitians to participate in research (Guyer et al., 1993). However, it took until well into the mid- $20^{\text {th }}$ century before the profession took a deeper look at its research needs (Byham-Gray, 2004).

A critical development occurred with the 1972 Study Commission on Dietetics' Report identifying research as the greatest need of the profession (Byham-Gray, 2004; Sims \& Simko, 1988). Despite this progress, it took several years before any changes were actually made (Schiller, 1992). In response to this issue, the American Dietetic Association created the Council on Research and, in 1982, this group was charged with dealing with the research needs of the profession (Byham-Gray, 2004; King et al., 2014; Langholz, 1982). In particular, the Council on Research created a plan to ensure dietetic professionals were conducting research (Smitherman \& Wyse, 1987).

Movement starting taking place with the 1984 Study Commission on Dietetics as it was recognized that the profession needed more emphasis on research (Byham-Gray et al., 2006; Fitz \& Winkler, 1989; Sims \& Simko, 1988; Wylie-Rosett et al., 1990). One key area of development was with education (Rinke \& Berry, 1987), because it was determined that research was an essential skill for all entry-level dietitians (Wood, 1993). This shift placed additional responsibility on dietetic educators, particularly program 
directors (Byham-Gray, 2004), because they were, and continue to be, the gatekeepers between education and practice.

Since these early struggles, the concept of research in dietetics has become quite mainstream within the profession. In fact, the Academy of Nutrition and Dietetics has a research philosophy (Academy of Nutrition and Dietetics, 2016a). Other notable efforts include the establishment of research priorities in the early 2000s (Castellanos, Myers, \& Shanklin, 2004), the creation of the Dietetics Practice-Based Research Network in 2003 (King, 2013), the creation of the Evidence Analysis Library in 2004 (Pavlinac, 2010), and the development of an online research toolkit, as well as various Nutrition Care Manuals, which are available through the Academy of Nutrition and Dietetics. Further, research is mentioned in the Code of Ethics (Code of Ethics Task Force, 2009) and the Standards of Practice and Standards of Professional Performance (Academy Quality Management Committee and Scope of Practice Subcommittee of the Quality Management Committee, 2013). It is also listed as a core competency for DI programs (Accreditation Council for Education in Nutrition and Dietetics, 2016c), and this will be discussed in detail later in this chapter, as this is the focus of the present study.

Though the profession of dietetics has been described as being rooted in research, the journey to fully embed research into education and practice has been, and continues to be, a long one. Despite these efforts, many argue that dietetic professionals do not have adequate research skills (Byham-Gray et al., 2006; Eck et al., 1998; Gardner et al., 2002; Guyer et al., 1993; King et al., 2014; Schiller et al., 1988; Slawson et al., 2000), suggesting that research is not as ingrained within the profession as it is seemingly portrayed throughout the professional literature. 


\section{Role of Research within Dietetics}

It is important to understand the role that research plays within the profession, even if the literature suggests that the expectations and reality of research within dietetics are not necessarily congruent. The profession of dietetics is centered upon the utilization of research and sound science to make informed decisions (Byham-Gray et al., 2006; Vaughan, 2003). Research has many purposes within dietetics, but two that are particularly relevant to this discussion are to advance the profession and to protect the public.

Many health care professionals use evidence-based practice, which stems from research, to make informed decisions (Bennett, Hoffmann, \& Arkins, 2011; Thomas, Saroyan, \& Dauphinee, 2011). Evidence-based practice is defined as a systematic process that is based on evidence, professional expertise, and patient/client preferences and values, which is used to improve patient/client outcomes (Thomas et al., 2011). Research plays an essential role in this endeavor for dietetic professionals as it "allows us to move forward the profession and the provision of care in nutrition and dietetics as an evidence-based practice" (Hand, 2014, p. 134). This can simultaneously advance the profession and protect the public because these practices have been shown to strengthen the knowledge base (Manore \& Meyers, 2003; Whelan \& Markless, 2012), optimize outcomes (Byham-Gray, 2005; Taylor, 1998), help with insurance reimbursement (Byham-Gray, 2005; King et al., 2014; Smith, 2003), assist with setting policy (Manore \& Meyers, 2003), and provide a continuity of care (Taylor, 1998).

Research plays many roles within dietetics, with the ultimate goals of advancing the profession and protecting the public by providing quality care based upon research. 
The importance of research is highlighted within the dietetic curriculum, as it is a core competency for DI programs (Accreditation Council for Education in Nutrition and Dietetics, 2016c), but this does not mean that it is being effectively implemented within these programs or that the function of research within dietetics is being maximized. The literature indicates that the definition of what constitutes research for dietetic professionals, particularly research competence, varies widely. This issue is discussed next.

\section{Research and Research Competence Defined}

The profession of dietetics was established with research at its core (Cassell, 1990), and it continues to be described in this manner (Academy of Nutrition and Dietetics, 2016a). As previously mentioned, research is a core competency for dietitians (Accreditation Council for Education in Nutrition and Dietetics, 2016c); thus, it is expected that dietitians are competent in research upon completing their formal educational training. However, multiple studies have shown that some dietitians lack the necessary knowledge and skills to conduct research (Byham-Gray et al., 2006; Eck et al., 1998; Gardner et al., 2002; Guyer et al., 1993; King et al., 2014; Schiller, 1988; Schiller et al., 1988; Slawson et al., 2000; Wylie-Rosett et al., 1990). This suggests that there is a misalignment within the research competence at the professional level. Therefore, it is necessary to take a closer look at the manner in which these terms are used.

ACEND defines research as "a type of scholarship that systematically tests a hypothesis or theory in order to discover facts or reach conclusions" (Accreditation Council for Education in Nutrition and Dietetics, 2016c, p. 82) and competency as a "set of specific knowledge, skills and values; behaviors expected of a practitioner; and the 
minimum level of performance requiring speed and accuracy consistent with providing optimal service or care to patients or clients" (Accreditation Council for Education in Nutrition and Dietetics, 2016c, p. 74). Further, competency CRD 1.5 set by ACEND for DI programs states that students must be able to "conduct projects using appropriate research methods, ethical procedures and data analysis" (Accreditation Council for Education in Nutrition and Dietetics, 2016c, p. 54). The individual definitions of research, competency, and competency CRD 1.5 are needed to fully understand the holistic meaning of research competence for dietitians. This is critical for all dietetic professionals, but particularly with DI Directors, because they are responsible for establishing a curriculum that promotes competence. Despite specific definitions from within the profession, there seems to be multiple ways to understand research and competency CRD 1.5. This will be discussed in the third section of this chapter.

\section{Summary}

It is evident that dietetic educators, particularly DI Directors, are critical gatekeepers in this process. Specifically, they are responsible for providing a curriculum that enables students to obtain experiences in research that will foster the required level of research competence. Experiential learning theory, which is the theoretical framework of this study, suggests that the types of experiences DI Directors have with research will influence the research curriculum within their program. Since research is a core competency for DI programs, it is imperative to look at this issue from an educational standpoint, which is the focus of the next section of this paper. 


\section{Educational Level}

Dietetic education has remained relatively stagnant for nearly the past century (Skipper \& Lewis, 2005). The requirements for individuals who aspire to be dietitians are to complete an approved didactic program in dietetics, complete an approved supervised practice experience, pass a nationally registered examination, and maintain continuing educational requirements (Academy of Nutrition and Dietetics, 2016b). Additionally, the most recent discussions indicate that a master's degree will be required for entry into the profession (Kicklighter et al., 2013). The ultimate reason behind requiring a master's degree is to "have better-prepared dietitians" who will have "a greater level of skill to better protect the public" (Kicklighter et al., 2013, p. 1714). The details for this requirement have not been fleshed out by the profession at the time of this writing. However, since research has historically been embedded with all facets of dietetics (Cassell, 1990), it seems reasonable that research will play an integral role in this educational step within the profession. In fact, the Academy of Nutrition and Dietetics' most recent Visioning Report indicates that "graduate programs might require more research and therefore strengthen research efforts within the profession" (Kicklighter et al., 2013, p. 1714).

In recent years, many dietitians have been earning advanced degrees; in fact, the 2008 Needs Assessment for the profession indicated that $34 \%$ of dietitians have an advanced degree in dietetics, food, nutrition, or a related field and an additional 6\% have an advanced degree in a non-dietetic related field (Rogers, 2009). These numbers are encouraging, as it will likely ease the transition to a master's level profession. However, studies show that dietitians often lack research competence (Byham-Gray et al., 2006; 
Eck et al., 1998; Gardner et al., 2002; Guyer et al., 1993; King et al., 2014; Schiller, 1988; Schiller et al., 1988; Slawson et al., 2000; Wylie-Rosett et al., 1990). This means that the curriculum must be carefully constructed to ensure research is at the forefront. It is unknown at this time whether or not ACEND will play a role in this endeavor, but since the other educational tracks for dietetics are under ACEND's umbrella, it is possible that the graduate programs might be managed in the same manner. Regardless of the future of the master's degree, ACEND has already embedded research within each of the current required educational steps (Accreditation Council for Education in Nutrition and Dietetics, 2016b; Commission on Dietetic Registration, 2016b).

Despite all of these educational steps, there is a growing concern among dietetic educators that dietetic students are not as prepared for the workforce as previously thought (Commission on Accreditation for Dietetic Education, 2010). Research has been embedded into didactic programs in dietetics, supervised practice, the registration exam, and within continuing education, and it is expected that it will be included into the required master's degree. However, this is clearly not enough, as dietitians and dietetic educators have been shown to lack the knowledge (Byham-Gray et al., 2006; Chrencik et al., 2008; Gardner et al., 2002; Guyer et al., 1993; Schiller et al., 1988; Slawson et al., 2000), skills (Byham-Gray et al., 2006; Chrencik et al., 2008; Eck et al., 1998; Gardner et al., 2002; Guyer et al., 1993; Schiller et al., 1988; Slawson et al., 2000), and confidence (Guyer et al., 1993; Wylie-Rosett et al., 1990) needed to conduct research. Accreditation has played a vital role in the process of developing research skills among dietitians. 


\section{Accreditation}

Accreditation is a voluntary process for higher education institutions, but Ewell (2008) is critical of this classification because institutions or programs that are not accredited are limited. For instance, accreditation is mandatory for the dietetics profession as a student cannot sit for the required registration exam without completing an ACEND accredited didactic program in dietetics and an ACEND accredited supervised practice experience (Academy of Nutrition and Dietetics, 2016b). Thus, accreditation is the linchpin to the profession of dietetics through its role in dietetic education.

The accreditation requirements for DI programs focus on the basic structure of the curriculum and program, the mission and goals, the competencies, and the supervised practice component (Accreditation Council for Education in Nutrition and Dietetics, 2016c). Some requirements are established by ACEND, such as competency CRD 1.5, while others must originate from the individual program (Accreditation Council for Education in Nutrition and Dietetics, 2016c). This allows for standardization of the educational curriculum, while providing flexibility for DI Directors to utilize institutional and program strengths. This is in line with the literature, which demonstrates that educators should use accreditation standards as a guide (Brittingham, 2009; Ewell, 2008), but that the standards must also enable the educators to personalize their programs to meet the needs of their students (Carraccio, Englander, Adams, Giudice, \& Olsen, 2010). As such, it has been noted that accrediting bodies are an essential force to make changes to the education system, especially for many health care professions (Batalden, Leach, Swing, Dreyfus, \& Dreyfus, 2002). 
The shift toward accreditation of dietetic programs began in 1927 with the publication of the first standardized outline for dietetic education and training (Committee on Education, 1927). The goal of the 1927 standardized outline for dietetic education and training was to build credibility for the profession, as it would help to ensure practicing dietitians had met the minimum requirements set by the committee (Committee on Education, 1927). This help set the stage for more formal measures, such as accreditation. The profession recognized the need to ensure quality programs, but program accreditation did not occur until 1974 (Accreditation Council for Education in Nutrition and Dietetics, 2016a). This process took some time to gain traction; in fact, the requirement that all supervised practice programs must be accredited did not occur for nearly two decades after the establishment of accreditation at the professional level (Accreditation Council for Education in Nutrition and Dietetics, 2016a).

Critics have referred to accreditation as utilizing a reductionist approach, because the process often focuses on the individual pieces of the curriculum rather than the symbiotic relationship of the educational experience as a whole (Nasca, Philbert, Brigham, \& Flynn, 2012). It is possible for educators to lose sight of the purpose of accreditation, which is improving student learning, and to focus on the end result of receiving or maintaining accreditation status. Although accreditation is essential for dietetic programs, it should not be the main focus. Dietetic educators, in particular, must work to their strengths and the strengths of the program and institution to plan and implement a curriculum that meets or exceeds the accreditation requirements.

Though it is important to have a standardized curriculum, it is also important for accrediting bodies to regularly reevaluate and modify their requirements to ensure the 
curriculum is relevant to the current job market and within the dynamic nature of higher education. The dietetic profession has many ongoing studies in place that influence ACEND's requirements for the educational curriculum, such as role delineation studies and practice audits (Gregoire, Lafferty, \& Dowling, 2006), as well as the workforce demand study (Hooker et al., 2012), and the visioning report (Kicklighter et al., 2013). The results from these studies and reports are used to improve the dietetic curriculum and to help ensure entry-level dietitians are adequately trained, as improvement is a key feature to the accreditation process. Despite these efforts, there is a growing concern among dietetic educators that dietetic students are not as prepared for the workforce as previously thought (Commission on Accreditation for Dietetic Education, 2010). The educational approach that dietetics has used over the past few years is one that is centered upon the utilization of competencies, and this will be discussed in the following section.

\section{Competency-Based Education}

The overarching goal with using competencies during the assessment and accreditation process is to enforce the link between education and practice (Palomba \& Banta, 2001). It should be noted that this type of educational system is complex and requires careful attention to the curriculum (Palomba \& Banta, 2001). It is often assumed that "if all the inputs were of high quality and the rules were closely followed, then something of high quality would have to result" (Muffo, 2001, p. 161). Competencies should be used as the framework for the development and implementation of the curriculum (Baskind, Shank, \& Ferraro, 2001; Lurie, Mooney, \& Lyness, 2009). In fact, they were created in an effort to better prepare students for the workforce (Shafer \& Knous, 2001). 
Specifically related to dietetics, competency-based education provides a framework where the competencies guide the educational curriculum to ensure adequate preparation for entry-level dietitians (Cassell, 1990; Chambers, Gilmore, O'Sullivan Maillet, \& Mitchell, 1996; Gilmore, Maillet, \& Mitchell, 1997). Competencies became the norm within dietetic education in the mid-1990s due to the results of national survey data suggesting that certain skills were needed to enter the profession (Accreditation Council for Education in Nutrition and Dietetics, 2016a; Gilmore et al., 1997). An important feature to this type of educational system was defining "student learning outcomes as measurable behavior rather than as discipline content and then to modify instructional practice (usually time spend on a task) to bring students to a common acceptable standard of performance" (Chambers et al., 1996 p. 614). Though time is still a factor in this system, as ACEND requires a minimum of 1200 supervised practice hours for DI programs, the emphasis should be on the learning that occurs. Currently, ACEND defines a competency as a "set of specific knowledge, skills and values; behaviors expected of a practitioner; and the minimum level of performance requiring speed and accuracy consistent with providing optimal service or care to patients or clients" (Accreditation Council for Education in Nutrition and Dietetics, 2016c, p. 74).

ACEND regularly modifies the required competencies for all dietetic programs, and they have currently set 35 required competencies for DI programs, one of which is competency CRD 1.5 (Accreditation Council for Education in Nutrition and Dietetics, 2016c). These competencies form the scaffolding of the DI curriculum, and DI Directors are responsible for aligning meaningful experiences with the required competencies to better ensure graduates are ready for entry-level positions. 
It has been noted that $30 \%$ of dietitians reported that they had to perform competencies at a higher level than they were taught, while $16 \%$ reported using competencies at a lower level on the job compared to what they were taught in their dietetic education programs (Gilmore et al., 1997). Seventeen percent of dietetic educators identified that the challenges they encountered with dietetic interns were related to the performance of the interns, including lacking skills, lacking knowledge, and lacking critical thinking skills (Lordly, 2007). More recently, the 2010 CDR practice audit indicated that entry-level dietitians are not as involved in management or research nearly as much as nutrition care, despite all of these being CADE (now ACEND) required competencies (Ward, Rogers, Mueller, Touger-Decker \& Sauer, 2011). These results are concerning because they indicate that, despite the implementation of a competency-based educational model, dietitians have been shown to lack competence in some areas within dietetic education and the workforce.

Competency within dietetics has been described as the "midpoint on a continuum of professional growth that normally extends over 10 to 12 years" (Chambers et al., 1996, p. 615). Dietetic educators, particularly DI Directors due to the timing of the internship, play a critical role in this process; they must understand this educational model in order to develop and implement an effective curriculum that meets or exceeds accreditation standards. The competence model that is used in dietetic education is discussed in the subsequent section.

Competence model. There are several competence models, but one in particular pertains to dietetic education, despite the fact that it is not mentioned by name in the dietetic literature. The Dreyfus model, created by Stuart and Hubert Dreyfus, is one of 
the classic competency models commonly used in healthcare fields (Batalden et al., 2002; Benner, 2004; Markowitsch \& Luomi-Messerer, 2008; Ogrinc et al., 2003). It is a fivestage model of adult skill acquisition, which includes a continuum of competency that ranges from novice, advanced beginner, competence, proficiency, and expertise (Dreyfus, 2004).

Dreyfus (2004) described the five stages as increasing in the level of knowledge and skills. Specifically, they are described as follows: Stage 1-Novice: The instructor has to break everything down so the learner can get a basic understanding of the information and steps needed without needing any context. Rules are an essential part of this process because the learner is not able to distinguish anything on their own. However, simply following rules is not adequate, so the learner must then understand the context surrounding rules. Stage 2-Advanced Beginner: Once the learner knows the rules, they can begin to notice the exceptions to the rules. This allows the learner to understand the context and that simply following the rules is not enough. This is referred to this as a maxim. At this stage, learning is detached, and the learner is not able to fully understand the context. Stage 3-Competence: At this stage, the learner is recognizing more and more exceptions to the rules. This creates stress and overload because the learner feels the pressure to make the best decision based upon previous experiences. Learners must devise their own plan to accommodate for the exceptions. The learner tries to avoid mistakes by utilizing rules and reasoning to find the best plan of action. Unlike the previous stages, the learner feels responsibility for the outcome because he or she had to make it on their own. As a result, the learner becomes more emotionally involved in the task, which is necessary for growth. In the dietetic literature, this has been described as 
the stage where the learner becomes independent (Chambers et al., 1996). Stage $4-$ Proficiency: As the learner obtains more and more experiences, the learner will be able to further distinguish exceptions to the rules and methods to overcome these exceptions. However, at this stage the learner has not experienced enough to see every possible option, so they cannot have rules or maxims for every situation. Regardless, they have enough experience to react to many situations automatically. The learner knows what needs to be done, but cannot always figure out the best way. Stage 5-Expertise: At this stage, the learner knows what needs to be done, and they are able to figure out how to do it because they have ample experiences. The learner is able to act or respond immediately because the situation is something they have seen before. The learner automatically recognizes what needs to be done and does it. It becomes intuitive, which is different than the other stages, which are all considered analytical.

The five levels are designed so that they are achieved in chronological order, but Markowitsch and Luomi-Messerer (2008) assert that the number of levels is irreverent and that the order may not be perfectly chronological in nature. Some situations might require more than five levels and some might require less. Regardless of the number of levels, Markowitsch and Luomi-Messerer (2008) acknowledge that it is important to have a standardized way to communicate the competencies, which is what the Dreyfus model attempts to accomplish.

Though the model is presented as a continuum, competence is relative (Markowitsch \& Luomi-Messerer, 2008). This means students might be competent in one area, but a novice in another (Jackson et al., 2007). According to this model, students are expected to graduate at the competent level for the identified competencies, and they will 
become more competent with greater experience, ultimately leading to the expert level.

The Dreyfus (2004) model can be used to assess the overall competency of an individual as well as the specific competencies that are aligned with a program or profession. When used holistically, it has been shown that it takes 1 to 2 years of practicing nursing to achieve competence because learners have gained more experience in the field and are able to use the experiences to plan for future experiences; however, decisions are not immediate because the learner is still processing the information as it comes early in their career (Benner, 2004). ACEND recognizes this and states that dietitians "may not be competent in all aspects of the field" and that they should "practice only in the focus areas in which they are competent" (Accreditation Council for Education in Nutrition and Dietetics, 2016c, p. 70). Regardless of the particular area a dietitian works in, all entry-level dietitians are expected to meet or exceed each of the ACEND required competencies.

Students must have a solid foundation before they can move into applying their knowledge and skills to the established competencies (Markowitsch \& Luomi-Messerer, 2008). Competency within dietetics has been described as the "midpoint on a continuum of professional growth that normally extends over 10 to 12 years" and as "the point where a learner has acquired enough understanding, skill, and appropriate values to continue professional development independently" (Chambers et al., 1996, p. 615). DI programs are designed to provide the opportunity for students to gain hands-on experience in the field. In order for students to gain competence, they must have experience. Likewise, in order for educators to be able to create a curriculum that leads to student competence, they must have experience. Competencies are often used to guide 
assessment practices (Palomba \& Banta, 2001) and the curriculum, but this should not imply that competency-based education is not compatible with experiential learning. Indeed, in "competence-based education, experiential learning offers the theory of learning most appropriate for the assessment of prior learning and for the design of competence-centered curricula" (Kolb, 1984, p. 18). Accordingly, experiential learning is the focus of the next section.

\section{Experiential Learning}

The discussions on experiential learning are clear that students do learn and grow as a result of the meaningful experiences they encounter (Dewy, 1938; Joplin, 1981; Kolb, 1984). In general, the literature illustrates that students deepen their disciplinespecific knowledge (Aldas, Crispo, Johnson, \& Price, 2010; Barr et al., 2002; Gates, Kris-Etherton, \& Green, 1990; Simons et al., 2012), enhance their ability to integrate theory with practice (Dewey, 1938; Gavigan, 2010; Green \& Halloway, 2006; Kolb, 1984; Mazurkewicz et al., 2012; Simons et al., 2012; Snyder, 2012; Stichman \& Farkas, 2005), and develop intrapersonal and professional skills, such as communication skills (Chabot \& Holben, 2003; Reddy \& Hill, 2002), teamwork (Green \& Ballard, 2010), collaboration (Chabot \& Holben, 2003), multicultural awareness (Simons et al., 2012), community awareness (Astin \& Sax, 1998), motivation (Yates, Drewery, \& MurdochEaton, 2002), and confidence (Barr et al., 2002; Green \& Holloway, 2006; Reddy \& Hill, 2002; Snyder, 2012). However, experience is not the only factor in learning; educators must ensure that the experiences that are provided are appropriate and meaningful. The present study uses experiential learning as the overarching theoretical framework. This educational theory aligns perfectly with DI programs, which focus on hands-on 
experiences to enable students to build upon and apply their didactic coursework.

In the early 1900s, John Dewey, who is often considered the founder of experiential learning, challenged the traditional form of education in favor of a more progressive version, which recognized the "intimate and necessary relation between the process of actual experience and education" (Dewey, 1938, p. 20). Traditional forms of education tend to focus solely on the didactic portion of the curriculum (Cohen \& Kisker, 2010), which is the aim of the didactic program in dietetics. Experiential learning does not discredit the importance of the didactic component of education. Rather, this theory touts the many benefits of experience (Dewey, 1938; Joplin, 1981; Kolb, 1984; Simons et al., 2012). Experiential learning is intended to provide a holistic approach to education (Kolb, 1984). From an educational view, the didactic portion of an education is complimented by the experience component of the experiential learning model. This perspective suggests that learners must experience something to truly learn (Dewey, 1938; Joplin, 1981; Kolb, 1984).

In the early years of the dietetic profession, Florence Corbett, who was an influential dietitian at the turn of the $20^{\text {th }}$ century, recognized that the dietetic coursework "should be balanced by a large amount of practice in handling the problems of routine and emergency character peculiar to the institutional dietary field" (Corbett, 1910, p. 503). In fact, she was such a proponent of this type of education that she formed the first DI in 1903, which was centered upon the hands-on approach to learning (Payne-Palacio \& Canter, 1996). This model has demonstrated its acceptance and sustainability in the profession as supervised practice, typically completed in the form of a DI, and it continues to be a requirement for any individual who aspires to become a dietitian. 
The supervised practice experience is designed to provide students with the opportunity to apply their knowledge in a real setting under the supervision of a qualified preceptor with the goal of transitioning skilled students into competent dietitians. Internships have been described as being the "primary seat of the professional education for dietetics" (Wenberg, Ingersoll \& Dohner, 1969, p. 297). Barr et al. (2002), who conducted a study using a self-reported survey that compared each component of the entry-level dietitian's education (undergraduate, internship, work experience, continuing education), was perceived to have contributed the most to five aspects of professional development, including knowledge, skills, competency, ability, and confidence. It was observed that the internship received the highest mean scores for all characteristics (Barr et al., 2002). This study utilized self-reported data, which makes it difficult to truly assess competence (Meyer-Adams, Potts, Koob, Dorsey, \& Rosales, 2011), but the study did note the importance of the application of knowledge and demonstration of skills (Barr et al., 2002). Therefore, the internship is often viewed as the educational component that contributes the most to the preparation of dietitians (Barr et al., 2002; Gates et al., 1990), seemingly due to the experiential learning that occurs during this time.

In 2008 the Accreditation Standards Committee, which included members of CADE (now ACEND) as well as individuals in education, research, practice, and the public, recognized the need for more supervised practice experience, as 900 hours was deemed to be inadequate (Commission on Accreditation for Dietetics Education, 2010). The call for more supervised practice experience was due to healthcare becoming increasingly complex, new dietetic professionals being identified as not fully competent in their first job by employers, and the fact that the new competencies and expectations 
established by CADE (now ACEND) were thought to require additional time (Commission on Accreditation for Dietetics Education, 2010). Currently, DIs must provide 1200 hours of supervised practice in a variety of areas in dietetics (Commission on Accreditation for Dietetics Education, 2010). The emphasis on experiential learning is encouraging, but simply adding additional hours does not guarantee competence. The experiences must be meaningful, which is the premise of experiential learning theory. Several dietetic educators have attempted to provide meaningful research experiences to dietetic students in an effort to develop research skills and competence (Brehm, Rourke, \& Cassell, 1999; Desbrow et al., 2014; Penumetcha, McCarroll, \& Smith, 2012; Peterson et al., 2008; Steiber \& Barkoukis, 2006; Whelan et al., 2007b). Brehm et al. (1999) found that undergraduate and graduate students who volunteered to participate in a clinical research project investigating the effects of weight loss on bone mass in adolescent females rated their knowledge and skills related to research higher than the group of students who graduated the year before and were not a part of a research project. In addition to improving research knowledge and skills, this research project was designed to enhance counseling, communication, education, and nutrition assessment skills (Brehm et al., 1999). It was found that students ranked research knowledge and skills lower on a 5-point Likert-type scale $(1=$ poor; $5=$ excellent $)$ than all other areas with a mean score of $3.5 \pm 1.1$ compared to $3.8 \pm 0.8$ for counseling, $3.9 \pm$ 0.8 for teaching, $4.0 \pm 0.6$ for communication, and $4.2 \pm 0.7$ for what is now referred to as the principles of the nutrition care process (Brehm et al., 1999). The authors acknowledge that the students did not help with data input and statistical analysis, which was likely the reason research skills were rated lower than the others; regardless, these 
findings suggest that students are able to apply concepts from a research project, which is the goal of experiential learning.

It has been suggested that “developing dietetic students' research skills early in their academic careers should result in dietetic professionals who are more comfortable with research and more likely to incorporate research into their practices" (Smith, 2001, p. 1472). Desbrow et al. (2014) found that graduate students at a university in Australia who participated in a research major where they were required to complete a research project attributed their gain in research knowledge and skills to the hands-on approach of conducting a research project. Further, the semi-structured interviews conducted with the students after graduation revealed that their experience with research had a positive impact on their employment, as evidenced by one student who stated that "...the fact that I've done my research and I had a published paper worked a long way to getting me a job" (Desbrow et al., 2014, p. 61). It should be noted that the students selected to participate in this study were described as "higher performing" (Desbrow et al., 2014, p. 58); thus, the results cannot be generalized to all students. However, these findings suggest that utilizing the principles of experiential learning to foster research skills during dietetic education can translate into more than the development of research competence.

Smith (2001) utilized the concept of Research Across the Curriculum (RAC) with 12 undergraduate dietetic students who were involved with four progressive research experiences that were integrated into three core foods courses and an independent studies course. Though research competence was not measured, it was observed that the majority of students involved in this study presented their findings to others (Smith, 2001). This demonstrates at least some level of competence and confidence, even if it was not 
quantified. Steiber and Barkoukis (2006) reported that students who participated in a structured research project during their time in the Coordinated Dietetic Internship/Master's Degree Program at Case Western Reserve University rated themselves as confident enough to complete an IRB application and to conduct a study on their own. These results are encouraging, as the projects were completed during an academic year, and it seems as though the students were quite involved in the process; however, the data were not presented in the article, making it difficult to draw meaningful conclusions.

Another study highlighted the difference between students who graduated from a coordinated program in dietetics before the initial accreditation research requirements and students who graduated after the research requirements were in place (Petersen et al., 2008). The results showed that students who graduated prior to the accreditation research requirement were less likely to report that they received research training during school (82\%, or 23 of 28 students) compared with students who graduated after the requirements were in place (97\%, or 28 of 29 students) (Petersen et al., 2008). This finding seems to show that educators were attempting to align the professional goals before it was mandated by the accrediting body. The authors did not provide a breakdown of which students were directly involved in research, but the data revealed that only $33 \%$ of the students reported that they were actually involved with an outcomes research project, and that $96 \%$ of students reported that they learned about outcomes research through coursework (Petersen et al., 2008). Further, despite the fact that all students had taken at least one statistics course, only $32 \%$ of students who graduated prior to the accreditation research requirements and $41 \%$ of students who graduated after the requirements rated 
their ability to utilize statistics to analyze data as "adequate" or "accomplished" (Petersen et al., 2008). This suggests that students need more than coursework in this area to fully understand how to apply the knowledge.

A combination of didactic courses and hand-on experience has shown to be an effective method for improving understanding and confidence in statistical methods for dietetic students (Penumetcha et al., 2012). Students enrolled in a coordinated dietetic program at Georgia State University and students enrolled in DI programs at Southern Regional Medical Center and Emory University Hospital were assessed both pre- and post-completion of a research project that was purposely aligned with the research competencies required by CADE (now ACEND) (Penumetcha et al., 2012). The results demonstrated a statistically significant improvement in their perceived ability with descriptive statistics, validations statistics, and correlation statistics $(n=41, p<0.005)$ (Penumetcha et al., 2012). These results highlight the importance of experiential learning for obtaining research skills.

Additionally, experiential learning can be used to help fulfill a community need (Simons et al., 2012). One dietetic program found that by utilizing a universitycommunity model for research projects, both students and the community benefited from the experience, as the students were able to conduct research in a real life setting and the members of the community facility received several weeks of free nutrition services that would not have been provided otherwise (Rebovich et al., 1994). Further, dietetic students in the United Kingdom who worked with community collaborators on a research project reported a statistically significant $(p \leq 0.02)$ greater involvement in all areas of a research project, except for developing a hypothesis than dietetic students who only 
worked with a faculty member (Whelan et al., 2007b). These studies show the importance of the educators, as it is possible to plan the curriculum to allow for opportunities that are beneficial for both the students and the community.

Experiential learning is a complex learning theory that highlights the importance of the learner in the process of creating knowledge and meaning out of experiences (Dewey, 1938; Joplin, 1981; Kolb, 1984). This approach stresses the cyclical nature of the learning process, which has been shown to enable learners to develop deeper understandings (Dewey, 1938; Furman \& Sibthorp, 2013; Green \& Halloway, 2006; Kolb, 1984; Mazurkewicz et al., 2012). Although experiential learning is rooted in the learner-centered paradigm, educators play important roles in the process. Academic leaders and educators cannot have the mentality that any experience results in learning, as this is the antithesis of true experiential learning. Rather, these individuals must carefully work to ensure all stages of the process align with the conceptual framework.

Though some research has been conducted on experiential learning in dietetics (Barr et al., 2002; Gates et al., 1990), more research is needed to gain a better understanding of this model within dietetic education, particularly as it relates to competency CRD 1.5. The future implications of this work will enable educators to better align the ACEND-required competencies with the principles of experiential learning. Ideally, this will enable dietetic educators to make more informed decisions to improve the dietetic curriculum.

\section{Issues within Dietetic Education}

Both competency-based education and experiential learning play major roles within dietetic education. Educators must ensure that the experiences aligned with the 
competencies are meaningful and result in the desired learning outcomes. Simply providing an experience to a student does not guarantee learning will occur (Dewey, 1938; Joplin, 1981; Kolb, 1984; Mazurkewicz et al., 2012; Roberts, 2006). Similarly, completing the supervised practice portion of a DI does not guarantee students are competent for entry-level positions (Gregoire, Sames, Dowling, \& Lafferty, 2005).

It is well-documented that experiential learning is more than providing experiences to students (Dewey, 1938; Joplin, 1981; Kolb, 1984; Mazurkewicz et al., 2012; Roberts, 2006). Simply adding more supervised practice hours does not ensure students are learning more. The theory of experiential learning is centered on the fact that the experience must be purposefully planned, executed, and evaluated (Dewey, 1938; Joplin, 1981; Kolb, 1984). Despite rigid curriculum requirements from ACEND, it appears that dietetic educators are not always able to utilize the principles of experiential learning to maximize student learning. Dietetic programs have been shown to use various activities to meet the ACEND-required research competencies, and several studies have demonstrated that students do not feel fully prepared to conduct research despite research training and participation in a structured research project (Hays \& Peterson, 2003; Peterson et al., 2008). Common issues that DI Directors have with the ACEND-based research competencies include having inappropriate definitions of experience, failing to provide holistic experiences, and lacking experience themselves.

Inappropriate definitions of experience. The dietetic curriculum for both the didactic and supervised practice programs is comprehensive, as ACEND has established the required knowledge, skills, and competencies for each level of education (Accreditation Council for Education in Nutrition and Dietetics, 2016b; Accreditation 
Council for Education in Nutrition and Dietetics, 2016c). However, there is no requirement on the manner in which these competencies are implemented. In order to execute an effective plan, DI Directors must have a clear understanding of the competency. Prior to the establishment of the ACEND-required research competencies, it was noted that the "lack of appropriate educational training is a major barrier to integration of research into practice settings" (Fitz \& Winkler, 1989, p. 1677). The lack of literature on this topic, coupled with the literature suggesting that dietitians are not competent in research (Byham-Gray et al., 2006; Eck et al., 1998; Gardner et al., 2002; Slawson et al., 2000), indicates that this issue continues to be a problem.

Research can be a difficult term to fully understand, as the term can have many meanings. For instance, a survey study in the UK of 140 dietitians found that only $16 \%$ of participants were able to completely match a standard definition of research for dietetics, while nearly 50\% partially matched, and over 30\% failed to match (Harrison, Brady, \& Kulinskaya, 2001). The standard definition of research that was used in this study was "a structured activity which is designed to provide new knowledge" and "whose findings are planned to be open to critical examination and accessible to all who could benefit from them" (Harrison et al., 2001, p. 326). This definition is different than the one ACEND uses for dietetic education in the US; nonetheless, the emphasis on research is also embedded into the dietetic curriculum in the UK. Additionally, this study did not specifically assess dietetic educators, but the notion that there is a lack of understanding of the term research is concerning. Inconsistent and incorrect interpretations of this competency might lead DI Directors to align inappropriate experiences that do not provide students with the true opportunity to attain competence. 
A common concern is that many dietetic educators feel exposure to an experience equates to learning (Gates \& Sandoval, 1998; Gilboy et al., 2010; Knoblock-Hahn et al., 2010), which is not in line with the principles of experiential learning theory. The literature on experiential learning is clear that experience alone does not equate to learning (Dewey, 1938; Joplin, 1981; Kolb, 1984; Mazurkewicz et al., 2012; Roberts, 2006). The experiences that are aligned with the specific competencies must be appropriate in order to elicit learning and competence, and this is ultimately the responsibility of the DI Director. In 1989, which was before the establishment of the ACEND competencies as well as the widespread use of the internet, it was found that despite the fact that the majority $(71 \%)$ of DI Directors and coordinated program directors who were surveyed required students to work on a research project in some capacity, research-related experiences were noted to rely heavily on observation, rather than application and synthesis (Fitz \& Winkler, 1989). For instance, DI Directors identified the leading research-learning activities that were used in their programs as observation in a research setting (59\%), attendance at a professional conference (52\%), and observation of research dietitian (52\%) (Fitz \& Winkler, 1989). Though these are important experiences, simple observation and attendance does not meet the principles of experiential learning nor does it reflect research competence. Students must have the opportunity to actually experience research. "If dietetic interns and students are unable to actively participate in research, the dietetic education system will continue to produce entry-level dietitians who cannot conduct research or critically evaluate the research of others" (Fitz \& Winkler, 1989, p. 1678). 
Observations are often utilized to measure competence in medical students (Lurie et al., 2009). This issue has also been noted in the dietetic literature; specifically, studies have shown that programs do not provide adequate experiences to allow students to become competent for the required research competency (Fitz \& Winkler, 1989), public policy competency (Gilboy et al., 2010), or cultural competency (Knoblock-Hahn et al., 2010), despite the fact that the individuals who are assessing the competence of the students rate the students as competent. Thus, the students progress through the profession without truly meeting the required competencies.

Failure to provide holistic experiences. It is common for educators to take a reductionist approach by simply breaking down each competency into measurable parts without regard to the overall context of the competency (Frank et al., 2010). Fragmenting a competency by breaking it into several parts can be useful, but it must be done carefully (Batalden et al., 2002). Experiential learning has been criticized for being too prescriptive, which can cause learning to be "so disconnected from the rest of the experience that it is not available under the actual connections of life" (Dewey, 1938, p. 48). It can be difficult for students to apply their knowledge in a realistic setting; thus, experiential learning provides an avenue for students to make connections between what is taught in the class and what happens in the real world. Though it can be difficult in an education setting, it is important to have students complete the competency in the most natural setting possible (Lurie et al., 2009).

Many educators fail to align the experiences with the principles of experiential learning theory (Clark et al., 2010). The curriculum must be purposeful and directed by educators (Mazurkewicz et al., 2012). It is not sufficient for students to simply 
participate in an experience because experience can occur without learning (Dewey, 1938; Joplin, 1981; Kolb, 1984). Synder (2012) cautions that educators must set realistic goals for experiential learning because the transformative learning that occurs with experiential learning can take more than a semester to develop. In reality, there is no true end to learning because "every experience both takes up something from those which have gone before and modifies in some way the quality of those which come after" (Dewey, 1938, p. 36). Learners use the experience as a moving force to construct meaning and to develop deeper understandings (Dewey, 1938; Joplin, 1981; Kolb, 1984). The cyclical nature of this model attempts to provide a holistic approach to education. Active participation in research is important, but dietetic educators must also ensure that the research experience is not simply isolated components of the research process. Though it is necessary to break up the stages of the research process into manageable sections for both the students and educators, it is not enough. The experiences that are used to meet the research competence need to be integrated to better ensure students understand how the pieces of the process fit together. The majority of dietetic students $(56 \%)$ in a study reported that research instruction and training did not adequately prepare them for participating in research (Peterson et al., 2008). The experiences must be meaningfully aligned with the competency and they must provide a holistic view of research.

One commonly made mistake is making the research too simplistic by only using one component of the process to measure competence. For example, a review of the literature was identified to be sufficient to meet the research requirement by $26 \%$ of DI Directors and coordinated program directors (Fitz \& Winkler, 1989). This issue has also 
been observed in medical programs, as nearly $25 \%$ of medical program directors reported that reviewing articles as a part of a journal club was an acceptable method to meet the research requirement (Levine, Hebert, \& Wright, 2005).

These types of experiences might serve to perpetuate an incorrect understanding of research or the view that one is competent in research when they do not have experience in it. Some experiences have been described as "mis-educative" which have the "effect of arresting or distorting the growth of further experience" (Dewey, 1938, p. 25). The experiences that are used to meet research competence in dietetic programs should provide students with a true understanding of the entire research process. Research is limited in this area because only programs that are attempting to provide exemplary research experiences for their students tend to publish.

For example, students enrolled in a Coordinated Dietetic Internship/Master's Degree Program at Case Western Reserve University who had to complete a research project, including design, IRB proposal, data collection, data analysis, poster and oral presentation, and a summary paper, were shown to enhance ownership of the project and thus confidence in completing the tasks on their own upon completion of the program (Steiber \& Barkoukis, 2006). Similarly, a coordinated program at the University of Missouri utilized a structured, research-training curriculum that consisted of a gradual increase in research experience, culminating in an original research project with a research manuscript (Hays \& Peterson, 2003). The data revealed that as a result of the students being involved with the research projects, they had an understanding of the complexities involved with research (Hays \& Peterson, 2003). However, the survey did not include a pre-test, so it is difficult to assess the self-reported post-test data. 
In addition to enhancing their research skills, knowledge, and overall research competence, dietetic students who engaged in intense research projects that required them to see the process as a whole reported that the benefits associated with involvement in research improved other skills (Desbrow et al., 2014). Examples of these included many transferable skills, such as organization, time management, interpersonal, collaboration, critical thinking, reflective practice, and self-directed learning (Desbrow et al., 2014). These results are encouraging, as it shows that involvement with research has a positive effect on other essential skills for dietetic students.

The research on this topic is limited, as it is typically conducted with one dietetic program, so it is difficult to generalize the data. However, the few studies on this topic indicate that dietetic programs might not be providing holistic research experiences to students. A possible explanation to this might stem from the lack of experience that program directors have with research. This will be discussed next.

Program directors lack experience. According to Dewey (1938), what one "has learned in the way of knowledge and skill in one situation becomes an instrument of understanding and dealing effectively with the situations which follow" (p. 44). The literature regarding the experience levels of dietetic program directors focuses on coordinated program directors (Gabel \& Pond-Smith, 1995; Nyland, Spears, \& Meyers, 1989), which are usually programs housed within a university setting. DI programs can be housed in a university setting as well as a medical center, governmental facility, industry, or other food and nutrition related facilities. Thus, there is likely variability in the amount of research experience DI Directors have, because the emphasis on research may not be as great in those who do not work in an institution that has pressure for tenure 
and promotion.

The research skills of dietitians have been well researched, but the research skill level of dietetic educators, particularly DI Directors, is lacking. Dietetic educators and dietitians have been shown to lack skills in research design, data collection, data analysis, and writing proposals and papers (Schiller, 1988; Schiller et al., 1988). Though these studies are over two decades old, the trend that dietitians lack research involvement is still apparent (Anchondo et al., 2014; Dougherty et al., 2015). Thus, there is still a disconnect between education and practice, and a novel population to assess for their influence on this issue is DI Directors.

Experiential learning is a complex learning theory that highlights the importance of the learner in the process of creating knowledge and meaning out of experiences (Dewey, 1938; Joplin, 1981; Kolb, 1984). This approach stresses the cyclical nature of the learning process, which has been shown to enable learners to develop deeper understandings (Dewey, 1938; Furman \& Sibthorp, 2013; Green \& Halloway, 2006; Kolb, 1984; Mazurkewicz et al., 2012). Although experiential learning is rooted in the learner-centered paradigm, educators play important roles in the process. Academic leaders and educators cannot have the mentality that any experience results in learning, as this is the antithesis of true experiential learning. It cannot be assumed that completing the supervised practice portion of a DI guarantees that students are competent for entrylevel positions (Gregoire et al., 2005). Rather, DI Directors must carefully work to ensure the alignment of their program within the conceptual framework.

In order to have a clear understanding of competency CRD 1.5, DI Directors must have a solid foundation of the principles of research. Studies have not looked exclusively 
at this population, but data from dietetic educators suggest that research competence is lacking (Gabel \& Pond-Smith, 1995; Nyland et al., 1989; Schiller et al., 1988; Whelan \& Markless, 2012). DI Directors play an important role in this process. Research on this population is certainly warranted, as this group has been left out of this empirical discussion.

\section{Summary}

Students are able to construct their own knowledge and meaning from their experiences, as they have an active role in the process. Though their work does not focus directly on experimental learning, Huba and Freed (2000) would likely classify this as a learner-centered paradigm. The faculty member is important in the process, but the student is responsible for his or her own learning. The educator should serve as a guide who ensures the experience is purposeful and structured (Dewey, 1938; Joplin, 1981; Kolb, 1984; Mazurkewicz et al., 2012). However, in order to be effective, DI Directors must have a foundation on which to develop and implement the curriculum. The individual level will be discussed next.

\section{Individual Level}

Research within dietetics is heavily promoted at the professional and educational levels, but this emphasis is not paralleled at the individual level. As previously mentioned, despite efforts to enforce the link of research within dietetics, numerous studies have shown that dietitians lack research competence (Byham-Gray et al., 2006; Eck et al., 1998; Gardner et al., 2002; Guyer et al., 1993; Schiller, 1988; Schiller et al., 1988; Slawson et al., 2000; Wylie-Rosett et al., 1990). This is concerning because the misalignment between the research expectations and the actual research involvement at 
the individual level likely perpetuates the cycle of dietitians who lack research competence.

\section{Research Involvement Continuum Model}

Wylie-Rosett et al. (1990) created the classic research continuum model to showcase the four levels of research involvement for dietitians. This model is widely accepted throughout the literature on this topic (Byham-Gray et al., 2006; Guyer et al., 1993; Howard, Ferguson, Wilkinson, \& Campbell, 2013; Morley-Hauchecorne \& Lepatourel, 2000; Whelan et al., 2013). According to the model, all dietitians should be at Level 1, which is the practice level where practitioners utilize the scientific approach (WylieRosett et al., 1990). Level 2 is considered the collaboration level where scientific knowledge is translated into practice and for publications (Wylie-Rosett et al., 1990). Level 3 and Level 4 require more time and a greater commitment to research; these levels are identified as the participation and leadership levels, respectively (Wylie-Rosett et al., 1990). The research continuum can be viewed as linear (Wylie-Rosett et al., 1990) or as a pyramid (Byham-Gray et al., 2006), but the overarching goal is the same. That is, a dietetic professional must be actively involved in a level before moving to the next level, because the knowledge and skills required for each level build upon one another, which leads to competence.

Using the research continuum model against competency CRD 1.5 as well as the other research-based competencies in domain one (Accreditation Council for Education in Nutrition and Dietetics, 2016c), it seems that the profession is aiming for DIs to get their students to Level 3, also known as the participation level, rather than Level 1, which was noted by Wylie-Rosett et al. (1990) as the level all dietitians should achieve. 
Participation in research has been interpreted as an active endeavor (Anchonodo et al., 2014) or a passive endeavor (Fitz \& Winkler, 1989), and this certainly influences the learning that occurs as a result of the experience.

The most recent Academy of Nutrition and Dietetics' survey on member research activities defined participation for dietitians as "preparing applications/proposals, designing and conducting studies, preparing manuscripts for publication, and presenting at professional meetings, as well as supervising any of these activities" (Anchonodo et al., 2014). This implies that participation in research is actually the combination of Levels 2, 3, and 4 from the research continuum, rather than strictly Level 3 as described by Wylie-Rosett et al. (1990). Though research participation is still a term used for the dietetic profession (Anchonodo et al., 2014), it is more commonly referred to as research involvement in the literature (Byham-Gray et al., 2006; Howard et al., 2013; Whelan \& Markless, 2012; Whalen et al., 2013). Regardless of the terminology used, the manner in which dietetic educators and professionals understand research and research competence is most important.

Literature on the interpretation of research within US dietitians and dietetic educators is lacking, but a study in the UK observed that the majority of dietitians surveyed were not able to accurately define research based upon the comparison of their definition of research with a standard definition of research for the profession (Harrison et al., 2001). The data revealed that only $16 \%$ of participants were able to completely match the standard definition of research, which was described as "a structured activity which is designed to provide new knowledge" and one "whose findings are planned to be open to critical examination and accessible to all who could benefit from them" (Harrison 
et al., 2001, p. 326). Further, dietetic educators have been shown to use literature reviews to meet research requirements (Fitz \& Winkler, 1989). In recent years, the literature has focused on the research skills of dietitians, but this discussion should start with what occurs at the educational level, as it is unknown exactly what DIs are using to meet the current research competencies. The inquiry into this topic was conducted before the current competencies were required (Hynak-Hankinson, Martin, \& Wirth, 1997; Steiber \& Barkoukis, 2006) or limited to individual programs (Penumetcha et al., 2012).

\section{Research Involvement of Dietitians}

Dietitians have been shown to report an interest in research (Eck et al., 1998; Gardner et al., 2002; Schiller, 1988). The professional interests of the individual dietitian influence what they will utilize for their required continuing education. This enables dietitians to customize their involvement with research during their career. Some may choose to be highly involved in research, while others may elect to be minimally involved, but research is paramount within all areas of the profession, not just for those who work exclusively with research or education. Though there is conflicting evidence, some studies suggest that students who are involved in research during their educational careers are more interested in research for their professional careers (Desbrow et al., 2014; Soloman, Tom, Pichert, Wasserman, \& Powers, 2003), and they tend to have more positive attitudes toward research compared to practicing dietitians (Whelan et al., 2007a). Regardless, dietetic students should be involved in research during their educational career because dietetics is described as being the foundation of the profession (Cassell, 1990; Manore \& Meyers, 2003), and it is a core competency for supervised practice (Accreditation Council for Education in Nutrition and Dietetics, 2016c). 
The Academy of Nutrition and Dietetics and the Commission on Dietetic Registration's analysis of the dietetic workforce revealed that about 5-10\% of dietitians worked in education and research from 2002-2009, and this section of the profession is expected to grow by $24 \%$ during 2010-2020 (Hooker et al., 2012). The dietetic literature commonly pairs education and research into one category of a practice area presumably because these two settings employ the leaders in dietetic research. Byham-Gray (2004) conducted a dissertation study assessing the influence of sociodemographic characteristics, education and training, professional experience, and employment setting on dietitians' perceptions, attitudes, and knowledge about evidence-based practice, and the four-tiered research continuum that was originally described by Wylie-Rosett et al. (1990). A quantitative questionnaire was pilot tested by the authors (Byham-Gray, 2004). It was disseminated to dietitians who belonged to certain dietetic practice groups, and 258 questionnaires were included in the data analysis (Byham-Gray, 2004). The research score was calculated using three questions for each of the four levels of the research continuum on a 5-point Likert-type scale; thus, the maximum research score was 60 (Byham-Gray, 2004). It was found that working in certain primary areas of practice $(r=$ $0.14, P<0.02$ ) was a predictor for research involvement among the dietitians in the study (Byham-Gray, 2004). Dietitians working in the three major areas of dietetics reported similar research scores: community $(\mathrm{n}=11,23.3 \pm 8.0)$, clinical $(\mathrm{n}=177,25.7 \pm 7.9)$, and management $(\mathrm{n}=23,27.2 \pm 7.0)$, while dietitians working in education $(\mathrm{n}=15,40.5$ $\pm 13.9)$ and research $(n=8,42.0 \pm 13.1)$ had the highest research scores (Byham-Gray, 2004). Harrison et al. (2001) reported that the relationship between the workplace setting and research involvement of dietitians in the UK was not statistically significant, but 
academia was not listed as a category in this study. A qualitative study utilizing focus groups found that research in the clinical setting often had a negative connotation; in fact, one participant commented that "dietitians did clinical because they did not want to do research" (Slawson et al., 2000, p. 1145).

Furthermore, the Academy of Nutrition and Dietetics recently conducted a follow-up study to survey the research activities, needs, and perceptions of dietitians who are members of the research dietetic practice group (Anchondo et al., 2014). The data revealed that the primary employment setting for participation in research was academia among those surveyed regardless of their education level (Anchondo et al., 2014). The results were broken down by dietitians who had a doctorate degree and dietitians who had a master's degree. The findings for those with a doctorate degree $(n=492)$ revealed that the employment setting where the majority had participated in research was in academia (64\%), compared to hospital or clinic (6\%), self-employed (7\%), government (5\%), industry (4\%), community (1\%), foundation (1\%), and other (3\%) (Anchondo et al., 2014). The majority of research participation also occurred in the academic setting $(34 \%)$ for those with master's degrees $(n=72)$, followed by hospital or clinic $(32 \%)$, government (9\%), self-employed (6\%), industry $(2 \%)$, community $(2 \%)$, foundation (2\%), and other (5\%) (Anchondo et al., 2014). It can be seen that research was not an employment setting category in this study, so it is possible that the academic setting might be slightly inflated to accommodate for this. At any rate, it is evident that the academic setting is a critical factor in the involvement of dietitians in research.

The 2008 Needs Assessment by the American Dietetic Association and Commission on Dietetic Registration revealed that $34 \%$ of dietitians held an advanced 
degree in a nutrition or dietetic related field, while $6 \%$ held advanced degrees in other areas (Rogers, 2009). The Academy of Nutrition and Dietetics is exploring the possibility of requiring a master's degree for entry into the profession, because:

The need to elevate entry-level RDN education to a graduate level is consistent with the knowledge, skills, and research base required in the field of nutrition and dietetics and is necessary to protect the public, remain competitive, and increase recognition and respect. (Kicklighter et al., 2013, p. 1714)

Further, it was noted that "graduate programs might require more research and therefore strengthen research efforts within the profession" (Kicklighter et al., 2013, p. 1714). The details of the required master's are not finalized at this time, but there seems to be an assumption that an advanced degree is needed to help dietitians function at an acceptable level for entry-level work, particularly as it relates to understanding and utilizing research.

This is in agreement with a quantitative study based upon a dissertation by Byham-Gray et al. (2006) who found a statistically significant relationship $(r=0.53, P<$ 0.0005) between the level of education and dietitians' involvement with research utilizing a pilot-tested survey that was administered to 258 dietitians who belonged to pre-selected dietetic practice groups. Similarly, a mixed methods study, which utilized a survey and telephone interviews, also found a statistically significant relationship with regard to education level and outcomes-based research for clinical dietitians $\left(\chi^{2}=6.46, P<0.05\right)$ (Gardner et al., 2002). These results suggest a link between advanced education and involvement with research, but it should be noted that there is the possibility that only dietitians who were interested in research participated in the studies, thereby providing data that cannot be generalized to the entire population. 
In addition to education, the nature of the job has been shown to influence research involvement, such as having research responsibilities as a part of the job description (B $=1.96, \beta=0.34, t=4.16, P<0.001$ ) (Howard et al., 2013). Additional factors that have been shown to predict research involvement at the individual level include having taken a research course $(r=0.40, P<0.0005)$, recently reading a research article $(r=0.35, P<0.0005)$, frequently reading professional materials $(r=0.32, P<$ 0.0005), being members of the professional dietetic association $(r=0.14, P<0.02)$, and being members of certain dietetic practice groups $(r=0.14, P<0.02)$, with membership in the research group showing the highest research score (Byham-Gray et al., 2006).

Though several studies have utilized the four-level research continuum as a framework (Byham-Gray et al., 2006; Guyer et al., 1993; Harrison et al., 2001; Howard et al., 2013), only one utilized a questionnaire with the goal of assigning participants to one of the four levels on the research continuum based upon the answers they provided (Byham-Gray et al., 2006). In this study, participants demonstrated the highest mean research score, which had a maximum of 15 , for Level 1 (10.8 \pm 2.7$)$, followed by Level $2(6.2 \pm 3.1)$, Level $3(5.6 \pm 3.1)$, and Level 4 (4.3 \pm 2.5$)$ (Byham-Gray et al., 2006). These results suggest that dietitians are most involved in the lowest possible level on the research continuum. This is in line with Wylie-Rosett et al. (1990), who stated that all dietitians should be involved in Level 1 and, by design of the model, less will be involved at the higher levels.

Measurement of research involvement. In addition to the lack of literature defining where dietitians fall on the research continuum, there is a lack of validated questionnaires to measure research involvement of dietitians, which led Whelan et al. 
(2013) to develop a reliable and valid instrument, the Research Involvement Questionnaire (RIQ), for this purpose. Content validity was measured by a panel of six experts who identified the relevance of the questionnaire items; data revealed a content validity index for the entire RIQ as 0.92 (Level $1=1.0$, Level $2=0.83$, Level $3=0.83$, Level $4=1.0$ ) (Whelan et al., 2013). In order to test for additional measures of validity, Whelan et al. (2013) quantified the research output of selected dietitians in the UK who were actively involved in research. Criteria were established to assign participants into one of the four levels on the research continuum based upon the quantified research output. Criterion validity was established as the participants who were identified in the higher levels of the RIQ also had higher levels of research output $(p<0.001$ for all four levels and the total score) (Whelan et al., 2013).

Similarly, construct validity was noted, as there was a relationship between the qualifications of the participants and the RIQ; for example, participants with a doctoral degree were more likely to be assigned to Level 4 on the RIQ than participants with other degrees $(p<0.001)$ (Whelan et al., 2013). Further, reliability testing revealed a Cronbach's a coefficient of 0.98 , and intrarater reliability was $86 \%$ with a $\mathrm{K}=0.81$ when participants completed the RIQ on two different occasions, one week apart (Whelan et al., 2013). The reliability and validity of the RIQ is impressive; however, since this instrument is new there is no published literature using it to assess the research involvement of DI Directors. Therefore, the present study sought to help fill this void in the literature.

Competency CRD 1.5 specifies that dietetic interns should be able to conduct research (Accreditation Council for Education in Nutrition and Dietetics, 2016c). It is 
unclear exactly where this might fall on the research continuum, but it is likely to be more advanced than Level 1, which is where the majority of dietitians have been shown to fall (Byham-Gray et al., 2006). Due to the focus on supervised practice, DIs are centered upon the principles of experiential learning; thus, the involvement of research must include actual experience with research. It has been shown that the more years of experience a dietitian in the UK has with research, the higher level of research engagement they displayed $(\mathrm{B}=0.489, \beta=0.318, t=2.67, P<0.009)$ (Howard et al., 2013). Though the literature shows that dietitians are involved in research, it is evident that involvement does not necessarily translate into research competence, because dietitians have continually been found to lack the necessary knowledge (Byham-Gray et al., 2006; Gardner et al., 2002; Guyer et al., 1993; Schiller et al., 1988; Slawson et al., 2000) and skills (Byham-Gray et al., 2006; Eck et al., 1998; Gardner et al., 2002; Guyer et al., 1993; Schiller et al., 1988; Slawson et al., 2000) to appropriately conduct research.

\section{Research Competence of Dietitians}

Perceived research competence is often a marker of research competence in the dietetic literature as well as other professions, presumably because it is difficult to ascertain actual competence. Thus, the actual research competence of dietitians is not well documented, though the literature seems to suggest that the research competence of individual dietitians is not in line with the expectations and aspirations at the professional and educational level. The studies on this topic are limited in scope, as they utilize a nonvalidated quantitative questionnaire and often have small sample sizes. Regardless, the next section of this paper compares the literature to show the need to improve the research competence of dietitians. 
The lack of perceived research competence in dietitians is widespread. Even though Byham-Gray et al. (2006) did not directly assess the actual or perceived research competence of dietitians, the low scores on the research involvement survey indicate that the dietitians in the study were not confident in their ability to understand or conduct research. Further, a small study $(\mathrm{n}=30)$ of clinical dietitians in Memphis, Tennessee, found that $50 \%$ of dietitians reported a lack of research skills, which impeded them from participating in research (Eck et al., 1998). A larger study surveying clinical dietitians in Florida $(n=155)$ showed similar results, as $43 \%$ perceived a lack of the necessary knowledge base to conduct research (Guyer et al., 1993). Dietitians in the UK have also been shown to lack research competence, as $39 \%$ of dietitians in one study found it hard to interpret research findings (Harrison et al., 2001). The data from a qualitative study conducted in the US also revealed a lack of perceived research competence; a focus group study with nine sessions and a total of 53 participants, consisting of dietitians ( $\mathrm{n}=$ 50) and dietetic interns $(n=3)$, revealed that $15.6 \%$ perceived a lack competence in research methodology, and 7.3\% described research as overwhelming (Slawson et al., 2000). Further, only $39 \%$ of renal dietitians who participated in a cross-sectional survey reported that neither their undergraduate program nor their internship prepared them to do research (Chrencik et al., 2008).

Research competence necessitates experience with research, per the experiential learning theory. Therefore, it would be expected that dietitians who have never conducted research would not be confident or capable in their abilities. As expected, a lack of research skills was found to be the number one barrier to participation in outcomes research for subjects who had never conducted research $(\mathrm{n}=111,65 \%)($ Gardner et al., 
2002). However, the lack of research skills was the number three barrier identified in those who had conducted research $(n=42,23 \%)$ (Gardner et al., 2002), suggesting that the lack of research skills was a concern for a large portion of the sample. This study sheds light on the importance of experience, as those with more experience had higher self-perceptions of their research skills. Nonetheless, the participants in this study were members of the Clinical Nutrition Mangers practice group of the American Dietetic Association (currently the Academy of Nutrition and Dietetics), and all had been involved in research projects, even if they had never conducted a study.

In an attempt to provide a structured research experience, Hays and Peterson (2003) created a research-training curriculum for students and preceptors who were involved in the coordinated dietetic program at the University of Missouri. Upon completing the curriculum, students and preceptors completed questionnaires that were specific to each group to evaluate the curriculum and their experiences with the research projects (Hays \& Peterson, 2003). The student questionnaire $(\mathrm{n}=14)$ utilized a 5-point scale where 1 = no ability, $2=$ poor ability, $3=$ fair ability, $4=$ good ability, and $5=$ excellent ability (Hays \& Peterson, 2003). The data showed that students rated their ability to interpret figures, charts, and tables in a research article as a mean of $3.9 \pm 0.8$, and they rated their ability to critique a research article as a $3.6 \pm 0.5$ (Hays \& Peterson, 2003). The preceptor questionnaire $(n=4)$ demonstrated a perceived increase in knowledge after completion of the research training curriculum with mean responses of $2.5 \pm 0.6$ before the study and $3.0 \pm 0.0$ after the study on a 4-point scale with $1=$ none, 2 = minimal, 3 = fair/some, and 4 = great (Hays \& Peterson, 2003). Despite the small sample size, this study serves to highlight the importance of a structured curriculum, 
though it is possible that the students and preceptors rated their perceived improvement in skills higher than reality.

A few studies have attempted to quantify the percentage of dietitians who report deficiencies in various research skills (Guyer et al., 1993; Schiller, 1988; Schiller et al., 1988). The skills that were perceived to be lacking in clinical dietitians in Florida included analyzing statistical data (79\%), getting funding (77\%), developing research designs (76\%), writing proposals (74\%), writing protocols (65\%), writing journal articles $(63 \%)$, presenting research articles $(63 \%)$, defining objectives $(52 \%)$, and identifying research problems (50\%) (Guyer et al., 1993). Schiller (1988) also found that many of the clinical dietitians in her study indicated that research skills were lacking; participants identified statistical analysis $(88.2 \%)$, obtaining funding $(78.5 \%)$, publishing papers $(61.8 \%)$, research design $(60.8 \%)$, writing proposals $(58.3 \%)$, writing protocols $(50.5 \%)$, writing papers and abstracts (47.3\%), defining research objectives (37.7\%), presenting papers $(35.1 \%)$, identifying research problems $(23.8 \%)$, and data collection $(24.5 \%)$ as skills that needed further development in order to conduct research. In a similar study by Schiller et al. (1988), the research skills of faculty $(n=1028$, with dietetic faculty at $n=$ 354 , as other allied health faculty were included in the study) were assessed, and it was found that the research skills that were most needed were getting funding (76.9\%), statistical analysis (67.7\%), writing protocols (50.5\%), publishing papers $(49.1 \%)$, developing research designs (46.1\%), writing proposals $(40.7 \%)$, writing papers $(26.7 \%)$, defining objectives $(22.9 \%)$, identifying research problems $(22.5 \%)$, data collection (17.2\%), and presenting papers (16.6\%). It should be noted that all of these studies utilized self-reported data, meaning actual competence was not measured. Collectively, 
the literature indicates that dietitians are not confident in their ability to conduct research; however, collaborations have been shown to have a positive impact on the self-perception of research competence of dietitians.

\section{Individuals Prefer Collaborations}

Collaborations have been identified as the preferred route to improve the research skills of dietitians (Eck et al., 1998; Gardner et al., 2002; Hays \& Peterson, 2003;

Slawson et al., 2000; Whelan et al., 2007b) and as the preferred route for involvement in research for dietitians (Gardner et al., 2002; Slawson et al., 2000) as well as for other allied health faculty (Waller et al., 1988). Further, dietetic students who work on collaborative projects, which include faculty members and dietitians working outside the university, have been shown to have a more positive experience with research than dietetic students who work on projects that are completed with only a faculty member (Whalen, Thomas, \& Madden, 2007). The need for collaborations with experienced researchers has been recognized in the literature, and this experience is often found in the academic setting (Eck et al., 1998; Hays \& Peterson, 2003; Slawson et al., 2000). In fact, a participant in a focus group on this topic reported that working with an academic dietitian on research projects "would be the best thing" because of their expertise and knowledge (Slawson et al., 2000, p. 1146). This perception was echoed by multiple participants in the study (Slawson et al., 2000). This is a promising means to improve the research competence of both dietetic students and dietitians, because it can serve to meet the ACEND-required research competencies, and it can help dietitians hone and enhance their research skills throughout their career. Both of these will help to advance the profession by providing opportunities in research that do not place the sole responsibility 
on the individual student or dietitian.

In spite of this, there are a few concerns with these collaborations. Dietitians have reported that their lack of research knowledge and skills might be embarrassing when working with an experienced faculty member, which may prohibit them from conducting research (Slawson et al., 2000). Furthermore, it cannot be assumed that all academic dietitians are competent in research (Eck et al., 1998), as the job descriptions for academic positions vary with regard to research expectations in the US (Gabel \& PondSmith, 1995; Nyland et al., 1989; Schiller et al., 1988) and the UK (Whelan \& Markless, 2012). Simply working in an academic setting does not guarantee research competence. Studies have assessed the research productivity and skills of coordinated program directors (Gabel \& Pond-Smith, 1995; Nyland et al., 1989), but not specifically of DI Directors.

\section{Directors}

Per ACEND, a DI Director is required to be a dietitian with a master's degree who has worked for at least 3 years post credentialing. Institutions may also have their own requirements for the position, but the minimal requirements outlined by ACEND must be followed. Although it is expected that DI Directors have experience with each competency since they have met the aforementioned requirements, it does not necessarily mean that they are truly competent in each area. The theory of experiential learning highlights this concept. According to this theory, learners must experience something before true learning can occur (Dewey, 1938; Joplin, 1981; Kolb, 1984); however, solely participating in an experience is not acceptable, because experience does not equate to learning (Dewey, 1938; Joplin, 1981; Kolb, 1984; Mazurkewicz et al., 2012; Roberts, 
2006). In the case of the competency CRD 1.5, DI Directors must have meaningful experiences with research in order to have a foundation to align proper learning activities and experiences to this competency.

As previously mentioned, despite the fact that research is a core competency for dietitians, many studies have demonstrated that dietetic professionals are not competent in research (Byham-Gray et al., 2006; Eck et al., 1998; Gardner et al., 2002; Guyer et al., 1993; Schiller, 1988; Schiller et al., 1988; Slawson et al., 2000; Wylie-Rosett et al., 1990). Though these studies have not been conducted exclusively with DI Directors, the results do suggest that there is a misalignment between the expectations and reality of the profession as it relates to research competence. This issue has been investigated for many years, but the influence of DI Directors has never been explored.

Therefore, it becomes necessary to expand the scope of the available literature, particularly the literature that focuses on the interpretation and implementation of dietetic competencies. A study assessed the perspective of DI Directors on their expectations of interns regarding nutrition education and counseling competencies (Sullivan, Schiller, \& Horvath, 1990). DI Directors $(n=66$, response rate $=65 \%)$ completed a survey indicating the competency of interns prior to starting their program, the amount of training the interns received during the internship, and the need for additional training post-internship (Sullivan et al., 1990). The results of this study indicated that the vast majority of DI Directors reported that their internship program provided moderate or extensive training in each of the categories that were used to measure the competencies; furthermore, the majority also reported that their interns would not need additional training post the internship (Sullivan et al., 1990). The authors note that this finding is 
not in alignment with the professional perspective that continuing education is important for these particular competencies (Sullivan et al., 1990). This suggests that the DI Directors have a different interpretation or understanding of these competencies. Similar results have been found when looking at the manner in which dietitians in the UK understand the term research, as only $16 \%$ were able to completely match a standard definition of the term (Harrison et al., 2001).

The implementation of competencies can also be challenging. Dietetic program directors are responsible for ensuring that appropriate experiences are aligned with each competency. However, it has been shown that directors often have problems with this task (Fitz \& Winkler, 1989; Gilboy et al., 2010; Knoblock-Hahn et al., 2010).

Only one published study aimed to identify the types of research activities included in the DI curriculum (Fitz \& Winkler, 1989); however, it should be noted that this study was done prior to the current ACEND-required research competencies. Data from the DI Directors $(n=74)$ revealed that $40 \%$ of programs required interns to collect research data, 33\% required interns to conduct their own research project, and 19\% required interns to conduct research that was designed by others (Fitz \& Winkler, 1989). The details of these projects were not mentioned; however, the authors note that the "levels of the research-related experience varied widely and ranged from observation to application and synthesis" (Fitz \& Winkler, 1989, p. 1677).

Similar findings have been reported with other competencies. Knoblock-Hahn et al. (2010) conducted a study to assess the extent cultural competence was addressed in the dietetics curriculum as well as the perceptions of didactic program directors $(n=58$, response rate $=28 \%)$, coordinated program directors $(n=20$, response rate $=40 \%)$, and 
DI Directors $(n=61$, response rate $=26 \%)$ on the most important areas of cultural competence for dietetic education. A survey was created by the researchers based upon information from the Office of Minority Health (Knoblock-Hahn et al., 2010). The committee that developed the survey made several revisions, which, the authors claim, assured face validity (Knoblock-Hahn et al., 2010). Results of the study indicated that program directors reported that many of the suggested cultural experiences in the survey should be offered, but they do not offer them as a part of their program (Knoblock-Hahn et al., 2010). In other words, the programs are not providing ample experiences to ensure cultural competence. This suggests that there is a discrepancy between what program directors feel is important and necessary to meet this competency and what they actually provide in their curriculum. Though the aim of the study was not to identify possible barriers to improve the dietetic education in regard to this competency, the authors did collect open-ended responses to get a general understanding of the perceived barriers from the view of the program directors. An interesting finding was that many program directors felt that simply exposing students to diverse populations should suffice as meeting the competency (Knoblock-Hahn et al., 2010). This suggests a lack of knowledge on the part of program directors on developing higher order skills. The authors argue that the lack of "specific and measurable competencies" makes it difficult for program directors to effectively measure cultural competence (Knoblock-Hahn et al., 2010).

Furthermore, Gilboy et al. (2010) investigated the ways the public policy competency was covered in the curriculum for didactic programs in dietetics and how this competency was measured. The authors of this study also created a survey, which 
was reviewed by a panel of four experts who were reported to have extensive experience in both dietetic education and survey development or public policy (Gilboy et al., 2010). After revisions were made based upon the feedback of the review panel, the survey was pilot tested by a group of undergraduate coordinated program directors. The actual survey was emailed to all didactic program directors $(n=223)$ on the CADE (now ACEND) website as of January 2009. The response rate of completed surveys was at $41 \%(\mathrm{n}=91)$. Results from the study indicated that, although public policy is a required competency, many dietetic educators did not feel their programs adequately addressed this topic, as the majority of directors reported that their programs only addressed the topics related to public policy "to some extent" (Gilboy et al., 2010).

\section{Summary}

It is unknown whether or not DI Directors have similar issues with the interpretation and implementation of the competency CRD 1.5. Many studies have shown that dietitians and dietetic faculty who are involved with research report a higher research capacity or confidence than those who are not involved in research (Harrison et al., 2001; Hays \& Peterson, 2003; Howard et al., 2013; Schiller et al., 1988; Whelan et al., 2007b). Therefore, based upon the theory of experiential learning, it seems that DI Directors who have a greater involvement in research activities will have a stronger research curriculum within their DI program. More research is warranted to explore this potential line of inquiry.

\section{Summary}

The professional level, educational level, and individual level of research competence within dietetics does not seem to be consistent based upon the reported 
literature. Despite many efforts by the dietetic profession, dietitians continuously report a lack of research knowledge and skills (Byham-Gray et al., 2006; Gardner et al., 2002;

Guyer et al., 1993; Schiller et al., 1988; Slawson et al., 2000). This misalignment has been explored for many years, but never from the perspective of the DI Directors who are responsible for designing and implementing the curriculum set by the profession.

Accordingly, the present study sought to investigate this gap in the literature. 


\section{CHAPTER III \\ METHODOLOGY AND PROCEDURES}

\section{Introduction}

This chapter describes the methodology and procedures that were utilized for the present study. This study sought to help fill a void in the literature regarding the influence of DI Directors' experience with research and how it affects the manner in which they manage their DI program as it relates to competency CRD 1.5. This was a cross-sectional study, which utilized survey research (Creswell, 2009). The details of the study follow.

\section{Problem Statement}

Research has been identified as a core competency for dietitians (Accreditation Council for Education in Nutrition and Dietetics, 2016c). However, a large body of evidence suggests that many dietetic educators and dietitians are not conducting research (Byham-Gray et al., 2006; Eck et al., 1998; Gardner et al., 2002; Guyer et al., 1993; Schiller, 1988; Schiller et al., 1988; Slawson et al., 2000; Whelan \& Markless, 2012; Wylie-Rosett et al., 1990). Previous research has investigated factors that influence the research involvement of dietitians (Byham-Gray et al., 2006; Whelan \& Markless, 2012), but none have looked strictly at the role of DI Directors. The present study sought to expand upon this area of inquiry. 


\section{Purpose of the Study}

The purpose of this study was to examine the relationship of the research involvement of DI Directors and their interpretation and implementation of competency CRD 1.5 for DI programs.

\section{Research Questions}

Research questions should guide the design, measurement and analysis of any inquiry (Vogt, 2007). The following research questions were used for this purpose in this study.

1. Where do DI Directors fall on the research involvement continuum as defined by the Research Involvement Questionnaire?

2. What types of factors influence DI Directors' involvement with research?

3. How do DI Directors interpret competency CRD 1.5?

4. What types of learning experiences are DIs using to fulfill competency CRD $1.5 ?$

5. What is the relationship of the research involvement of DI Directors and their interpretation and implementation of competency CRD 1.5?

6. What are the curricular/professional implications for utilizing experiential learning for competency CRD 1.5 in DI programs and how might this affect the profession as a whole?

\section{Participants}

The target population for this study was DI Directors who manage ACENDaccredited DI programs in the United States, which includes Puerto Rico. Currently, there are 247 DI programs (Accreditation Council for Education in Nutrition and 
Dietetics, 2015). The contact information for each DI Director was publicly available, as it is listed on ACENDs website. In order to obtain as many participants as possible, all DI Directors who were not involved with the present study were contacted to participate in this study. As of July 30, 2015, ACENDs website listed 247 DI programs, with 246 DI Directors, as two programs were a consortium with the same DI Director. Further, two DI Directors were directly involved in the present study; one was the researcher of this study and the other was a dissertation committee member. Thus, a total of 244 DI Directors were contacted for participation in this study.

\section{Ethical Considerations}

All attempts were made to ensure the quality and integrity of the research. This study was approved prior to data collection by the Institutional Review Board (IRB) at Illinois State University and the Committee on the Use of Human Subjects in Research (CUHSR) at Bradley University. Participation was voluntary and required informed consent (Appendix A). Though minimal risks were associated with this study, participants had the opportunity to skip questions and to quit the study at any time. Additionally, the survey was anonymous, and it did not have any identifying information in an effort to protect participant confidentiality.

\section{Instruments}

A survey was developed by the researcher that combined multiple components from the literature on this topic, including a validated instrument, which was originally developed by Whalen et al. (2013). The survey can be found in Appendix B. The present survey is the first of its kind, as it expanded the scope of the validated instrument by means of additional questions to assess the participants as well as their interpretation 
and implementation of competency CRD 1.5. The survey contained three sections, which are described in the order they appear on the survey.

\section{Section 1}

The first four questions on the survey were used to measure the interpretation and implementation of competency CRD 1.5. The concept utilized by Harrison et al. (2001) to measure interpretation of research was incorporated into the survey. An open-ended item was used to allow participants to describe their interpretation of competency CRD 1.5 using their own words. Then, with the use of a multiple-choice item, participants had to select the definition that they felt best matched their interpretation of competency CRD 1.5. Similar to Harrison et al. (2001), participants' responses were classified as a complete, partial, or failed match. The implementation of competency CRD 1.5 was assessed using an open-ended item by having participants briefly describe the experience(s) aligned with competency CRD 1.5 within their DI program curriculum. Then with a multiple-choice item, participants selected the specific components that comprise of the experience(s) aligned with competency CRD 1.5. The experiences on the survey were informed by several studies (Anchonodo et al., 2014; Fitz \& Winkler, 1989; Hays \& Peterson, 2003; Howard et al., 2013; Hynak-Hankinson et al., 1997; Peterson et al., 2008; Steiber \& Barkoukis, 2006; Whelan et al., 2007b). An important distinction that was noted in the literature was between original, hypothesis-driven research and other scholarly activities (Levine et al., 2005); therefore, this distinction was made in the present survey. Participants selected all components that were aligned with competency CRD 1.5 for their program. Answers were classified as a complete, partial, or failed match depending upon the components that were selected. 


\section{Section 2}

The second part of the survey contained a series of 24 questions that measured the research involvement of DI Directors, which was developed and previously described by Whalen et al. (2013). The validated Research Involvement Questionnaire (RIQ), which has a content validity index of 0.92 and internal consistency using Cronbach's coefficient of 0.98 (Whelan et al., 2013), was utilized in the present study with permission from the author. This questionnaire was based upon the four levels of the research continuum: practice, collaboration, participation, and leadership (Wylie-Rosett et al., 1990). The RIQ contains six questions for each of the four levels on the research continuum, with answers ranging from involvement of: not at all (0), a little (1), quite a bit (2), a lot (3), and a great deal (4). Thus, the maximum values for each level and for overall were 24 and 96 , respectively.

\section{Section 3}

The final section of the survey contained questions designed to gain a better perspective of the participants. The categories were modified from Byham-Gray (2004) by including in this section sociodemographic (sex, age, race/ethnicity), education and training (educational level, completion of thesis/dissertation, formal and informal education), professional experience (years RD, years DI Director, how often and how frequent research was read), research experience (author/co-author of article, involvement with group and individual projects, involvement with research in current and past positions, confidence with research), and employment setting (type of institution, type of program). 
The survey was administered through the use of Qualtrics (Provo, Utah).

Qualtrics is a web-based survey software tool that has a quantitative statistical platform. After generating the survey in Qualtrics, the link to the survey was disseminated to all participants in the recruitment email (Appendix C) and the reminder email (Appendix D).

\section{Procedures}

A quantitative survey, which included a few open-ended questions, was developed for this study (Appendix B). The survey was informed by the literature (Byham-Gray, 2004; Harrison et al., 2001; Levine et al., 2005; Whelan et al., 2013). Section two of the survey contained the validated Research Involvement Questionnaire, which was developed and validated by Whelan et al. (2013). Permission was granted by Whelan to utilize this questionnaire for the present study. Per the author's request, no changes were made to this questionnaire. Additional permission was obtained thorough Copyright Clearance Center’s RightsLink service.

\section{Expert Panel}

Five content experts were utilized to provide input to the survey prior to data collection. Three experts were dietitians as well as dietetic educators who had been involved in research in both their educational and professional careers, with two of these individuals having had experience working with dietetic interns on research. Two experts were also dietetic faculty who had worked directly with dietetic interns on research projects and both of these individuals were instructors of research methods and statistical courses. The content experts were asked to review the entire survey, despite the fact that section two, the validated RIQ, could not be changed, per the request of the author. The purpose of the expert panel review was to provide content validity to sections one and 
three of the survey, as these sections were not statistically validated.

The content experts made multiple suggestions for improvement to the survey. Some were wording changes to clarify the question, while others were to help obtain more meaningful data. For instance, the questions about interpretation originally used the term "understanding"; however, members from the expert panel thought using the term "interpretation" would provide answers that were more in line with the focus of this study. Additionally, the description of competency CRD 1.5 was only included in the first question, but the expert panel recommended to repeat it for each question that referred to it to eliminate confusion. Also, there was concern that participants would not be able to remember how many research methods or statistic courses they had completed; thus, these questions were modified to differentiate between formal and informal experiences. Options for participants to provide open-ended feedback to clarify answers were encouraged to be included in the final survey. Finally, due to the growing number of distance learning options, it was suggested to ask participants about this type of program. Feedback from the content experts and the dissertation committee were incorporated into the final survey, which can be found in Appendix B.

\section{Current Study}

This study was designed to look exclusively at the influence of DI Directors. In an attempt to obtain responses from as many participants as possible, all DI Directors who managed an ACEND-approved DI program, and who were not involved in the present study $(n=244)$ were contacted regarding this study. Email addresses for every DI Director were publicly available on ACEND's website (http://www.eatrightacend.org/ACEND/content.aspx?id=10760). 
Participants were contacted directly via email. The recruitment email with the link to the survey can be found in Appendix C. This email was sent on July 30, 2015, and it was blind copied to all DI Directors listed on ACENDs website, except for the two who were involved in the present study $(\mathrm{n}=244)$. Reminder emails were sent to all DI Directors who received the recruitment email. Reminder emails were sent on August $6^{\text {th }}$, August $31^{\text {st }}$ and September $8^{\text {th }}$, and the survey closed on September 11, 2015. The reminder email is located in Appendix D.

\section{Data Analysis}

Data were collected using Qualtrics and analyzed using SPSS Version 23.

Statistical significance was set at the 0.05 level. The procedures for data analysis are presented relative to the respective research question.

\section{Research Question 1}

Where do DI Directors fall on the research involvement continuum as defined by the Research Involvement Questionnaire (RIQ)? The RIQ has six questions for each of the four levels of research involvement. Respondents answered 24 questions on a 5-point Likert-type scale regarding their involvement with research $(0=$ not at all, $1=$ a little, $2=$ quite a bit, $3=\mathrm{a}$ lot, $4=$ a great deal). The data are presented as a total score for each of the four levels by calculation of a sum for the six questions that are associated with the level (maximum $=24)$, and a total score for all levels by summation of the scores for all 24 questions (maximum $=96$ ). Descriptive analysis, such as frequencies, measures of central tendency, and standard deviations, were run to describe DI Directors' level of research involvement. 


\section{Research Question 2}

What types of factors influence DI Directors' involvement with research? Descriptive analysis, including frequencies, means, standard deviations, and percentages were calculated to describe the DI Director's level of research involvement for each of the variables associated with independent variables of sociodemographic, education/training, professional experience, research experience, and employment setting. One-way analysis of variance (ANOVA) tests were run to evaluate the differences in the means between research involvement and each of the independent variables. Correlations were also computed to assess the relationship between each of the variables. Results from the ANOVA and correlations were used to conduct a linear regression model to determine the influence of the independent variables on the dependent variable of research involvement as measured by the overall, summed RIQ.

\section{Research Question 3}

How do DI Directors interpret competency CRD 1.5? First, respondents were asked to describe their interpretation of competency CRD 1.5. The open-ended responses were reviewed for general themes and the findings were used to provide insight into the quantitative data. Second, respondents were asked to select one of three possible answers to the question: "Which of the following best describes your interpretation of ACEND's Core Competency CRD 1.5, which reads 'conduct projects using appropriate research methods, ethical procedures and data analysis'? Please describe the concept in your own words and without consulting any document or (re)source.” The answers were classified as a complete, partial, or failed match based upon ACEND's definition of research. Specifically, the selection of "interns must be familiar with the basic concepts of research 
but do not need to be able to conduct research" was classified as a failed match; selection of "interns must be able to conduct components of a research project, but not every step" was classified as a partial match; and selection of "interns must be able to conduct a full research project, which includes systematically testing research questions, a hypothesis, or a theory in order to discover new information" was classified as a complete match. Descriptive data consisting of the frequencies and percentages were used to analyze and present the DI Director's responses to this section of the survey. Additionally, a two-way contingency table was created to summarize the relationship between the interpretation of competency CRD 1.5 and the variables in the sociodemographic, education/training, professional experience, research experience, and employment setting categories. Cohen's guidelines, which vary based upon the $d f$, were used to classify the relationship as a small effect, medium effect, or large effect (Gravetter \& Wallnau, 2009).

\section{Research Question 4}

What types of learning experiences are DIs using to fulfill competency CRD 1.5? Two survey questions were associated with this research question. The first was an openended question that asked participants to provide the specific experience(s) within their DI curriculum that they had aligned with competency CRD 1.5. The data gathered from the open-ended items were reviewed to ascertain the experiences that were aligned with competency CRD 1.5. These responses were reviewed for general themes and they were used to provide insight into the quantitative data. The second survey question that was aligned with this research question required participants to select various components of the research process that interns must complete in order to fulfill the experience that was aligned with competency CRD 1.5 in their program. The components included analysis 
of data, collection of data, completion of IRB protocol, completion of ethics tutorials, completion of the Academy's Online Research Toolkit, critical evaluation of research articles, design of research protocol, formulation of research questions/hypothesis, presentation of an original research paper/report, production of a literature review, and production of an original research paper/report. A complete match was intended to include all of the components listed, except for the completion of the Academy's toolkit, as this is not a necessary step in the research process, though it is certainly helpful. Participants who selected at least one of the components, not counting the Academy's toolkit, were classified as a partial match, and participants who selected zero of the components were considered a failed match. However, data analysis revealed some issues with this design; this is discussed in Chapter IV of this paper. Descriptive data, consisting of the frequencies and percentages, were calculated to describe the experiences and to describe the categories of DI Directors who provided complete, partial, or failed matches for the implementation of competency CRD 1.5. Similar to research question three, a two-way contingency table was created to explore the relationship between the implementation of competency CRD 1.5 and the variables in the sociodemographic, education/training, professional experience, research experience, and employment setting categories.

\section{Research Question 5}

What is the relationship of the research involvement of DI Directors and their interpretation and implementation of competency CRD 1.5? Discriminant analysis was utilized to answer this question, as it is a statistical technique used to classify participants into groups based upon one or more measures (Green \& Salkind, 2008; Mertler \& 
Vannatta, 2005). Specifically, discriminant analysis was conducted to determine whether the independent variables of the four levels of research involvement, as measured on a scale of $0-24$, could predict the dependent variables of interpretation and implementation, which were both measured by a complete, partial, and failed match. Thus, the discriminant analysis was used to distinguish the dependent variable category based upon the linear combinations of the predictor independent variable measures (Green \& Salkind, 2008; Mertler \& Vannatta, 2005). It should be noted that two separate analyses were run for each of the dependent variables.

The discriminant analysis contained all four of the typical parts, including group differences, significance tests, discriminant function coefficients, and group classifications (Mertler \& Vannatta, 2005). The Wilks's Lambda, which is series of chisquare significance tests, was used to determine whether there were significant differences among the groups in the predictor variables, after the effects of the previous discriminant functions were removed (Green \& Salkind, 2008; Mertler \& Vannatta, 2005). The effect size was determined using the canonical correlation, which is a derivative of the eigenvalue, but the canonical correlation is easier to interpret because it has an upper limit, unlike the eigenvalue (Green \& Salkind, 2008). The classification results were used to determine how well group membership was predicted. In order to correct for chance agreements and to assess the accuracy with the prediction of group membership, kappa was computed (Green \& Salkind, 2008).

\section{Research Question 6}

What are the curricular/professional implications for utilizing experiential learning for competency CRD 1.5 in DI programs and how might this affect the 
profession as a whole? The findings from research questions one through five were used to ascertain the implications on the program and the field as a whole. This will be addressed in the final chapter of the study.

\section{Summary}

This study sought to explore the influence the research involvement of DI Directors has on their interpretation and implementation of competency CRD 1.5 for DI programs, using a quantitative approach. The methodology employed for this research was driven by the purpose of the study and the research questions. Participants for this cross-sectional study were contacted via email and asked to complete an anonymous survey. The survey consisted of three sections. Two sections were based upon the literature on this topic and one section was the validated, RIQ developed by Whalen et al. (2013). The survey was distributed though Qualtrics and analyzed with SPSS. Efforts were taken to maximize the ethical nature of the study as well as the trustworthiness and authenticity of the data. The findings of this study are presented in the next chapter. 


\section{CHAPTER IV \\ RESULTS AND ANALYSIS}

\section{Introduction}

The purpose of this study was to examine the research involvement of DI

Directors and the manner in which this influences their interpretation and implementation of the research competency, CRD 1.5, for DI programs. Five research questions guided the design, data collection, and data analysis of the study. The data were generated from a survey sent to all DI Directors listed on ACEND's website as of July 30, 2015, and those not involved in the present study. The survey contained the validated, RIQ (Whalen et al., 2013) as well as two other sections. Both sections were developed by the researcher and reviewed by an expert panel in an effort to provide content validity. Statistical significance was set at $p \leq .05$ for all analyses. This chapter presents the study results.

\section{Participant Profile}

A total of 244 DI Directors were contacted for participation in this study, with 152 consenting to participate in the study. This was an overall response rate of $62.3 \%$. Out of the 152, 56 did not complete the survey leaving a total of 96 usable responses and a response rate of $39.3 \%$. The majority of the 96 participants who provided usable data completed all three sections of the survey; however, four participants only completed section one, and two participants only completed sections one and three of the survey. The issues surrounding the missing data will be discussed further in the presentation of the findings as they relate to the research questions. 
Table 1 highlights the frequencies and percentages of selected demographic characteristics of the participants of the study. The majority of participants were female (99\%), between 46 to 65 years old (64\%), Caucasian (89\%), had been a dietitian for more than 25 years (45\%), and a DI Director for 5 years or less $(51 \%)$.

\section{Table 1}

Participant Demographic Characteristics

\begin{tabular}{|c|c|c|}
\hline Demographic Characteristics & Frequency $^{\mathrm{a}}(\mathrm{n})$ & $(\%)$ \\
\hline \multicolumn{3}{|l|}{ Sex } \\
\hline Female & 91 & 98.9 \\
\hline Male & 1 & 1.1 \\
\hline \multicolumn{3}{|l|}{ Age } \\
\hline $25-35$ & 8 & 8.7 \\
\hline $36-45$ & 21 & 22.8 \\
\hline $46-55$ & 30 & 32.6 \\
\hline $56-65$ & 29 & 31.5 \\
\hline$>65$ & 4 & 4.3 \\
\hline \multicolumn{3}{|l|}{ Race/ethnicity } \\
\hline African American & 3 & 3.3 \\
\hline Asian or Pacific Islander & 2 & 2.2 \\
\hline Asian Indian or South Asian & 2 & 2.2 \\
\hline Caucasian & 80 & 88.9 \\
\hline Latino & 2 & 2.2 \\
\hline Native American & 0 & 0.0 \\
\hline Another racial identity & 1 & 1.1 \\
\hline \multicolumn{3}{|l|}{ Years RD } \\
\hline $3-5$ & 2 & 2.3 \\
\hline $6-10$ & 10 & 11.5 \\
\hline $11-15$ & 6 & 6.9 \\
\hline $16-20$ & 12 & 13.8 \\
\hline $21-25$ & 18 & 20.7 \\
\hline$>25$ & 39 & 44.8 \\
\hline \multicolumn{3}{|l|}{ Years DI Director } \\
\hline $0-2$ & 22 & 24.4 \\
\hline $3-5$ & 24 & 26.7 \\
\hline $6-10$ & 18 & 20.0 \\
\hline $11-15$ & 9 & 10.0 \\
\hline $16-20$ & 9 & 10.0 \\
\hline $21-25$ & 5 & 5.6 \\
\hline$>25$ & 3 & 3.3 \\
\hline
\end{tabular}

${ }^{a}$ Due to missing data, total may be less than 96. 
Table 2 depicts the frequencies and percentages of the educational characteristics of the participants. The highest degree earned by the majority of the participants was a master's (62\%) and a PhD (23\%). A master's thesis was completed by $62 \%$, and a doctoral dissertation was completed by $31 \%$ of the participants.

\section{Table 2}

Participant Educational Characteristics

\begin{tabular}{lrc}
\hline Educational Characteristics & Frequency $^{\mathrm{a}}(\mathrm{n})$ & $(\%)$ \\
\hline Highest education & & \\
Master's degree & 56 & 61.5 \\
Working toward doctoral degree & 6 & 6.6 \\
PhD & 21 & 23.1 \\
EdD & 7 & 7.7 \\
Other & 1 & 1.1 \\
Master's thesis & & \\
Yes & 57 & 62.0 \\
No & 34 & 37.0 \\
In progress & 1 & 1.1 \\
Doctoral dissertation & & \\
Yes & 28 & 31.1 \\
No & 58 & 64.4 \\
In progress & 4 & 4.4 \\
\hline
\end{tabular}

${ }^{\mathrm{a}}$ Due to missing data, total may be less than 96.

The frequencies and percentages of the research experiences of the participants are presented in Table 3. Nearly half of participants (48\%) responded that they had either been the author or co-author on a published, research-based article, and $4 \%$ of participants reported that they had no research experience. Participants had most frequently worked on a research project for their master's thesis $(50 \%)$ and for a professional project for their job (48\%). More participants were involved with research 
within their current position $(51 \%)$ compared to their past position $(41 \%)$. The majority of participants had worked on 1-5 group projects (44\%) and on 1-5 independent projects (51\%). Confidence in conducting research was measured by having participants self-rate how confident they were with their own research skills (not confident at all, not very confident, somewhat confident, very confident). This question was set up differently than the rest of section three of the survey, as can be seen in Appendix B. The answers were provided horizontally rather than vertically. The reason for this was to streamline the format of all Likert-type questions on the survey. Section two contained the RIQ, which had 24 Likert-type questions. However, section three only contained 1 Likert-type question, confidence with research, which was toward the end of the survey. It is likely that participants accidentally skipped over this question, as answers were missing from 41 participants (57\% response rate). Regardless, the data show that the most frequent answer for confidence was "somewhat confident" $(51 \%, \mathrm{n}=55)$.

Table 4 shows the frequencies and percentages of the institutional characteristics of the dietetic internship programs that the participants, who are DI Directors, manage. The most frequent institutional type represented in this study was a university (62\%), followed by a hospital (12\%), and a governmental agency (11\%). The least frequent institutional type was industry (2\%). The majority of programs were described as supervised practice only (44\%) and as an on-site program (84\%). 
Table 3

Participant Research Experience

\begin{tabular}{|c|c|c|}
\hline Research Experiences & Frequency $^{\mathrm{a}}(\mathrm{n})$ & $(\%)$ \\
\hline Author/coauthor & 43 & 48.3 \\
\hline \multicolumn{3}{|l|}{ Research involvement $^{\mathrm{b}}$} \\
\hline Master's thesis & 48 & 50.0 \\
\hline Professional project & 46 & 47.9 \\
\hline Doctoral dissertation & 28 & 29.2 \\
\hline Master's non-thesis & 25 & 26.0 \\
\hline DI project & 20 & 20.8 \\
\hline Other & 19 & 19.8 \\
\hline Undergraduate project & 18 & 18.8 \\
\hline None & 4 & 4.2 \\
\hline \multicolumn{3}{|c|}{ Research involvement in job/position } \\
\hline Current position & 46 & 50.5 \\
\hline Past position & 37 & 41.1 \\
\hline \multicolumn{3}{|l|}{ Group projects } \\
\hline 0 & 17 & 18.7 \\
\hline $1-5$ & 40 & 44.0 \\
\hline $6-10$ & 15 & 16.5 \\
\hline $11-20$ & 9 & 9.9 \\
\hline$>20$ & 10 & 11.0 \\
\hline \multicolumn{3}{|l|}{ Independent projects } \\
\hline 0 & 40 & 44.0 \\
\hline $1-5$ & 46 & 50.5 \\
\hline $6-10$ & 1 & 1.1 \\
\hline $11-20$ & 4 & 4.4 \\
\hline$>20$ & 0 & 0 \\
\hline \multicolumn{3}{|l|}{ Confidence $^{c}$} \\
\hline Not at all & 7 & 12.7 \\
\hline Not very & 12 & 21.8 \\
\hline Somewhat & 28 & 50.9 \\
\hline Very & 8 & 14.5 \\
\hline
\end{tabular}

${ }^{\mathrm{a}}$ Due to missing data, total may be less than 96.

${ }^{\mathrm{b}}$ Participants could select multiple options.

${ }^{\mathrm{c}}$ Due to set-up of question, only $55(57.3 \%)$ answered this question

It should be noted that several participants selected the "other" option for the type of DI; however, the participants comments provided on the survey indicated some confusion on the categories. For instance, three participants selected "other" and 
commented that their program was a supervised practice program with graduate credit, which would fit into the "some master's credit only" category. In total, eight participants selected "other" and based upon the clarification provided in the comment section, all eight responses were placed into the most appropriate category for the type of DI.

Table 4

Institutional Characteristics

\begin{tabular}{lcr}
\hline Institutional Characteristics & Frequency $^{\mathrm{a}}(\mathrm{n})$ & $(\%)$ \\
\hline Institution type & & \\
Governmental agency & 10 & 11.0 \\
Hospital & 11 & 12.1 \\
Industry & 2 & 2.2 \\
University & 56 & 61.5 \\
University-based hospital & 7 & 7.7 \\
Other & 5 & 5.5 \\
DI type & & \\
Supervised practice only & 40 & 44.0 \\
Some master's credit only & 27 & 29.7 \\
Master's degree only & 9 & 9.9 \\
Both master's and non-master's tracks & 15 & 16.5 \\
Distance learning & & \\
No & 76 & 83.5 \\
Yes, both distance and on-site & 10 & 11.0 \\
Yes, exclusively distance & 5 & 5.5 \\
\hline${ }^{a}$ Due to missing data, total may be less than 96 & &
\end{tabular}

${ }^{\mathrm{a}}$ Due to missing data, total may be less than 96

As shown in Tables 1 through 4, the participants in this study were quite varied in some aspects of their demographic characteristics, educational characteristics, research experience, and institutional characteristics of their employment setting. However, minimal dispersion was shown with the responses for several variables within these categories, with the most pronounced noted for sex (99\% female). These demographic data are discussed in context in Chapter V. 


\section{Results}

\section{Research Question 1}

Where do DI Directors fall on the research involvement continuum as defined by the Research Involvement Questionnaire? The research continuum has four levels (Wylie-Rosett et al., 1990), and the RIQ was designed to measure research involvement based upon the aforementioned four levels (Whelan et al., 2013). Six questions on the survey corresponded to each of the four levels on the research continuum; thus, a total of 24 questions were utilized for data analysis. Table 5 shows the questions on the survey that corresponded to each level. The full survey can be found in Appendix B.

Prior to data analysis, the RIQ data were recoded to the same format utilized by Whalen et al. (2013). Qualtrics automatically coded the 5-point Likert-type scale, which ranged from "not at all" to "a great deal" on a scale of 1-5; however, Whalen et al. (2013) utilized a scale of 0-4. Missing data were also addressed. Six participants completely skipped the RIQ section (section 2) of the survey; therefore, they were deleted from this data analysis. Additionally, of the 24 questions associated with the RIQ, 11 participants skipped one question, and one participant skipped two questions. Since these 12 participants completed the majority of the RIQ, and since the questions that were missed were widespread (10 different questions of the 13 that were missing), the missing values were replaced with the series mean via SPSS. The resulting analysis contained responses from 90 participants. 
Table 5

Corresponding Questions to Each Level on the RIQ

\begin{tabular}{|c|c|}
\hline $\begin{array}{l}\text { Survey } \\
\text { question }\end{array}$ & Corresponding Survey Question \\
\hline \multicolumn{2}{|l|}{ Level 1} \\
\hline 1 & Interpreting basic aspects of data analysis when reading journal articles \\
\hline 4 & $\begin{array}{l}\text { Using the literature to identify what research studies still need to be conducted within } \\
\text { general areas }\end{array}$ \\
\hline 7 & Appreciating the ethical framework in which research should be conducted \\
\hline 12 & $\begin{array}{l}\text { Critically appraising aspects of research methods when reading journal articles. This } \\
\text { includes understanding the appropriate use of different study designs }\end{array}$ \\
\hline 13 & $\begin{array}{l}\text { Undertaking comprehensive literature searches using electronic databases in order to } \\
\text { inform your practice }\end{array}$ \\
\hline 24 & $\begin{array}{l}\text { Using the findings from journal articles/original research studies when making } \\
\text { decisions within your area of practice }\end{array}$ \\
\hline \multicolumn{2}{|r|}{ 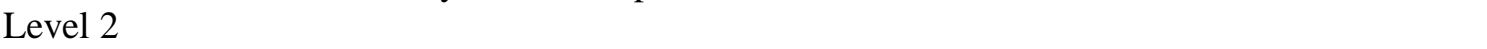 } \\
\hline 3 & Participating in research as part of a collaborative team \\
\hline 10 & Understanding and interpreting advanced data analysis when reading journal articles \\
\hline 11 & Participating in research under the supervision or mentorship of colleagues \\
\hline 16 & $\begin{array}{l}\text { Internal presentation of results from research projects in which you have been } \\
\text { involved }\end{array}$ \\
\hline 21 & $\begin{array}{l}\text { Using the literature and your experience to identify what research studies still need to } \\
\text { be conducted within your area of interest }\end{array}$ \\
\hline 23 & $\begin{array}{l}\text { External presentation of results from research projects in which you have been } \\
\text { involved }\end{array}$ \\
\hline \multicolumn{2}{|l|}{ Level 3} \\
\hline 2 & External presentation of results from research projects that you have led \\
\hline 5 & $\begin{array}{l}\text { Developing the research budget and subsequently managing funding, staffing and } \\
\text { time management issues for a research project }\end{array}$ \\
\hline 9 & $\begin{array}{l}\text { Applying for approval from research ethics and R\&D departments, and managing } \\
\text { projects in line with research governance frameworks }\end{array}$ \\
\hline 15 & $\begin{array}{l}\text { Leading the development and design of a research protocol following an appropriate } \\
\text { literature review, including identifying appropriate research methods and statistical } \\
\text { analyses }\end{array}$ \\
\hline 17 & $\begin{array}{l}\text { Independently formulating research questions or hypotheses within your area of } \\
\text { practice }\end{array}$ \\
\hline 22 & Participating in the review of the research of others \\
\hline \multicolumn{2}{|r|}{ - } \\
\hline 6 & Educating colleagues in research methodology and methods \\
\hline 8 & Extensively involved in reviewing the research of others \\
\hline 14 & Developing and leading programs of research \\
\hline 18 & Supervising and mentoring colleagues to undertake research \\
\hline 19 & $\begin{array}{l}\text { Influencing the research of others through active participation in research-related } \\
\text { committees or external organizations }\end{array}$ \\
\hline 20 & Undertaking research as a major component of your current job description \\
\hline
\end{tabular}


Participants rated their involvement with research on a 5-point Likert-type scale $(0=$ not at all, $1=$ a little, $2=$ quite a bit, $3=$ a lot, $4=$ a great deal $)$ for each of the 24 questions. Descriptive statistics consisting of the frequencies and measures of central tendency were calculated to answer this research question. Tables 6 through 9 show the frequencies and means for each of the questions in the four levels of the research continuum. The frequencies are presented as the percentage of participants who selected each response. The majority of participants either selected "not at all" or "a little" for each question, which suggests relatively little research involvement.

As the research involvement level increased, the majority of responses shifted from "a little" to "not at all" indicating less research involvement at the higher levels on the continuum. That is, for Level 1, the majority of participants selected "a little" for five of the six questions; this decreased to three of six questions for Level 2, and one of six questions for Level 3. Further, the majority of participants in Level 4 selected "not at all" for all six questions. This inverse trend can also be seen with the overall mean for each of the levels. The mean decreased as the research continuum levels increased. The means for Level 1, 2, 3, and 4 were 1.7, 1.1, 0.9, and 0.7, respectively. Level 1 and Level 2 had means that fell between 1 (a little) and 2 (quite a bit) with the mean of Level 1 at the higher end. Similarly, Level 3 and Level 4 had means between 0 (not at all) and 1 (a little) with Level 4 having a lower mean, indicating less research involvement by the participants. 
Table 6

Frequencies and Means for RIQ Level 1 Items

\begin{tabular}{lllllrl}
\hline $\begin{array}{l}\text { Survey } \\
\text { question \# }\end{array}$ & $\begin{array}{l}\text { Not at all } \\
(\%)\end{array}$ & $\begin{array}{l}\text { A little } \\
(\%)\end{array}$ & $\begin{array}{l}\text { Quite a } \\
\text { bit }(\%)\end{array}$ & $\begin{array}{l}\text { A lot } \\
(\%)\end{array}$ & $\begin{array}{l}\text { A great } \\
\text { deal }(\%)\end{array}$ & Mean $^{\mathrm{a}}$ \\
\hline 1 & 13.3 & 42.2 & 22.2 & 17.8 & 4.4 & 1.6 \\
4 & 24.4 & 32.2 & 23.3 & 13.3 & 6.7 & 1.5 \\
7 & 17.0 & 29.5 & 23.9 & 13.6 & 15.9 & 1.8 \\
12 & 13.5 & 40.4 & 23.6 & 15.7 & 6.7 & 1.6 \\
13 & 18.9 & 30.0 & 25.6 & 14.4 & 11.1 & 1.7 \\
24 & 12.4 & 16.9 & 37.1 & 19.1 & 14.6 & 2.1 \\
Overall & & & & & & 1.7 \\
\hline
\end{tabular}

${ }^{\mathrm{a}} 0=$ not at all, $1=\mathrm{a}$ little, $2=$ quite a bit, $3=\mathrm{a}$ lot, $4=\mathrm{a}$ great deal

Table 7

Frequencies and Means for RIQ Level 2 Items

\begin{tabular}{lllcrll}
\hline $\begin{array}{l}\text { Survey } \\
\text { question \# }\end{array}$ & $\begin{array}{l}\text { Not at all } \\
(\%)\end{array}$ & $\begin{array}{l}\text { A little } \\
(\%)\end{array}$ & $\begin{array}{l}\text { Quite a } \\
\text { bit }(\%)\end{array}$ & $\begin{array}{c}\text { A lot } \\
(\%)\end{array}$ & $\begin{array}{l}\text { A great } \\
\text { deal }(\%)\end{array}$ & Mean $^{\mathrm{a}}$ \\
\hline 3 & 21.1 & 41.1 & 16.7 & 13.3 & 7.8 & 1.5 \\
10 & 26.7 & 45.6 & 15.6 & 7.8 & 4.4 & 1.2 \\
11 & 45.5 & 38.6 & 8.0 & 5.7 & 2.3 & 0.8 \\
16 & 43.3 & 36.7 & 13.3 & 5.6 & 1.1 & 0.8 \\
21 & 30.3 & 42.7 & 15.7 & 10.1 & 1.1 & 1.1 \\
23 & 45.6 & 33.3 & 10.0 & 7.8 & 3.3 & 0.9 \\
Overall & & & & & & 1.1 \\
\hline
\end{tabular}

${ }^{\mathrm{a}} 0=$ not at all, $1=\mathrm{a}$ little, $2=$ quite a bit, $3=\mathrm{a}$ lot, $4=\mathrm{a}$ great deal

Table 8

Frequencies and Means for RIQ Level 3 Items

\begin{tabular}{lllclll}
\hline $\begin{array}{l}\text { Survey } \\
\text { question \# }\end{array}$ & $\begin{array}{l}\text { Not at all } \\
(\%)\end{array}$ & $\begin{array}{l}\text { A little } \\
(\%)\end{array}$ & $\begin{array}{l}\text { Quite a } \\
\text { bit }(\%)\end{array}$ & $\begin{array}{l}\text { A lot } \\
(\%)\end{array}$ & $\begin{array}{l}\text { A great } \\
\text { deal }(\%)\end{array}$ & Mean $^{\text {a }}$ \\
\hline 2 & 45.6 & 33.3 & 7.8 & 6.7 & 6.7 & 1.0 \\
5 & 62.2 & 18.9 & 10.0 & 5.6 & 3.3 & 0.7 \\
9 & 58.9 & 22.2 & 11.1 & 4.4 & 3.3 & 0.7 \\
15 & 50.0 & 28.9 & 14.4 & 4.4 & 2.2 & 0.8 \\
17 & 34.8 & 41.6 & 12.4 & 9.0 & 2.2 & 1.0 \\
22 & 51.7 & 23.6 & 13.5 & 9.0 & 2.2 & 0.9 \\
Overall & & & & & & 0.9 \\
\hline
\end{tabular}

${ }^{\mathrm{a}} 0=$ not at all, $1=\mathrm{a}$ little, $2=$ quite a bit, $3=\mathrm{a}$ lot, $4=\mathrm{a}$ great deal 
Table 9

Frequencies and Means for RIQ Level 4 Items

\begin{tabular}{lllcccc}
\hline $\begin{array}{l}\text { Survey } \\
\text { question \# }\end{array}$ & $\begin{array}{l}\text { Not at all } \\
(\%)\end{array}$ & $\begin{array}{l}\text { A little } \\
(\%)\end{array}$ & $\begin{array}{l}\text { Quite a } \\
\text { bit }(\%)\end{array}$ & $\begin{array}{l}\text { A lot } \\
(\%)\end{array}$ & $\begin{array}{l}\text { A great } \\
\text { deal }(\%)\end{array}$ & Mean $^{\text {a }}$ \\
\hline 6 & 70.0 & 25.6 & 4.4 & 0 & 0 & 0.3 \\
8 & 55.6 & 20.0 & 11.1 & 10.0 & 3.3 & 0.9 \\
14 & 51.1 & 24.4 & 14.4 & 6.7 & 3.3 & 0.9 \\
18 & 74.2 & 18.0 & 3.4 & 4.5 & 0 & 0.4 \\
19 & 51.7 & 36.0 & 7.9 & 4.5 & 0 & 0.7 \\
20 & 60.2 & 21.6 & 9.1 & 8.0 & 1.1 & 0.7 \\
Overall & & & & & & 0.7 \\
\hline
\end{tabular}

${ }^{\mathrm{a}} 0=$ not at all, $1=\mathrm{a}$ little, $2=$ quite a bit, $3=\mathrm{a}$ lot, $4=\mathrm{a}$ great deal

The responses to each of the questions on the RIQ were summed using the compute variable function in SPSS to generate a combined score for each of the four levels as well as a total score. Using the previously described 0-4 scale, the six questions associated with each level were summed (maximum $=24$ ), and all 24 questions were summed for the total score (maximum $=96$ ). Table 10 illustrates the descriptive statistics for the summed scores for the four levels and the overall RIQ. The minimum score for each level shows that some participants selected "not at all" for all six questions in the corresponding levels. Of those, two participants selected "not at all" for all 24 questions as indicated by 0 for the minimum overall score. The maximum scores indicate that some participants selected "a great deal" for most of the questions in Levels 1, 2, and 3. The maximum overall score was 76 out of a total of 96 .

The summed means also displayed an inverse trend with the four levels of the research continuum. Level 1 had the highest mean $(10.23 \pm 5.51)$, followed by Level 2 $(6.27 \pm 5.08)$, Level $3(5.04 \pm 5.43)$, and Level $4(3.78 \pm 4.23)$. These data suggest that fewer participants were involved with research at the higher levels on the research 
continuum. The overall summed mean for the RIQ was $25.33 \pm 18.76$. This represents about $26 \%$ (25/96) of the possible involvement with research as measured by the RIQ.

Table 10

Descriptive Statistics for Summed RIQ Scores for Levels 1, 2, 3, 4, and Overall

\begin{tabular}{lccccrc}
\hline & Minimum & Maximum & Median & Mode & Mean & SD \\
\hline Level 1 $^{\mathrm{a}}$ & 0 & 22 & 10 & 6 & 10.23 & 5.51 \\
Level 2 $^{\mathrm{a}}$ & 0 & 22 & 5 & 4 & 6.27 & 5.08 \\
Level 3 $^{\mathrm{a}}$ & 0 & 23 & 3 & 0 & 5.04 & 5.43 \\
Level 4$^{\mathrm{a}}$ & 0 & 18 & 2 & 0 & 3.78 & 4.23 \\
Overall $^{\mathrm{b}}$ & 0 & 76 & 19.5 & 15 & 25.33 & 18.76 \\
\hline
\end{tabular}

Note. $\mathrm{n}=90$

${ }^{\mathrm{a}}$ maximum possible $=24$,

${ }^{\mathrm{b}}$ maximum possible $=96$

Utilizing the research continuum classification system as described by Whalen et al. (2013), participants were assigned to one of the four levels of research involvement. The criteria for the classification system are presented in Table 11. Participants were assigned to the highest level based upon these criteria. A new variable, which identified the level the participant placed on the research continuum as measured by the RIQ, was created in SPSS for each participant.

Table 11

Criteria for Assigning Participants to Research Involvement Continuum Level

\begin{tabular}{ll}
\hline Level assigned & Criteria from $\mathrm{RIQ}^{\mathrm{a}}$ \\
\hline Level 1 & Level 1 score $1-5$ \\
Level 2 & Level 2 score $6-8$ \\
Level 3 & Level 3 score $9-14$ \\
Level 4 & Level 4 score $15-24$ \\
\hline
\end{tabular}

${ }^{a}$ Level was assigned based upon the highest level indicated by scores 
Table 12 shows the frequency distribution of each level on the research continuum based upon the criteria in Table 11. Two participants selected "not at all" for all 24 questions; thus, they did not meet the minimum requirement for placement into any of the levels. Regardless, their data are shown in Table 12 because these findings are relevant to the present study. The majority of participants were identified as being classified into Level 1 of the research continuum. In fact, more participants attained Level 1 on the research continuum than those in Levels 2, 3, and 4 combined.

Table 12

Frequency of Participants into the Four Levels of the Research Involvement Continuum

\begin{tabular}{lcrr}
\hline & Frequency (n) & $(\%)$ & Valid \% \\
\hline No level $^{\mathrm{a}}$ & 2 & 2.2 & \\
Level 1 & 47 & 52.2 & 53.4 \\
Level 2 & 23 & 25.6 & 26.1 \\
Level 3 & 15 & 16.7 & 17.0 \\
Level 4 & 3 & 3.3 & 3.4 \\
\hline
\end{tabular}

${ }^{\mathrm{a}}$ Did not meet minimum score for placement into a level

Overall, the data from the RIQ indicated that participants were involved with research at all levels on the research continuum. However, the majority of participants were identified to be at Level 1, which is the lowest level. Several factors likely contribute to research involvement, and these are discussed next.

\section{Research Question 2}

What types of factors influence DI Directors' involvement with research? The independent variables for this research question were considered to be all of the variables in the sociodemographic, education/training, professional experience, research 
experience, and employment setting categories, while the dependent variable was research involvement as measured by the overall, summed RIQ score. In order to answer this research question, two types of analyses were conducted. First, the relationship between research involvement and the independent variables was assessed using a oneway analysis of variance (ANOVA) as well as correlations. Second, using the ANOVA and correlations analyses, a regression analysis was conducted to determine if any independent variables could predict research involvement.

Tables 13 through 16 show the descriptive statistics for each of the variables in the sociodemographic/professional experience, education/training, research experience, and employment setting categories, respectively. As previously described, the majority of participants were female and Caucasian; thus, descriptive statistics for sex and race/ethnicity should be interpreted with caution. There was a positive relationship between the overall RIQ and age up to 65 years; however, this trend was not observed with overall RIQ and how long a participant had been an RD or a DI Director.

Furthermore, as indicated in Table 14, participants with higher education levels displayed higher RIQ scores. For example, the overall RIQ score of participants who had a PhD was $42.04 \pm 20.18$ compared to those with a master's degree $(17.83 \pm 13.97)$. Similarly, participants who completed a doctoral dissertation had an overall RIQ of 40.25 \pm 19.76 compared to those who did not $(17.45 \pm 13.89)$. In addition to education level, the frequency of reading influenced the overall RIQ. Participants who read daily had an overall RIQ of $61.00 \pm 17.09$, which was much higher than those who read once a year $(8.31 \pm .44)$. 
Table 13

Descriptive Statistics for RIQ by Participant Demographics

\begin{tabular}{|c|c|c|}
\hline $\begin{array}{l}\text { Sociodemographic and } \\
\text { professional characteristics }\end{array}$ & $\begin{array}{l}\text { Mean overall } \\
\text { RIQ }^{\mathrm{a}}\end{array}$ & SD \\
\hline \multicolumn{3}{|l|}{ Sex } \\
\hline Female & 25.53 & 18.77 \\
\hline Male & 7.00 & $\mathrm{~N} / \mathrm{A}^{\mathrm{b}}$ \\
\hline \multicolumn{3}{|l|}{ Age } \\
\hline $25-35$ & 19.20 & 14.55 \\
\hline $36-45$ & 21.78 & 16.94 \\
\hline $46-55$ & 24.95 & 17.88 \\
\hline $56-65$ & 31.03 & 22.08 \\
\hline$>65$ & 17.52 & 8.05 \\
\hline \multicolumn{3}{|l|}{ Race/ethnicity ${ }^{\mathrm{b}}$} \\
\hline African American & 24.33 & 2.08 \\
\hline Asian or Pacific Islander & 2.50 & .71 \\
\hline Asian Indian or South Asian & 27.50 & 7.78 \\
\hline Caucasian & 25.34 & 18.94 \\
\hline Latino & 25.40 & 11.88 \\
\hline Native American & 0 & $\mathrm{~N} / \mathrm{A}^{\mathrm{b}}$ \\
\hline Another racial identity & 74.00 & $\mathrm{~N} / \mathrm{A}^{\mathrm{b}}$ \\
\hline \multicolumn{3}{|l|}{ Years RD } \\
\hline $3-5$ & 30.00 & $N / A^{b}$ \\
\hline $6-10$ & 24.04 & 17.48 \\
\hline $11-15$ & 30.74 & 23.26 \\
\hline $16-20$ & 13.08 & 7.18 \\
\hline $21-25$ & 24.18 & 17.77 \\
\hline$>25$ & 29.09 & 21.21 \\
\hline \multicolumn{3}{|l|}{ Years DI Director } \\
\hline $0-2$ & 23.86 & 17.41 \\
\hline $3-5$ & 21.10 & 18.24 \\
\hline $6-10$ & 32.13 & 22.15 \\
\hline $11-15$ & 14.96 & 13.94 \\
\hline $16-20$ & 34.56 & 23.89 \\
\hline $21-25$ & 27.60 & 7.16 \\
\hline$>25$ & 32.94 & 8.79 \\
\hline
\end{tabular}

${ }^{\mathrm{a}}$ Maximum score is 96;

${ }^{\mathrm{b}}$ Only 1 participant 
Table 14

Descriptive Statistics for RIQ by Participant Education/Training and Professional Experience

\begin{tabular}{|c|c|c|}
\hline $\begin{array}{l}\text { Education/Training and } \\
\text { Professional Experiences }\end{array}$ & $\begin{array}{l}\text { Mean overall } \\
\text { RIQ }^{\mathrm{a}} \\
\end{array}$ & $\mathrm{SD}$ \\
\hline \multicolumn{3}{|l|}{ Highest education } \\
\hline Master's degree & 17.83 & 13.97 \\
\hline Working toward doctoral degree & 28.97 & 15.62 \\
\hline $\mathrm{PhD}$ & 42.04 & 20.18 \\
\hline EdD & 35.12 & 19.00 \\
\hline Other & 28.00 & N/A \\
\hline \multicolumn{3}{|l|}{ Master's thesis } \\
\hline Yes & 28.24 & 19.12 \\
\hline No & 20.53 & 17.70 \\
\hline In progress & 28.00 & N/A \\
\hline \multicolumn{3}{|l|}{ Doctoral dissertation } \\
\hline Yes & 40.25 & 19.76 \\
\hline No & 17.45 & 13.89 \\
\hline In progress & 37.95 & 6.42 \\
\hline \multicolumn{3}{|l|}{ Formal education } \\
\hline Yes & 27.04 & 19.27 \\
\hline No & 14.17 & 9.60 \\
\hline \multicolumn{3}{|l|}{ Additional training } \\
\hline Yes & 34.98 & 21.82 \\
\hline No & 17.77 & 11.75 \\
\hline \multicolumn{3}{|l|}{ Read often } \\
\hline Once a year & 8.31 & .44 \\
\hline Once every 6 mo & 16.67 & 17.79 \\
\hline Once every 3 mo & 16.02 & 12.30 \\
\hline Once a mo & 19.81 & 15.79 \\
\hline Bimonthly & 19.15 & 12.26 \\
\hline Weekly & 33.51 & 18.90 \\
\hline Daily & 61.00 & 17.09 \\
\hline \multicolumn{3}{|l|}{ Read time } \\
\hline Over 6 months ago & 11.21 & 5.03 \\
\hline 2-6 months ago & 9.95 & 8.70 \\
\hline 1 month ago & 12.97 & 10.90 \\
\hline 2 weeks ago & 19.99 & 17.30 \\
\hline Last week & 28.26 & 14.63 \\
\hline This week & 34.90 & 21.25 \\
\hline
\end{tabular}


Table 15

Descriptive Statistics for RIQ by Participant Research Experience

\begin{tabular}{lcr}
\hline $\begin{array}{l}\text { Research } \\
\text { Experiences }\end{array}$ & $\begin{array}{c}\text { Mean overall } \\
\text { RIQ }^{\mathrm{a}}\end{array}$ & $\mathrm{SD}$ \\
\hline Author/coauthor & & \\
$\quad$ Yes & 36.14 & 20.09 \\
$\quad$ No & 15.00 & 10.32 \\
Current position & & \\
$\quad$ Yes & 35.23 & 19.66 \\
$\quad$ No & 15.40 & 11.29 \\
Past position & & \\
Yes & 32.28 & 20.52 \\
$\quad$ No & 20.43 & 16.16 \\
Group projects & & \\
0 & 11.68 & 9.13 \\
$1-5$ & 19.09 & 12.81 \\
$6-10$ & 37.25 & 21.00 \\
$11-20$ & 36.01 & 17.42 \\
$>20$ & 44.93 & 20.13 \\
Independent projects & & \\
0 & 16.15 & 13.27 \\
$1-5$ & 29.83 & 16.72 \\
$6-10$ & 58.00 & N/A \\
$11-20$ & 61.75 & 23.92 \\
$>20$ & N/A & N/A \\
Confidence & & \\
Not at all & 8.57 & 7.25 \\
Not very & 15.36 & 11.30 \\
Somewhat & 26.68 & 16.93 \\
Very & 40.61 & 19.79 \\
\hline
\end{tabular}

${ }^{\mathrm{a}}$ Maximum score is 96.

${ }^{b}$ Due to set-up of question, only $55(57.3 \%)$ answered this question.

Experience with research certainly plays a role in research involvement (see Table 15); however, the data show a similar overall RIQ for those who were involved in research in both their current position $(35.23 \pm 19.66)$ and past position $(32.28 \pm 20.52)$. A positive relationship was observed between overall RIQ and involvement in research projects as a group member or an individual member as measured by the number of 
projects participants had worked on, and confidence with research skills. These

differences will be discussed in more detail later in this section.

As shown in Table 16, participants who worked in a university-based hospital or a university setting had the highest mean overall RIQ, while those who reported working in a hospital setting or in "other" setting had the lowest mean overall RIQ. Further, participants who were DI Directors of programs that had a full master's degree track displayed higher mean overall RIQ scores than participants who ran programs that did not have master's degree programs. Participants who managed programs that were exclusively distance programs demonstrated the lowest overall RIQ, but those who had at least some on-site experiences were similar.

Table 16

Descriptive Statistics for RIQ by Institutional Characteristics

\begin{tabular}{lcc}
\hline Institutional Characteristics & $\begin{array}{c}\text { Mean overall } \\
\text { RIQ }^{\mathrm{a}}\end{array}$ & $\mathrm{SD}$ \\
\hline Institution type & & \\
$\quad$ Governmental agency & 23.27 & 20.54 \\
Hospital & 20.50 & 13.81 \\
Industry & 26.00 & 15.56 \\
University & 27.14 & 19.12 \\
University-based hospital & 31.29 & 24.50 \\
Other & 12.94 & 14.94 \\
DI type & & \\
Supervised practice only & 22.71 & 15.75 \\
Some master's credit only & 22.11 & 17.56 \\
Master's degree only & 35.30 & 24.84 \\
Both master's and non-master's tracks & 32.33 & 22.36 \\
Distance learning & & \\
No & 25.88 & 19.91 \\
Yes, both distance and on-site & 26.08 & 14.21 \\
$\quad$ Yes, exclusively distance & 17.52 & 6.36 \\
\hline${ }^{a}$ Maximum score was 96 &
\end{tabular}

${ }^{\mathrm{a}}$ Maximum score was 96 
Results from the ANOVA analysis showed no statistically significant relationship between the overall RIQ and sociodemographic or employment setting. On the other hand, statistical significance was found for four education/training variables, two professional experience variables, and six research experience variables. Tables 17 and 18 show the means and standard deviations for the summed scores of Levels 1, 2, 3, and 4 for these statistically significant variables. As to be expected, the mean summed scores decreased as the levels increased, showing less research involvement at the higher levels.

Table 19 displays the results for the ANOVA analysis for all variables within the sociodemographic, education/training, professional experience, research experience, and employment setting categories. Of all of the variables, the variance was most explained $(37 \%)$ by the participants involvement with group research $(\mathrm{F}(4,84)=12.24, p<.01$, partial $\left.\eta^{2}=.37\right)$, followed by individual research $(34 \%)$, and authorship (31\%). Within the education/training category, the variance was most explained by completion of a doctoral dissertation (33\%) and highest degree earned (30\%), while in the professional experience category the variance was most explained by frequency of reading (32\%) and last time research was read (24\%). These data were used to determine the variables for the regression analysis, which is discussed later in this section. 
Table 17

Mean Research Involvement Score for Statistically Significant Variables in Education/ Training and Professional Experience Categories per Research Involvement Level

\begin{tabular}{|c|c|c|c|c|c|c|c|c|}
\hline & \multicolumn{2}{|c|}{ Level $1^{\mathrm{a}}$} & \multicolumn{2}{|c|}{ Level $2^{\mathrm{a}}$} & \multicolumn{2}{|c|}{ Level $3^{\mathrm{a}}$} & \multicolumn{2}{|c|}{ Level $4^{\mathrm{a}}$} \\
\hline & $\mathrm{M}$ & SD & $\mathrm{M}$ & SD & $\mathrm{M}$ & SD & $\mathrm{M}$ & SD \\
\hline \multicolumn{9}{|l|}{ Education/Training } \\
\hline \multicolumn{9}{|l|}{ Highest education } \\
\hline Master's degree & 8.32 & 4.91 & 4.51 & 4.19 & 2.83 & 3.39 & 2.18 & 3.03 \\
\hline $\begin{array}{l}\text { Working toward } \\
\text { doctoral degree }\end{array}$ & 11.50 & 4.76 & 7.13 & 4.24 & 5.83 & 4.17 & 4.50 & 3.94 \\
\hline $\mathrm{PhD}$ & 14.05 & 5.35 & 10.50 & 5.64 & 10.10 & 5.98 & 7.38 & 5.00 \\
\hline EdD & 13.26 & 4.98 & 7.71 & 4.03 & 8.00 & 7.77 & 6.14 & 3.85 \\
\hline Other & 14.00 & N/A & 7.00 & N/A & 5.00 & N/A & 2.00 & N/A \\
\hline \multicolumn{9}{|l|}{ Formal education } \\
\hline Yes & 10.72 & 5.52 & 6.70 & 5.27 & 5.50 & 5.58 & 4.12 & 4.38 \\
\hline No & 7.00 & 4.43 & 3.50 & 2.24 & 2.08 & 2.97 & 1.58 & 2.02 \\
\hline \multicolumn{9}{|l|}{ Doctoral dissertation } \\
\hline Yes & 13.85 & 5.18 & 9.78 & 5.34 & 9.56 & 6.40 & 7.06 & 4.69 \\
\hline No & 8.24 & 4.94 & 4.40 & 4.15 & 2.71 & 3.37 & 2.10 & 3.00 \\
\hline In progress & 13.50 & 1.29 & 9.70 & 1.70 & 8.25 & 2.22 & 6.50 & 3.11 \\
\hline \multicolumn{9}{|l|}{ Additional training } \\
\hline Yes & 12.63 & 5.79 & 8.71 & 6.00 & 7.76 & 6.49 & 5.88 & 5.17 \\
\hline No & 8.28 & 4.45 & 4.35 & 3.22 & 2.94 & 3.29 & 2.20 & 2.48 \\
\hline \multicolumn{9}{|l|}{ Professional } \\
\hline \multirow{2}{*}{\multicolumn{9}{|c|}{$\begin{array}{l}\text { Experience } \\
\text { Read often }\end{array}$}} \\
\hline & & & & & & & & \\
\hline Once a year & 5.31 & .98 & 2.00 & 1.41 & .50 & .71 & .50 & .71 \\
\hline Once every 6 months & 5.00 & 4.36 & 5.67 & 5.03 & 3.33 & 4.93 & 2.67 & 3.79 \\
\hline Once every 3 months & 6.26 & 4.66 & 3.25 & 2.66 & 3.75 & 3.28 & 2.76 & 2.18 \\
\hline Once a month & 8.20 & 4.48 & 4.96 & 3.75 & 4.00 & 5.38 & 2.65 & 3.46 \\
\hline Bimonthly & 9.37 & 4.50 & 4.58 & 3.78 & 2.95 & 2.93 & 2.25 & 2.52 \\
\hline Weekly & 13.00 & 4.97 & 8.42 & 5.52 & 6.70 & 5.63 & 5.39 & 4.91 \\
\hline Daily & 19.75 & 3.30 & 15.25 & 4.86 & 15.50 & 5.26 & 10.50 & 5.26 \\
\hline \multicolumn{9}{|l|}{ Read time } \\
\hline Over 6 months ago & 6.21 & 1.70 & 3.33 & 2.52 & 1.33 & 1.53 & .33 & .58 \\
\hline 2-6 months ago & 3.83 & 2.86 & 2.83 & 2.79 & 2.00 & 2.76 & 1.28 & 1.53 \\
\hline 1 month ago & 6.17 & 3.90 & 3.25 & 3.25 & 2.25 & 2.93 & 1.31 & 2.07 \\
\hline 2 weeks ago & 9.14 & 4.87 & 4.31 & 4.01 & 3.54 & 6.08 & 3.00 & 3.54 \\
\hline Last week & 11.58 & 4.77 & 7.09 & 4.00 & 5.86 & 4.62 & 3.73 & 3.09 \\
\hline This week & 13.00 & 5.43 & 8.68 & 6.05 & 7.21 & 6.20 & 6.00 & 5.27 \\
\hline
\end{tabular}

${ }^{\mathrm{a}}$ Maximum score was 24 
Table 18

Mean Research Involvement Score for Statistically Significant Variables in Research Experience Category per Research Involvement Level

\begin{tabular}{|c|c|c|c|c|c|c|c|c|}
\hline \multirow{2}{*}{$\begin{array}{l}\text { Research } \\
\text { Experiences }\end{array}$} & \multicolumn{2}{|c|}{ Level $1^{\mathrm{a}}$} & \multicolumn{2}{|c|}{ Level $2^{\mathrm{a}}$} & \multicolumn{2}{|c|}{ Level $3^{\mathrm{a}}$} & \multicolumn{2}{|c|}{ Level $4^{\mathrm{a}}$} \\
\hline & $\mathrm{M}$ & SD & $\mathrm{M}$ & SD & $\mathrm{M}$ & SD & $\mathrm{M}$ & SD \\
\hline \multicolumn{9}{|c|}{ Author/coauthor } \\
\hline Yes & 13.19 & 4.89 & 9.00 & 5.52 & 7.90 & 6.24 & 6.04 & 4.96 \\
\hline No & 7.27 & 4.51 & 3.57 & 2.88 & 2.38 & 2.81 & 1.77 & 1.96 \\
\hline \multicolumn{9}{|c|}{ Current position } \\
\hline Yes & 12.39 & 5.12 & 8.93 & 5.36 & 7.93 & 5.97 & 5.99 & 4.66 \\
\hline No & 8.04 & 5.13 & 3.64 & 3.06 & 2.16 & 2.65 & 1.57 & 2.15 \\
\hline \multicolumn{9}{|l|}{ Past position } \\
\hline Yes & 12.21 & 5.11 & 8.03 & 5.64 & 6.81 & 6.28 & 5.23 & 5.14 \\
\hline No & 8.82 & 5.51 & 5.09 & 4.37 & 3.78 & 4.45 & 2.74 & 3.18 \\
\hline \multicolumn{9}{|c|}{ Group projects } \\
\hline 0 & 6.61 & 3.77 & 2.63 & 2.96 & 1.50 & 2.53 & .94 & 1.77 \\
\hline $1-5$ & 9.04 & 5.29 & 4.79 & 3.43 & 2.95 & 3.21 & 2.31 & 2.58 \\
\hline $6-10$ & 13.07 & 5.44 & 9.33 & 5.96 & 8.20 & 5.41 & 6.65 & 5.42 \\
\hline $11-20$ & 12.01 & 3.87 & 8.89 & 4.83 & 8.67 & 6.08 & 6.44 & 3.84 \\
\hline$>20$ & 14.90 & 5.38 & 11.28 & 5.53 & 11.19 & 6.66 & 7.57 & 4.91 \\
\hline \multicolumn{9}{|c|}{ Independent projects } \\
\hline 0 & 8.00 & 4.84 & 3.95 & 3.73 & 2.48 & 3.71 & 1.76 & 2.42 \\
\hline $1-5$ & 11.38 & 5.06 & 7.45 & 4.61 & 6.18 & 4.81 & 4.82 & 4.06 \\
\hline $6-10$ & 20.00 & N/A & 14.00 & N/A & 18.00 & N/A & 6.00 & N/A \\
\hline $11-20$ & 18.00 & 5.48 & 15.50 & 7.19 & 15.75 & 6.60 & 12.50 & 6.66 \\
\hline$>20$ & N/A & N/A & N/A & N/A & N/A & N/A & N/A & N/A \\
\hline \multicolumn{9}{|l|}{ Confidence $^{c}$} \\
\hline Not at all & 4.57 & 2.76 & 2.43 & 2.88 & 1.14 & 2.19 & .43 & .79 \\
\hline Not very & 7.88 & 4.26 & 3.83 & 3.49 & 2.00 & 2.66 & 1.64 & 2.20 \\
\hline Somewhat & 9.97 & 4.94 & 6.66 & 4.82 & 5.67 & 4.68 & 4.38 & 4.07 \\
\hline Very & 15.23 & 3.33 & 9.51 & 6.01 & 9.25 & 6.48 & 6.63 & 5.40 \\
\hline
\end{tabular}

${ }^{\mathrm{a}}$ Maximum score was 24 
Table 19

Results from ANOVA for Overall RIQ and Sociodemographic,

Education/Training, Professional Experience, Research

Experience, and Employment Setting

\begin{tabular}{lrrrr}
\hline & $\mathrm{df}$ & $\mathrm{F}$ & partial $\eta^{2}$ & $p$ \\
\hline Sociodemographic & & & & \\
$\quad$ Sex & 1,88 & .96 & .01 & .33 \\
Age & 4,85 & 1.21 & .05 & .31 \\
Race/ethnicity & 5,82 & 2.02 & .11 & .09 \\
Education/training & & & & \\
$\quad$ Highest degree & 4,84 & 9.14 & .30 & $\mathbf{. 0 0}$ \\
Formal education & 1,88 & 5.13 & .06 & $\mathbf{. 0 3}$ \\
Master's thesis & 2,87 & 1.82 & .04 & .17 \\
Doctoral dissertation & 2,85 & 20.52 & .33 & $\mathbf{. 0 0}$ \\
Additional training & 1,87 & 22.87 & .21 & $\mathbf{. 0 0}$ \\
Professional & & & & \\
Years RD & 5,79 & 1.45 & .08 & .22 \\
Years DI Director & 6,81 & 1.54 & .10 & .18 \\
Frequency of reading & 6,82 & 6.45 & .32 & $\mathbf{. 0 0}$ \\
Last time read & 5,82 & 5.05 & .24 & $\mathbf{. 0 0}$ \\
Research & & & & \\
Author/co-author & 1,85 & 38.85 & .31 & $\mathbf{. 0 0}$ \\
Group projects & 4,84 & 12.24 & .37 & $\mathbf{. 0 0}$ \\
Individual projects & 3,85 & 14.62 & .34 & $\mathbf{. 0 0}$ \\
Current position & 1,87 & 33.85 & .28 & $\mathbf{. 0 0}$ \\
Past position & 1,86 & 9.17 & .10 & $\mathbf{. 0 0}$ \\
Confidence & 3,50 & 6.94 & .29 & $\mathbf{. 0 0}$ \\
Employment setting & & & & \\
Institution type & 5,83 & .83 & .05 & .53 \\
DI type & 4,84 & 2.39 & .10 & .06 \\
$\quad$ Distance & 2,86 & .46 & .01 & $\mathbf{. 6 3}$ \\
\hline
\end{tabular}

Correlation coefficients were computed to assess the degree of interaction

between each of the variables. The correlations as well as the ANOVA analyses were used to determine the variables that might best predict the overall RIQ. The correlations between the 12 variables that were identified to be significant in the ANOVA analysis were reviewed. The strongest correlation was found between the highest level of 
education and completion of doctoral dissertation $(r=-.80, p<.01)$. Thus, these two variables were significantly related and were not used in combination for the prediction equation even though both were found to be statistically significant in the ANOVA analysis. Since completion of doctoral dissertation displayed weaker correlations with the other variables, it was used in the final prediction model instead of highest education level.

Initially, it was anticipated that the prediction equation for the overall RIQ would have one variable from each of the categories, including sociodemographic, education/training, professional experience, research experience, and employment setting. However, since no statistically significant relationship between the overall RIQ and sociodemographic or employment setting was found, these two categories were not utilized for the regression analysis. The other three categories contained variables that were shown to have a statistically significant relationship with the overall RIQ. Two prediction models were created from these data. One included a variable for each of the three categories, and the other contained two variables from each of the categories.

Therefore, two multiple linear regression analyses were conducted to evaluate the prediction of the overall RIQ from the education/training, professional experience, and research experience of the participants. Table 20 shows the multiple linear regression analysis using one predictor from each of the three categories. These predictors were significantly related to the overall RIQ, $(\mathrm{F}(3,83)=24.49, p<.01)$ with $\mathrm{r}^{2}=.47$, indicating that approximately $47 \%$ of the variance of the overall RIQ can be accounted for by the linear relationship of the predictors. Standardized regression coefficients have the advantage of comparability, as the scores are reported as z-scores (Vogt, 2007). 
Involvement with group research projects showed the highest beta weight ( beta $=.44$ ), indicating this variable had the most influence on the overall RIQ. It should be noted that the negative influence of the doctoral dissertation is due to the way the variables were coded for this question $(0=$ completed dissertation, $1=$ did not complete dissertation, $2=$ dissertation in progress).

Table 20

Regression Analysis with One Variable for Education/Training, Professional Experience, and Research Experience as Predictors for Overall RIQ

\begin{tabular}{lcllrrr}
\hline & \multicolumn{3}{c}{ Unstandardized coefficients } & \multicolumn{3}{c}{ Standardized coefficients } \\
\cline { 2 - 3 } \cline { 6 - 7 } & B & Std. Error & & Beta & $t$ & Sig \\
\hline Constant & -2.11 & 9.97 & & -.21 & .83 \\
Doctoral dissertation & -7.40 & 2.99 & & -21 & -2.48 & .02 \\
Frequency of reading & 4.03 & 1.22 & .28 & 3.30 & $<.01$ \\
Group research & 6.76 & 1.31 & .44 & 5.14 & $<.01$ \\
\hline
\end{tabular}

The second regression analysis was conducted using two variables from each category of education/training, professional experience, and research experience; thus, a total of six predictor variables were included in the model. Table 21 shows the multiple linear regression analysis using the six variables. These predictors were significantly related to the overall RIQ, $(\mathrm{F}(6,78)=17.61, p<.01)$ with $\mathrm{r}^{2}=.58$. This prediction is stronger than the first model, as approximately $58 \%$ of the variance of the overall RIQ can be accounted for by the linear relationship of these predictors. Involvement with research projects that the participant was solely responsible for showed the highest beta weight $($ beta $=.31)$, indicating this variable had the most influence on the overall RIQ. Involvement with group research projects, which showed the highest beta weight (beta= 
.44) in the first regression model (Table 20), displayed the second highest influence on the overall RIQ $($ beta $=.27)$. As mentioned with the first regression model, completion of a doctoral dissertation showed a negative influence, as did the completion of additional training $(0=$ yes, $1=$ no $)$.

Table 21

Regression Analysis with Two Variables Each for Education/Training, Professional Experience, and Research Experience as Predictors for Overall RIQ

\begin{tabular}{lcccccr}
\hline & \multicolumn{3}{c}{ Unstandardized coefficients } & \multicolumn{3}{c}{ Standardized coefficients } \\
\cline { 2 - 3 } \cline { 5 - 6 } & $\mathrm{B}$ & Std. Error & & Beta & $t$ & Sig \\
\hline Constant & 2.53 & 12.28 & & .21 & .84 \\
Doctoral dissertation & -3.46 & 2.91 & & -.10 & -1.19 & .24 \\
Additional training & -7.17 & 3.21 & & -.19 & -2.24 & .03 \\
Frequency of reading & 1.20 & 1.48 & & .08 & .81 & .42 \\
Last time read & 2.02 & 1.34 & & .15 & 1.51 & .14 \\
Group research & 4.08 & 1.35 & & .27 & 3.02 & $<.01$ \\
Sole research & 8.15 & 2.36 & & .31 & 3.45 & $<.01$ \\
\hline
\end{tabular}

In sum, the factors that influenced the participants' involvement with research were their education/training, professional experience, and research experience. These findings serve to better understand participants who are marginally involved with research, as well as those who are highly involved with research, based upon the RIQ. It is also essential to better understand the manner in which participants interpret and implement competency CRD 1.5, which is discussed in the next two sections of this paper.

\section{Research Question 3}

How do DI Directors interpret competency CRD 1.5? Two questions on the survey (See Appendix B) corresponded to this research question. The first was an open- 
ended question that asked participants to describe their interpretation of competency

CRD 1.5. Though a comprehensive analysis was not conducted on the open-ended responses, the data were reviewed to gain a better understanding of the manner in which participants interpreted the competency, and this will be discussed later in this section. Additionally, a second question on the survey was used to quantify participants' interpretation of competency CRD 1.5. This survey question asked participants to select the answer that best described their interpretation of competency CRD 1.5. The three answers were designed to be a failed, partial, or complete match based upon ACEND's definition of research. Specifically, selection of "interns must be familiar with the basic concepts of research, but do not need to be able to conduct research" was classified as a failed match; selection of "interns must be able to conduct components of a research project, but not every step" was classified as a partial match; and selection of "interns must be able to conduct a full research project, which includes systematically testing research questions, a hypothesis, or a theory in order to discover new information" was classified as a complete match. Table 22 shows the frequency distribution of the interpretation of competency CRD 1.5. The majority of participants selected the partial match (45.7\%), while $40.4 \%$ selected the complete match. The mean score was $2.27 \pm$ 0.69 , indicating the majority of participants fell between the selections of partial and complete $(1=$ failed, $2=$ partial, $3=$ complete $)$. 
Table 22

Frequency of Participant Interpretation

of Competency CRD 1.5

\begin{tabular}{lcc}
\hline & Frequency $^{\mathrm{a}}$ (n) & $\%$ \\
\hline Failed & 13 & 13.8 \\
Partial & 43 & 45.7 \\
Complete & 38 & 40.4 \\
\hline
\end{tabular}

${ }^{\mathrm{a}}$ Due to missing data, total is less than 96

Utilizing SPSS, responses were sorted into failed, partial, or complete matches in order to compare the data provided in the open-ended question on the survey. The majority of participants who completed this question provided responses that varied in the degree of research involvement. Comments from participants who selected the failed match tended to have more vague responses compared to the other two groups, some of which were clearly influenced by the wording of the question, such as the following comment that included all three aspects of the competency: "completes assigned projects using appropriate research methods, behaves in an ethical manner, and analyzes the data in a variety of ways." However, several in this group mentioned components of research projects, including data collection, development of hypothesis, and IRB proposals. The partial group, which was the most frequent response (46\%), contained a wide variety of responses, but two in particularly seemed noteworthy. Two participants commented that they had previously interpreted this competency to mean that students had to conduct a full research project but had recently changed the requirement based upon feedback from other DI Directors who did not interpret it in this manner. Participants who selected the complete match response placed emphasis on interns completing a full, original project; however, some comments reflected partial projects. Thus, there seem to be multiple 
ways to describe the interpretation of this competency.

A two-way contingency table analysis was conducted to evaluate whether there was a statistical relationship among interpretation of competency CRD 1.5 (failed, partial, complete) and the variables representing sociodemographic, education/training, professional experience, research experience, and employment setting. Table 23 depicts the results of these analyses. Interpretation of competency CRD 1.5 was found to be significantly related with three variables in the education/training category and one variable in the research category. Specifically, interpretation was found to be significantly related with the highest level of education $\left(\right.$ Pearson $\chi^{2}(8, \mathrm{~N}=89)=16.93, p$ $=.03)$, Cramér's $\mathrm{V}=.31)$; completion of doctoral dissertation $\left(\right.$ Pearson $\chi^{2}(4, \mathrm{~N}=88)=$ 9.94, $p=.04)$, Cramér's $\mathrm{V}=.24)$; additional training $\left(\right.$ Pearson $\chi^{2}(2, \mathrm{~N}=89)=6.36, p=$ $.04)$, Cramér's $\mathrm{V}=.27$ ); and having authored or co-authored a research-based article $\left(\right.$ Pearson $\left.\chi^{2}(2, \mathrm{~N}=87)=8.49, p=.01\right)$, Cramér's $\left.\mathrm{V}=.31\right)$. Cramér's $V$ ranges between zero and one and indicates the strength of a relationship (Green \& Salkind, 2008). Based upon Cohen's standards for interpreting Cramér's $V$, a small relationship was indicated for additional training, and a medium relationship was indicated for authored or coauthored a research-based article as well as for highest level of education and completion of a doctoral dissertation (Gravetter \& Wallnau, 2009). Though follow-up pairwise comparisons were not conducted, review of the crosstabs data showed that participants who had higher levels of education, particularly $\mathrm{PhDs}$, as well as participants who had completed additional training, and who had authored or co-authored a research-based article selected the partial or complete match more frequently for the interpretation of competency CRD 1.5 than the other participants. 
Table 23

Comparisons of Interpretation of Competency CRD 1.5

\begin{tabular}{lrcc}
\hline Comparison with & $\begin{array}{c}\text { Pearson } \\
\text { chi-square }\end{array}$ & $P$ value & Cramér's V \\
Interpretation & 1.52 & .47 & .13 \\
\hline Sociodemographic & 11.27 & .19 & .25 \\
$\quad$ Sex & 10.79 & .37 & .25 \\
Age & & & \\
Race/ethnicity & 16.93 &. $\mathbf{0 3}$ & .31 \\
Education/training & 2.23 & .33 & .16 \\
$\quad$ Highest degree & 2.25 & .69 & .11 \\
Formal education & 9.94 &. $\mathbf{0 4}$ & .24 \\
Master's thesis & 6.36 &. $\mathbf{0 4}$ & .27 \\
Doctoral dissertation & & & \\
Additional training & 3.54 & .97 & .14 \\
Professional & 9.30 & .68 & .23 \\
$\quad$ Years RD & 10.85 & .54 & .25 \\
Years DI Director & 15.80 & .11 & .30 \\
Frequency of reading & & & \\
$\quad$ Last time read & 8.49 &. $\mathbf{0 1}$ & .31 \\
Research & 13.50 & .10 & .28 \\
$\quad$ Author/co-author & 9.09 & .17 & .23 \\
Group projects & 3.38 & .18 & .20 \\
Individual projects & 2.92 & .23 & .18 \\
Current position & 5.51 & .48 & .23 \\
Past position & & & \\
Confidence & 7.28 & .70 & .20 \\
Employment setting & 5.93 & .66 & .18 \\
Institution type & .76 & .10 \\
DI type & & & \\
Distance option & & & \\
\hline
\end{tabular}

These results shed light on factors that may influence the manner in which DI Directors understand competency CRD 1.5, namely highest level of education, completion of doctoral dissertation, additional training, and having authored or coauthored a research-based article, as these were all statistically significant $(p<.05)$. However, the data should be interpreted with caution. Analysis of the crosstab output revealed that the majority of comparisons between the interpretation of competency CRD 
1.5 and the variables within the sociodemographic, education/training, professional experience, research experience, and employment setting categories had cells that contained less than the preferred minimum of five responses. It is ideal to have frequencies for all cells to be greater than or equal to five, or for larger analyses, to have less than $20 \%$ of the cells meet this requirement (Green \& Salkind, 2008). The variables of additional training and research in current position did not have any cells with less than five responses, and the variables of author/co-author and research in past position contained about $17 \%$ of cells that did not have more than five responses. The remaining variables exceeded the $20 \%$ cut-off, which may affect the validity of the results (Green \& Salkind, 2008).

Findings from this study showed that the interpretation of competency CRD 1.5 among DI Directors who participated in this study varied greatly. The majority of participants interpreted the competency to mean that interns had to conduct components of the research process, but that completion of a full, original research project was not necessary to meet this competency. Though it is helpful to understand the manner in which DI Directors interpreted competency CRD 1.5, their interpretation of the competency does not necessarily parallel with the manner in which they implement competency CRD 1.5 within their DI programs. Implementation of competency CRD 1.5 is critical because the learning experiences that are aligned with this competency should be designed to lead to research competence.

\section{Research Question 4}

What types of learning experiences are DIs using to fulfill competency CRD 1.5? Similar to research question three, two questions on the survey in Appendix B 
corresponded to this research question. The first was an open-ended question that asked participants to provide the experience(s) in their program that are aligned with competency CRD 1.5. Also similar to the analysis of research question two, a comprehensive analysis was not conducted on the data from the open-ended questions, but the responses were reviewed to gain a better understanding of the manner in which participants implemented the competency, and this will be discussed later in this section.

The second question on the survey that aligned with this research question was used to quantify the implementation of competency CRD 1.5. Participants had the ability to select all answers that applied to the question asking about the required components for the experience(s) that are used to meet competency CRD 1.5. Table 24 lists the options for this survey question as well as the frequencies of each answer. Nearly all participants required interns to complete an analysis of data $(93 \%)$, while only $6 \%$ required the use of the Academy's Online Research Toolkit.

Table 24

Frequencies of Experiences Aligned with Competency CRD 1.5

\begin{tabular}{lcc}
\hline & $\begin{array}{c}\text { Frequency } \\
\text { (n) }\end{array}$ & $\%$ \\
\hline Analysis of data & 89 & 92.7 \\
Collection of data & 84 & 87.5 \\
Critical evaluation of research articles & 75 & 78.1 \\
Literature review & 67 & 69.8 \\
Research questions/hypothesis & 62 & 64.6 \\
Design research protocol & 52 & 54.2 \\
Presentation of paper/report & 50 & 52.1 \\
Ethics tutorials & 47 & 49.0 \\
Research paper/report & 44 & 45.8 \\
IRB protocol & 33 & 34.4 \\
Academy's Online Research Toolkit & 6 & 6.3 \\
\hline
\end{tabular}

Note. Participants had the option to select all that apply; thus, overall \% exceeds 100 . 
In an attempt to streamline the interpretation and implementation variables, the answers to this survey question were categorized as a failed, partial, or complete match. A failed match was defined as selecting none of the answers. Originally, a complete match was to be defined by selecting all answers, except for the Academy's Online Research Toolkit, as it is a helpful tool, but not a necessary step in the completion of a research project. However, careful review of the data revealed two issues. First, many participants selected either "completion of IRB protocol" or "completion of ethics tutorials." Ethical procedures are mentioned in competency CRD 1.5, and it is possible for interns to gain experience via completion of an IRB protocol or ethics tutorials. Secondly, many participants selected either "presentation of an original research paper/report" or "production of an original research paper/report." Both of these focus on the production of original work, regardless of the format. This is an important distinction because competency CRD 1.5 does not specify the end product. Therefore, a complete match was defined as the selection of either "completion of IRB protocol" or "completion of ethics tutorials," the selection of "presentation of an original research paper/report" or "production of an original research paper/report," and the selection of the remaining six answers. Participants who selected at least one, but not all of the necessary components of a complete match, were categorized as a partial match. Table 25 shows the criteria that were utilized for each category. 
Table 25

Criteria Utilized to Classify Implementation of Competency

CRD 1.5 into Complete, Partial, or Failed Match

\begin{tabular}{l} 
Criteria \\
\hline 1. Analysis of data \\
2. Collection of data \\
3. Critical evaluation of research articles \\
4. Design research protocol \\
5. Research questions/hypothesis \\
6. Literature review \\
7. IRB protocol OR ethics tutorials \\
8. Presentation OR production of paper/report \\
Note. A complete match is defined by selection of all 8, \\
a partial match is defined by selection of $\geq 1$, but $\leq 7$, \\
and a failed match is defined by selection of 0.
\end{tabular}

The frequency distribution of the new variable based upon the aforementioned criteria is presented in Table 26. All participants selected at least one of the components; thus, none had a failed match $(0 \%)$. The majority of participants fell into the partial match category (78\%), which was also noted with the interpretation of competency CRD 1.5 from research question three. Due to the high percentage of participants in the partial category, another new variable was created to better understand the data. Based upon the criteria listed in Table 25, participants were given one point for each criterion. As such, all participants who had a complete match earned eight points. Participants who received a partial match could have a range of one to seven points based upon the number of criterion they selected for the survey question. For instance, a participant who selected “critical evaluation of research articles" and "production of a literature review" would receive two points for this variable. Table 27 depicts the frequencies and percentages for each of the new variables. The majority of participants in the partial category selected six 
of the options (19\%), which was closely followed by selection of seven options (18\%).

Selection of eight options meant that the participant had a complete match, which explains $22 \%$ listed for the frequency for this group in both Table 26 and Table 27.

Table 26

Breakdown of Participant Implementation of Competency CRD 1.5

\begin{tabular}{lcr}
\hline & $\begin{array}{c}\text { Frequency }^{\mathrm{a}} \\
(\mathrm{n})\end{array}$ & $\%$ \\
\hline Failed & 0 & 0 \\
Partial & 75 & 78.1 \\
Complete & 21 & 21.9 \\
\hline
\end{tabular}

Table 27

Number of Implementation Options

Selected by Participants

\begin{tabular}{ccr}
\hline $\begin{array}{c}\text { Total \# } \\
\text { selected }\end{array}$ & $\begin{array}{c}\text { Frequency }^{\mathrm{a}} \\
(\mathrm{n})\end{array}$ & $\%$ \\
\hline Partial & & \\
2 & 5 & 5.2 \\
3 & 9 & 9.4 \\
4 & 13 & 13.5 \\
5 & 13 & 13.5 \\
6 & 18 & 18.8 \\
7 & 17 & 17.7 \\
Complete & & \\
8 & 21 & 21.9 \\
\hline
\end{tabular}

Despite the issues with the two-way contingency table analysis discussed with research question three, this analysis was conducted to evaluate whether there was a statistical relationship among implementation of competency CRD 1.5 (failed, partial, complete) as defined by the aforementioned criteria and the variables representing 
sociodemographic, education/training, professional experience, research experience, and employment setting. The results from these analyses are presented in Table 28.

Implementation of competency CRD 1.5 was found to be significantly related with one variable in the education/training category, two variables in the research category, and one variable in the employment setting category. Specifically, implementation was found to be significantly related with completion of doctoral dissertation (Pearson $\chi^{2}(2, \mathrm{~N}=90)$ $=8.32, p=.01)$, Cramér's $\mathrm{V}=.30)$; group research $\left(\right.$ Pearson $\chi^{2}(4, \mathrm{~N}=91)=14.18, p=$ $.01)$, Cramér's $\mathrm{V}=.40)$; and research in current position $\left(\right.$ Pearson $\chi^{2}(1, \mathrm{~N}=91)=6.13, p$ $=.01)$, Cramér's $\mathrm{V}=.26$ ). Based upon Cohen's guidelines a small effect, medium effect, and large effect were indicated for research in current position, completion of doctoral dissertation, and group research, respectively (Gravetter \& Wallnau, 2009).

As with the analysis of research question three, follow-up pairwise comparisons were not conducted; however trends in the crosstabs data were noted for the variables that were identified to be significantly related to implementation. A greater percentage of participants who had completed a doctoral dissertation fell into the complete match category compared to those who had not completed a doctoral dissertation. Further, participants who had worked on five or less research projects within a group had a greater frequency of being classified into the partial match category compared to those who had worked on more than five group projects; however, the trend was not linear. Finally, participants who were involved with research in their current position were more likely to be identified as having a complete match for the implementation of competency CRD 1.5 . 
Table 28

Comparisons of Implementation of Competency CRD 1.5

\begin{tabular}{|c|c|c|c|}
\hline $\begin{array}{l}\text { Comparisons with } \\
\text { Implementation }\end{array}$ & $\begin{array}{l}\text { Pearson } \\
\text { chi-square }\end{array}$ & $P$ value & Cramér's V \\
\hline \multicolumn{4}{|l|}{ Sociodemographic } \\
\hline Sex & .28 & .60 & .06 \\
\hline Age & 2.01 & .73 & .15 \\
\hline Race/ethnicity & 7.14 & .21 & .28 \\
\hline \multicolumn{4}{|l|}{ Education/training } \\
\hline Highest degree & 3.80 & .43 & .20 \\
\hline Formal education & 1.09 & .30 & .11 \\
\hline Master's thesis & .36 & .84 & .06 \\
\hline Doctoral dissertation & 8.32 & .02 & .30 \\
\hline Additional training & .53 & .47 & .08 \\
\hline \multicolumn{4}{|l|}{ Professional } \\
\hline Years RD & 4.76 & .45 & .23 \\
\hline Years DI Director & 7.35 & .29 & .29 \\
\hline Frequency of reading & 3.30 & .77 & .19 \\
\hline Last time read & 4.72 & .45 & .23 \\
\hline \multicolumn{4}{|l|}{ Research } \\
\hline Author/co-author & 1.41 & .24 & .13 \\
\hline Group projects & 14.18 & .01 & .40 \\
\hline Individual projects & 5.95 & .11 & .26 \\
\hline Current position & 6.13 & .01 & .26 \\
\hline Past position & .01 & .91 & .01 \\
\hline Confidence & 2.52 & .47 & .21 \\
\hline \multicolumn{4}{|l|}{ Employment setting } \\
\hline Institution type & 5.68 & .34 & .25 \\
\hline DI type & 13.12 & .01 & .38 \\
\hline Distance option & 1.43 & .49 & .13 \\
\hline
\end{tabular}

As previously mentioned, the data should be interpreted with caution due to many of the cells containing less than the preferred minimum of five responses (Green \& Salkind, 2008). Four of the variables that were analyzed with crosstabs met the aforementioned requirement. These included the variables of additional training, author/co-author, research in current position, and research in past position. The 
remaining variables exceeded the $20 \%$ cut-off, which, as previously mentioned, may affect the validity of the results (Green \& Salkind, 2008).

The responses from the open-ended survey question that was aligned with implementation were analyzed in the same manner as they were for interpretation. That is, using the sorting feature of SPSS, responses were sorted into failed, partial, or complete matches in order to compare the data provided in the open-ended question on the survey. The responses from this open-ended question varied widely, particularly the responses in the partial match category. Adjectives used by many of the participants in the partial match category to describe the experiences in their programs that are used to meet competency CRD 1.5 were related to participation and involvement. For instance, one participant commented that competency CRD 1.5 was met through "participation in departmental original research projects directed by faculty and graduate students."

On the other hand, some participants in this group described completion of full research projects, often in the form of thesis research and coursework, and a few participants commented on their research rotations. Similarly, the majority of the participants in the complete match category also commented that they used original, research projects, which were also often in the form of thesis research and coursework, to meet competency CRD 1.5, with one requiring students to "complete a manuscript for journal submission." It was expected that participants who have aligned an original research project, such as a thesis project, with competency CRD 1.5 would have a complete match for the implementation of the competency. However, several participants mentioned that the research projects were often already established, commonly due to faculty research lines and grants; thus, research design was not always 
selected for these projects resulting in a partial match. Additionally, participants in both the partial and complete match category reported that full, food science research projects were aligned with competency CRD 1.5. Based upon feedback from one participant in the partial group, IRB protocols are not always required, as humans may not be used in the food science projects. Though participants had the option to select the "completion of ethics tutorials," this may have seemed like too formal of an option for the ethical component of the research process, which might explain why participants did not select these option resulting in a partial match.

Some other specific examples of experiences that participants in the partial match had aligned with competency CRD 1.5 were needs assessments, audits, journal clubs, plate waste studies, case studies, article reviews, and literature reviews. Some of the participants explicitly stated that their interns did not conduct research with these projects, while others considered projects such as presenting one article to faculty or preceptors to fulfill this competency. Other responses were vague, making it difficult to determine the nature of the project. For instance, one participant commented that the project aligned with competency CRD 1.5 was the "completion of several research projects that require use of scholarly references and presentations to peers." One participant indicated that their current project contains some of the components and they are in the process of making sure the experiences aligned with competency CRD 1.5 truly meet the competency.

Based upon the comments from the participants in this study, there was no consistent way to implement CRD 1.5. Further, statistical significance was observed among implementation of CRD 1.5 and variables in the education/training and research 
experience categories. These findings were similar to the findings for the interpretation of CRD 1.5. In order to better describe the interpretation and implementation of CRD 1.5, the RIQ must be taken into consideration; thus, the RIQ was utilized in the final research question.

\section{Research Question 5}

What is the relationship of the research involvement of DI Directors and their interpretation and implementation of competency CRD 1.5? The independent variables were the summed research involvement score for each of the four levels. All four research involvement levels were measured on a scale of 0-24. The DI Directors' interpretation and implementation were considered the dependent variables for the two analyses. Both variables were measured on three levels (failed match, partial match, and complete match).

The first discriminant analysis was conducted to determine whether the four predictors of the summed score for the four levels of research involvement could predict the interpretation of competency CRD 1.5. The overall Wilks's lambda was significant, $\left(\Lambda=.81, \chi^{2}(8, N=88)=17.90, p=.02\right)$, indicating that overall the predictors differentiated among the three levels of interpretation of competency CRD 1.5. Based upon the canonical correlation (.43), $18.5 \%$ of the variability in this discriminant function was accounted for by the differences among the four levels of research involvement. However, the residual Wilks's lambda was not significant, $\left(\Lambda=.99, \chi^{2}(3, N=88)=.98\right.$, $p=.81$ ), demonstrating that the predictors did not differentiate significantly among the three levels of interpretation after partialling out the effects of the first discriminant function. 
The within-group correlations between the predictors and the discriminant functions as well as the standardized weights are presented in Table 29. Based upon these coefficients, the summed score for research involvement at Level 3 displayed the strongest relationship with the first discriminant function. The means of the discriminant functions are consistent with these results. Participants in the complete match category $(M=.57)$ had the highest mean, followed by those in the partial match category $(M=-$ $.33)$, and failed match category $(M=-.54)$. Overall, $58 \%$ of the cases were correctly classified. A kappa coefficient was calculated to take into account chance agreement (Green \& Salkind, 2008). Kappa was .24, indicating a better than chance-level prediction, as the kappa score is greater than 0 (Green \& Salkind, 2008).

Table 29

Standardized Coefficients and Correlations of Research Involvement Predictor Variables for Interpretation of Competency CRD 1.5

\begin{tabular}{lccccc}
\hline & \multicolumn{2}{c}{$\begin{array}{c}\text { Correlation coefficients } \\
\text { with discriminant functions }\end{array}$} & & \multicolumn{2}{c}{$\begin{array}{c}\text { Standardized coefficients } \\
\text { for discriminant functions }\end{array}$} \\
\cline { 2 - 3 } \cline { 5 - 6 } Predictors & Function 1 & Function 2 & & Function 1 & Function 2 \\
\hline Level 1 & .57 & .10 & .24 & -.52 \\
Level 2 & .64 & .35 & -1.15 & 1.66 \\
Level 3 & .90 & .33 & & 1.26 & 1.03 \\
Level 4 & .81 & -.06 & & .57 & -2.08 \\
\hline
\end{tabular}

As described in the research question four section of this paper, no participants were classified into the failed match for the implementation of competency CRD 1.5 based upon the criteria in Table 25. Therefore, to answer research question five, another approach was utilized to better distinguish the three categories for this variable. Participants who were classified as a partial match for the implementation of competency 
CRD 1.5 were further assessed to differentiate those who selected a few of the required components for the experience(s) that were aligned with the competency in their program with those who selected several of the required components. As previously described, a partial match consisted of selection of one to seven components on the survey question, while a failed match was selection of zero components, and a complete match was selection of all eight components on the survey. Based upon the frequency data for the number of implementation options selected by the participants on the survey, which were shown in Table 27, 14.6\% of participants selected less than four required components for the survey question on implementation of competency CRD 1.5. Specifically, 5.2\% selected two components, and $9.4 \%$ selected three components, which totals $14.6 \%$. Since $13.8 \%$ of participants selected a failed match for the interpretation of competency CRD 1.5, which is shown in Table 22, this cut-off was used for the analysis of this research question. Thus, the partial match group was divided into a failed match (selection of $<3$ components) and a partial match (4-7 components). The complete match group remained the same. Table 30 illustrates the breakdown that resulted from this modification.

\section{Table 30}

Breakdown of Modification of Participant

Implementation of Competency CRD 1.5

\begin{tabular}{lcc}
\hline & $\begin{array}{c}\text { Frequency }^{\mathrm{a}} \\
(\mathrm{n})\end{array}$ & $\%$ \\
\hline Failed & 14 & 14.6 \\
Partial & 61 & 63.5 \\
Complete & 21 & 21.9 \\
\hline
\end{tabular}


The second discriminant analysis was conducted to determine whether the four predictors of the summed score for the four levels of research involvement could predict the implementation of competency CRD 1.5. The findings were similar to the interpretation in that only the first discriminant function was statistically significant. The overall Wilks's lambda was significant, $\left(\Lambda=.72, \chi^{2}(8, N=90)=28.42, p<.01\right)$, indicating that overall the predictors differentiated among the three levels of implementation of competency CRD 1.5. Based upon the canonical correlation (.51), $26 \%$ of the variability in this discriminant function was accounted for by the differences among the four levels of research involvement. Similar to interpretation, the residual Wilks's lambda for implementation was not significant, $\left(\Lambda=.97, \chi^{2}(3, N=90)=2.68, p\right.$ $=.44$ ), demonstrating that the predictors did not differentiate significantly among the three levels of implementation after partialling out the effects of the first discriminant function.

Table 31 shows the within-group correlations between the predictors and the discriminant function, and the standardized weights. The means of the discriminant functions are consistent with these finding, as participants in the complete match category $(M=.81)$ had the highest mean. This was followed by those in the partial match category $(M=-.00)$, and those in the failed match category $(M=-1.18$.$) . Overall, 63.3 \%$ of the cases were correctly classified based upon the cross-validated data. Kappa was .23, indicating a better than chance-level prediction, which was similar to that of interpretation. 
Table 31

Standardized Coefficients and Correlations of Research Involvement

Predictor Variables for Implementation of Competency CRD 1.5

\begin{tabular}{lccccc}
\hline & \multicolumn{2}{c}{$\begin{array}{c}\text { Correlation coefficients } \\
\text { with discriminant functions }\end{array}$} & \multicolumn{2}{c}{$\begin{array}{c}\text { Standardized coefficients } \\
\text { for discriminant functions }\end{array}$} \\
\cline { 2 - 3 } \cline { 5 - 6 } Predictors & Function 1 & Function 2 & & Function 1 & Function 2 \\
\hline Level 1 & .72 & -.27 & & 1.18 & -1.05 \\
Level 2 & .40 & .18 & -1.88 & .11 \\
Level 3 & .61 & .47 & & 1.32 & 1.81 \\
Level 4 & .48 & .20 & .19 & -.81 \\
\hline
\end{tabular}

Overall, the four predictors of the summed score for the four levels of research involvement significantly differentiated among the three levels of interpretation and implementation of CRD 1.5, though the prediction appeared slightly stronger for implementation. Further, a better than chance-level prediction was identified for both interpretation and implementation of CRD 1.5. These findings demonstrated that the research involvement of the participants influenced the manner in which they interpreted and implemented CRD 1.5.

\section{Summary}

Findings from this study highlighted the importance of the research experience of DI Directors on the research curriculum with DI programs. The data revealed that the majority of participants in this study were involved with research at the lowest level on the research continuum. Sociodemographic and employment setting were not found to influence research involvement. However, several variables within the education/training, professional experience, and research experience categories were shown to significantly influence the research involvement of the DI Directors in this study as well as their interpretation and implementation of competency CRD 1.5. Further, the research 
involvement of the participants, as measured by the four levels of the research continuum, was able to generate a better than chance-level prediction for both interpretation and implementation of competency CRD 1.5. Thus, their involvement and experience with research was shown to influence the manner in which they interpret and implement competency CRD 1.5 within their DI programs. The implications of these findings will be discussed in the following chapter as well as recommendations for future studies in this area of inquiry. 


\section{CHAPTER V \\ SUMMARY, DISCUSSIONS, IMPLICATIONS, AND RECOMMENDATIONS \\ Introduction}

This final chapter provides a summary of this study, including the purpose, scope, participants, design, methodology, and findings. Additionally, the findings of the present study will be discussed in relation to the literature, though, as previously mentioned, little research has been conducted in this area with DI Directors. The chapter will close with a discussion on the implications of this research as well as recommendations for continued work in this important area of inquiry.

\section{Purpose and Scope of the Study}

Research is considered to be the foundation of the profession of dietetics (Cassell, 1990). In fact, it is a core competency for DI programs (Accreditation Council for Education in Nutrition and Dietetics, 2016c). However, there is ample evidence to support the notion that dietetic professionals struggle with research (Byham-Gray et al., 2006; Dougherty et al., 2015; Eck et al., 1998; Gardner et al., 2002; Guyer et al., 1993; Schiller, 1988; Schiller et al., 1988; Slawson et al., 2000; Wylie-Rosett et al., 1990). Despite the emphasis on research within dietetics, a research-competency gap between curriculum and practice is evident.

The purpose of this study was to examine the relationship of the research involvement of DI Directors and their interpretation and implementation of competency 
CRD 1.5 for DI programs. Though DI Directors have a significant role in the development and implementation of their curriculum, little is known about their influence on competency CRD 1.5. Utilizing experiential learning as the overarching theoretical framework, this study sought to investigate whether DI Directors' experience with research influenced the manner in which they managed their DI program as it relates to competency CRD 1.5.

\section{Participants}

The participants for this study were DI Directors who manage ACEND-accredited DI programs in the United States, including Puerto Rico. All DI Directors who were not involved with the present study were contacted to participate in this study via email. The recruitment and reminder emails can be found in Appendix C and Appendix D, respectively. Usable data were collected from 96 participants, indicating a response rate of $39.3 \%$. Though the majority of participants were female (99\%) and Caucasian (89\%), this is in alignment with the current demographic breakdown of the profession. The Commission on Dietetic Registration (2016a) reported that, as of January 11, 2016, the demographic landscape of the profession was largely female (94\%) and white (81\%). Furthermore, it should be noted that only $3.5 \%$ of dietitians identify their area of practice as education (Commission on Dietetic Registration, 2016a). The present study focused exclusively on DI Directors, who seemingly had much experience prior to their current position, as the majority of participants had been an RD for more than 25 years (45\%), but had only been a DI Director for 5 years or less $(51 \%)$. 


\section{Research Design and Methodology}

A cross-sectional survey design was utilized for this study. As recommended by Vogt (2007), the research questions guided the design, measurement, and analysis of data gathered for this study. Two sections of the survey were developed by the researcher in conjunction with the literature (Byham-Gray, 2004; Harrison et al., 2001; Levine et al., 2005), and one section of the survey was the validated, RIQ (Whelan et al., 2013). The survey was reviewed by five content experts prior to data collection. The final survey can be found in Appendix B. The survey contained both open and closed questions in an effort to obtain the most meaningful data to answer the research questions. Briefly, the survey had questions designed to measure the participants' interpretation and implementation of competency CRD 1.5, as well as their research involvement, which was measured by the validated RIQ (Whalen et al., 2013). Additionally, sociodemographic, education/training, professional experience, research experience, and employment setting were also measured based upon the findings from a previous study (Byham-Gray, 2004).

All DI Directors who were listed on ACEND's website at the time of data collection, except for the two who were involved in the present study, were sent the recruitment email (Appendix C) and the reminder emails (Appendix D). The survey was administered through Qualtrics and data were analyzed using SPSS Version 23. Statistical significance was set at $p \leq .05$. A summary and discussion of the findings are presented relative to the respective research question. 


\section{Summary and Discussion of the Findings}

\section{Research Question 1}

Where do DI Directors fall on the research involvement continuum as defined by the Research Involvement Questionnaire? Based upon the RIQ, the majority of participants were not very involved in research activities. Although the research involvement of DI Directors has not been reported in the literature, these results are in agreement with other studies that have shown a lack of research involvement of dietitians (Byham-Gray et al., 2006; Eck et al., 1998; Gardner et al., 2002; Guyer et al., 1993; Schiller, 1988; Schiller et al., 1988; Slawson et al., 2000; Whelan \& Markless, 2012). The present study is the first to quantify the research involvement of DI Directors.

Results from this study indicated that more participants fell into Level 1 of the research continuum than in Levels 2, 3, and 4 combined. Additionally, two participants scored a zero on the RIQ, indicating that they selected "not at all" for all 24 questions on the survey, which resulted in them not placing on the research continuum. Wylie-Rosett et al. (1990), who first described the research continuum in relation to dietitians, indicated that all dietitians should be involved in Level 1. The results of the present study seem to confirm that DI Directors are most involved at Level 1 . This is in agreement with a similar finding from Dougherty et al. (2015), as dietitians mostly participated in basic research activities $(\mathrm{n}=4134)$. However, as competency CRD 1.5 specifies that dietetic interns should be able to conduct research (Accreditation Council for Education in Nutrition and Dietetics, 2016c), the disconnect between education and practice seems evident based upon the results of this study. 
Not surprisingly, research involvement decreased at the higher levels on the research continuum, as the mean for the summed RIQ (maximum $=24$ ) for Levels 1, 2, 3, and 4 , were $10.23 \pm 5.51,6.27 \pm 5.08,5.04 \pm 5.43$, and $3.78 \pm 4.23$, respectively Byham-Gray (2004) noted a similar trend using a different instrument with a 15-point scale, as dietitians who were placed in each of the four levels on the research continuum had mean scores of $10.8 \pm 2.7,6.2 \pm 3.1,5.6 \pm 3.1$, and $4.3 \pm 2.5$ for Levels $1,2,3$, and 4, respectively.

In addition to classification of scores based upon level, the overall RIQ score was calculated to provide a total score for the RIQ. The mean overall score was $25.33 \pm$ 18.76, which accounts for about $26 \%$ (96-point scale). This was lower than what was found by Byham-Gray (2004), which was a mean of $26.9 \pm 9.5$, or about $45 \%$ (60-point scale). Similar findings have been reported for dietitians in Australia $(5.1 \pm 1.7)$ or about $51 \%$ (10 point scale) (Howard et al., 2013) and dietitians in Canada (4.7 \pm 2.8$)$, or about 33\% (14-point scale) (Morley-Hauchecorne \& Lepatourel, 2000). Though none of the other studies utilized the RIQ, which makes comparisons difficult, the trend that dietitians are not highly involved in research seems to be supported.

\section{Research Question 2}

What types of factors influence DI Directors' involvement with research? The results of this study indicated that sociodemographic and employment setting were not found to be statistically significant with overall RIQ. Though the literature on DI Directors is lacking, these findings are in agreement with a study on dietitians in the UK that found no statistical relationship between research involvement and age, workplace, or type of position (Harrison et al., 2001) as well as with another study of Australian 
dietitians that found no statistical relationship between research involvement and workplace setting, sex, or work status (Howard et al., 2013). Administrative responsibilities have been reported to negatively influence the research involvement of dietetic faculty in the UK (Whelan \& Markless, 2012). However, since all participants in this study were DI Directors, which requires a substantial amount of administrative work, this was not addressed in the present study. Further, it should be noted that the present study was rooted in experiential learning theory; thus, current administrative responsibilities do not diminish previous experience with research.

The variables in the present study that were shown to influence the research involvement of DI Directors were within the education/training (highest level of education, formal education, completion of doctoral dissertation, additional training), professional experience (frequency of reading, last time read research), and research experience (authorship, involvement with group research projects, involvement with individual research projects, research in current position, research in past positions, confidence with research) categories. These findings are also consistent with the literature on this topic. Relevant studies in each of the three categories are discussed next.

First, involvement with research often occurs at the educational level through the completion of coursework, a thesis, a dissertation, or other research projects (Schiller et al., 1988). In fact, $44 \%$ of dietitians in one study reported that research experience was exclusively obtained through formal education (Dougherty et al., 2015). Accordingly, the data from this study showed that participants who had higher levels of education, namely doctoral degrees, had higher levels of research involvement. Similar findings have been reported for Coordinated Program Directors, as those with a doctorate rated both the 
importance of research and the amount of time spent on research higher than those with a master's degree (Nyland et al., 1989). Further illustrating this point, data from a survey of 258 dietitians indicated that those with a doctorate degree earned the highest mean research score, while those with a bachelor's degree earned the lowest score (ByhamGray et al., 2006). Taken together, it seems that research involvement is influenced by educational level. However, this does not mean that graduate degrees equate to research involvement or research competence. Currently, a bachelor's degree is required to become a dietitian, and a minimum of a master's degree is required to become a DI Director. However, as mentioned in research question one, the findings from this study demonstrated that practicing dietitians often scored higher for their research involvement than the participants in the present study, all of whom had a minimum of a master's degree. Thus, education is important, but the extent of research involvement and degree of research competence attained during formal education can vary greatly.

Though the structure of dietetic education has not changed since 1928 (Skipper \& Lewis, 2005), the specific requirements and competencies are continually updated by ACEND. Therefore, it was not surprising that there was no relationship between overall research involvement and years of experience in the present study. That is, the more recently credentialed dietitians may have had stronger research requirements within their dietetic education due to changing accreditation requirements. However, this was not observed by Howard et al. (2013), who found that dietitians in Australia with more years of experience had higher research engagement.

Two variables within the professional experience category were found to influence the overall research involvement in the present study. Specifically, participants 
who frequently read professional journals and who recently read peer-reviewed research articles were shown to have greater research involvement than those who read less often. These results were in line with Byham-Gray et al. (2006). These two variables were selected for the present study based upon the findings from Byham-Gray et al. (2006), although these variables were classified in the education/training category, rather than the professional experience category.

The third category, research experience, contained six variables on the survey, and all were found to be significantly related to the overall research involvement of the participants. As the present study is centered upon the principles of experiential learning, these results are not surprising. Direct experience with research translates into higher research involvement, which theoretically leads to greater research competence. Involvement in at least one research project was reported in $71 \%$ of the participants from the present study, which is similar to another study on this topic in dietetic professionals, which found $81 \%$ of participants to be involved in at least one research project (Dougherty et al., 2015). Accordingly, participants who were involved with more research projects had higher research involvement scores. A similar trend was noted for dietitians in Australia (Howard et al., 2013). Not unexpectedly, research involvement within a position increased scores in the present study with DI Directors. Research skills were rated higher for participants who had $10 \%$ or more of their position geared towards research and who had been involved with five or more research activities (Howard et al., 2013).

Further, nearly half of the participants in the present study (48\%) had been an author or co-author on a published, research-based article. This finding is consistent with 
a larger study, consisting of mostly Academy of Nutrition and Dietetic members (99.8\%), which found that $53 \%$ of participants had published or presented data, with only $16 \%$ with a first-author publication (Dougherty et al., 2015). However, studies that looked exclusively at dietetic educators found higher frequencies of publications, with $74 \%$ for dietetic educators, which consisted of a quarter of the sample being program directors (Schiller et al., 1988), and 60\% for Coordinated Program Directors in the past 3 years prior to data collection (Gabel \& Pond-Smith, 1995). Tenure-track faculty typically have pressures to publish, which likely explains the higher publishing rates compared to other dietetic educators. However, since some DI Directors work in non-academic institutions, it is likely that this pressure does not exist for all, resulting in fewer published articles.

Based upon the principles of the theory of experiential learning, as individuals gain experience, they become more confident and competent. A positive trend with selfreported research confidence and overall research involvement was noted in this study. Participants who selected that they were very confident in their research skills scored the highest on the RIQ. Semi-structured interviews with faculty revealed the importance of confidence in regards to research involvement (Whalen \& Markless, 2012). Unfortunately, dietitians have been shown to lack confidence with their research skills and knowledge (Guyer et al., 1993; Wylie-Rosett et al., 1990).

Additionally, two multiple linear regressions were conducted to generate prediction models for the overall RIQ. Of the five categories of independent variables, three were shown to have a statistically significant relationship with the overall RIQ. These included the education/training, professional experience, and research experience categories. The regression model that utilized one predictor from each of the three 
categories (completion of doctoral dissertation, frequency of reading, and involvement with group research) was shown to be statistically significant and able to explain $47 \%$ of the variance with these predictors. Though Byham-Gray et al. (2006) utilized slightly different predictors (level of education, last time read research, and taken a research course), the variance explained by the model was similar at $35 \%$ for dietitians. The second regression model in the present study was stronger than the first, as it explained $58 \%$ of the variance of the overall RIQ using two predictors from each of the three categories (completion of doctoral dissertation, additional training, frequency of reading, last time read research, involvement with group research, and involvement with individual research). Taken together, these results show that education/training, professional experience, and research experience are important predictors of the research involvement of DI Directors and other dietitians. This is certainly in alignment with the principles of experiential learning, which is the theoretical framework of this study.

\section{Research Question 3}

How do DI Directors interpret competency CRD 1.5? Findings from this study suggest that the participants interpreted competency CRD 1.5 in a variety of ways, ranging from involvement with the components of the research process to production of a full, original research project. The wide array of responses highlights a common criticism of competency-based education, which is that many educators tend to view the curriculum from a reductionist perspective (Frank et al., 2010). That is, the competency can be reduced to parts of the research process, rather than viewed in its entirety.

In response to the question "which of the following best describes your interpretation of ACENDs Core Competency CRD 1.5," participants selected one of three 
answers, which were based upon ACEND's definition of research. Answers were classified as a failed, partial, or complete match. The majority of participants selected a partial match $(\sim 46 \%)$, followed by a complete match $(\sim 40 \%)$, and a failed match $(\sim 14 \%)$. These results suggest that some of the participants in this study seemingly interpreted competency CRD 1.5 from a reductionist perspective.

Dietitians in the UK were found to have similar results with their interpretation of research as defined by their professional organizations, but only for the partial match category, as it was the most prevalent $(\sim 50 \%)$ (Harrison et al., 2001). Twice as many participants in the UK study had a failed match (30\%) compared to the present study $(\sim 14 \%)$, while only $15 \%$ were classified as a complete match, compared to $40 \%$. This study focused exclusively on DI Directors, who are dietetic educators; thus, it is possible that they might be quite familiar with ACENDs terminology, as they must maintain accreditation.

While many participants described their interpretation of competency CRD 1.5 to include extensive involvement in a research project, some described their interpretation of the competency to simply be participation in a research project. It is unclear exactly what might constitute as participation, as no follow-up data were collected. However, other studies have shown that dietetic educators have identified that exposure can equate to learning (Gates \& Sandoval, 1998; Gilboy et al., 2010; Knoblock-Hahn et al., 2010). Though these studies did not explore the interpretation of a DI competency, the notion that simple exposure to a competency further highlights the concerns associated with utilizing a reductionist approach. DI Directors and other dietetic educators must truly understand competency-based education in order to ensure their programs provide 
meaningful experiences. Experiential learning, which was the theoretical framework utilized in this study, provides an ideal avenue to ensure competence for both educators and students (Kolb, 1984). This theory highlights the necessity of experience to yield learning (Dewey, 1938; Joplin, 1981; Kolb, 1984).

The present study focused exclusively on the role of DI Directors because they have a pivotal role in the development and implementation of the DI curriculum. Specific to this study, the theory of experiential learning suggests that DI Directors must have experience with competency CRD 1.5 and the research process in order to fully understand what is needed to ensure alignment of meaningful experiences with this competency. Findings from this study supported this theoretical framework, as participants who had higher levels of education, completed a doctoral dissertation, completed additional research training, and authored or co-authored a research-based article were found to have a statistically significant relationship with their interpretation of competency CRD 1.5. Accordingly, the manner in which DI Directors interpret competency CRD 1.5 likely influences the implementation of the competency. Therefore, the interpretation of competency CRD 1.5 is discussed next.

\section{Research Question 4}

What types of learning experiences are DIs using to fulfill competency CRD 1.5? The data from this study demonstrated that participants utilized many different learning experiences for competency CRD 1.5, which, similar to the interpretation of the competency described in research question three, also ranged from involvement with the components of the research process to production of a full, original research project. Based upon the criteria discussed in Chapter IV, participants were classified as a partial 
match $(78 \%)$ or a complete match $(22 \%)$ for the implementation of competency CRD 1.5.

The high percentage of participants who were classified into the partial match indicated that fragmentation of the competency was common. Breaking down competencies into individual components can be an effective method to teach competence, as it helps guide the learning process; however, Batalden et al. (2002) warn that this must be done carefully. A few participants in the present study noted that an article review and presentation of said article were used to meet competency CRD 1.5 within their programs. While article critiques and communication of the literature are important components of the research process, students who only have experience in these areas are not likely truly competent. The concept of using a review of the literature to meet a research requirement is not new within dietetics, as this has been reported for $26 \%$ of DI Directors and coordinated program directors (Fitz \& Winkler, 1989), though this was many years before ACEND's current research requirement. Similarly, nearly $25 \%$ of medical program directors noted that article reviews were utilized to meet the research requirement for medical students (Levine et al., 2005).

Although the reliance on observations to build research skills has been noted for dietetic students (Fitz \& Winkler, 1989) and medical students (Lurie et al., 2009), participants in this study did not allude to the use of observations to meet competency CRD 1.5. All participants selected at least one of the components of the research process listed on the survey, and all comments reflected participation-level experiences. This is especially interesting, as ACEND includes the word observation within their definition of experiential learning, which can be found in the important terms section of Chapter I (Accreditation Council for Education in Nutrition and Dietetics, 2016c). 
Since this study was rooted in the theory of experiential learning, it is necessary to discuss the interpretation of competency CRD 1.5 from this framework. Similar to research question three, participants who had research experience in terms of a doctoral dissertation, involvement with group research projects, and involvement with research in their current position were found to have a statistically significant relationship with their implementation of competency CRD 1.5. That is, the more experience they had in these areas, the more likely they were to select a complete match for their implementation of competency CRD 1.5. Thus, it seems this is an appropriate theoretical framework for this type of inquiry.

\section{Research Question 5}

What is the relationship of the research involvement of DI Directors and their interpretation and implementation of competency CRD 1.5? Past studies have investigated components of this research question, as evidenced by the literature cited for research questions one through four, but no published studies have looked at the interaction between these variables. Additionally, few studies have focused on the role of DI Directors or on competency CRD 1.5. Therefore, this study was the first to examine this critical gap in the literature.

The findings from this study indicated that the participants' interpretation and implementation of competency CRD 1.5 could be predicted by using the summed score for the four levels of research involvement. A better than chance-level prediction was noted for both interpretation and implementation of competency CRD 1.5 based upon the kappa coefficients. However, the prediction appeared slightly stronger for implementation, as $63 \%$ of the cases were correctly classified, while only $58 \%$ of the 
cases were correctly classified for interpretation. Taken together, the findings from this study highlight the importance of experiential learning on the research curriculum in DI programs. DI Directors must have experience with research in order to understand competency CRD 1.5 and to have meaningful experiences aligned with this competency.

Certainly, additional research is necessary within this novel area of inquiry; however, dietetic educators can use the findings from this study to help bridge the research-competency gap within dietetics. Based upon the results of this study, it seems that the lack of research experience on the part of DI Directors serves to perpetuate this gap. DI Directors who have minimal experience with research are not equipped to ensure research experience within their DI curriculum. Experiential learning is essential for both educators and students. John Dewey, who is often identified as the founder of experiential learning, describes an "intimate and necessary relation between the processes of actual experience and education" which "depends upon having a correct idea of experience" (Dewey, 1938, p. 20). Thus, it is likely that DI Directors who lack research experience will not have the "correct idea" of research experience, which will negatively impact the manner they interpret and implement research within their programs. Though the impact this might have on students and the profession was not investigated in the present study, based upon the principles of experiential learning, it is likely that it is significant. The implications of this study are discussed next.

\section{Implications and Strategies}

\section{Research Question 6}

What are the curricular/professional implications for utilizing experiential learning for competency CRD 1.5 in DI programs and how might this affect the 
profession as a whole? The results of this study confirmed the importance of the experiences DI Directors had with research on the research curriculum within DI programs, specifically as it relates to competency CRD 1.5. That is, DI Directors must have meaningful experiences with research in order to effectively develop and implement meaningful experiences within their DI program. The implications of this study will be discussed first, including the critical role of DI Directors in the research-competency gap that has been observed within dietetics. This section will close with strategies that might help close the research-competency gap, including both educational requirements and opportunities for additional training for DI Directors.

Research-competency gap. The findings from this study indicated that the vast majority of participants were not highly involved with research, as they were classified into the lowest level on the research continuum. This illustrates the research-competency gap that has been described in the literature (King et al., 2014). Despite the emphasis placed on research within the dietetic educational curriculum and within the dietetic profession, many of the DI Directors in this study did not seem to have the necessary experiences to attain research competence. Per the theory of experiential learning, the lack of experiences on the part of educators makes it difficult, if not impossible, for them to align meaningful experiences for students. As a result, student learning is compromised. Accordingly, this leads to entry-level dietitians who are not prepared to be consumers or producers of research. Figure 2 depicts one example of the perpetuation of this cycle, which is based upon the theory of experiential learning. For the purpose of this topic, the cycle begins with DI Directors, which is shown on the upper left side of the figure. 


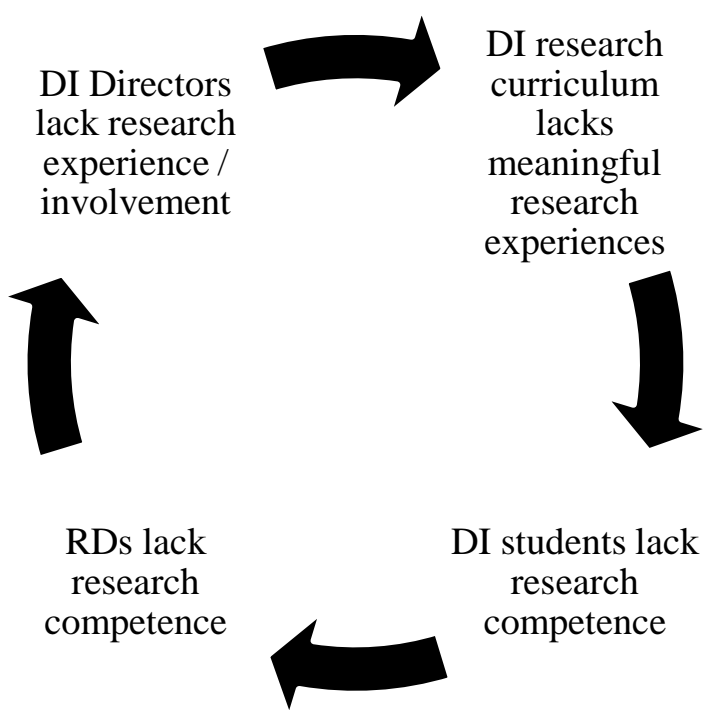

Figure 2. Cycle Perpetuating the Lack of Research Competence within Dietetics

On the other hand, as shown by this study, DI Directors who were involved with research at higher levels on the research continuum were more likely to employ a meaningful research curriculum within their DI programs. Although this study did not measure research competence, application of the theory of experiential learning indicates greater research competence for students and dietitians as a result of the DI Directors' experience and involvement with research. Figure 3 illustrates this proposed cyclical model. This cycle highlights the importance of research experience and research involvement of educators. The implications of this model could serve to help close the researchcompetency gap between dietetic education and practice. Similar to Figure 2, this cycle begins with on the upper left side of the figure with the DI Directors' experience and involvement with research. 


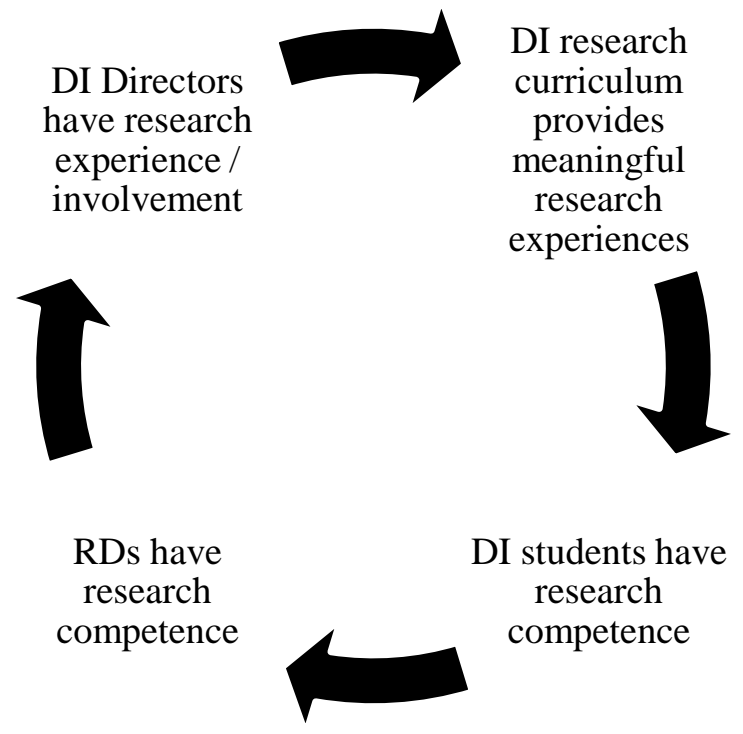

Figure 3. Proposed Cycle to Help Close the Research-Competency Gap within Dietetics

Within dietetics, research has been shown to strengthen the knowledge base of the profession (Manore \& Meyers, 2003; Whelan \& Markless, 2012), optimize outcomes (Byham-Gray, 2005; Taylor, 1998), help with reimbursement for services (Byham-Gray, 2005; Dougherty et al., 2015; Kicklighter et al., 2013; King et al., 2014; Smith, 2003), offer economic benefits (King et al., 2014; Whelan \& Markless, 2012), help establish policy (Manore \& Meyers, 2003), and provide a continuity of care (Byham-Gray, 2005; Taylor, 1998). Since research plays such a vital role in dietetics, the lack of research involvement and competence among dietitians is concerning. In particular, when dietetic educators lack the necessary experiences with research they may "inculcate a false security in students by giving them the impression that collecting data, conducting literature reviews, or serving as a research assistant provides adequate preparation for independent research" (Schiller et al., 1988, p. 1074). Thus, students and faculty likely believe students achieve competence during their educational career, but this may not be 
the case. It may be assumed that the proposed cycle depicted in Figure 3 is being implemented, when the cycle shown in Figure 2 is the reality. The results of this study demonstrated that one potential avenue that could help close the research-competency gap within dietetics stems from DI Directors.

Strategies. Strategies that could be employed to bridge this gap center around ensuring that DI Directors and other dietetic educators have the necessary experience with research. The findings from this study demonstrated that participants who had research in their formal education $(27.04 \pm 19.27)$ and who had additional training in research $(34.98 \pm$ 21.82) had a higher mean overall RIQ than those who did not have research in their formal education $(14.17 \pm 9.60)$ or those who did not have additional training in research $(17.77 \pm$ 11.75) (See Table 14). Though these results are encouraging, it should be noted that the maximum score for the overall RIQ was 96, which shows there is substantial room for improvement. Therefore, the strategies that have been identified based upon the findings and implications of this study focus on the educational requirements of DI Directors and opportunities for additional training.

Educational requirements. Dietetic educators have been described as being positioned to be leaders in research (Hynak-Hankinson et al., 1997; Whelan \& Markless, 2012), which is the highest level on the research continuum (Wylie-Rosett et al., 1990). Nevertheless, as has been discussed throughout this paper, educators must have meaningful experience with research in order to reach this level on the research continuum. Currently, a master's degree is required for the position of DI Director; however, there is no requirement for the discipline or the type of graduate program. Additionally, there is no requirement for the completion of a research project. Particularly in light of the upcoming requirement for a 
master's degree for entry into the dietetics profession, it seems necessary to reevaluate the educational requirements of dietetic educators.

The majority of the participants in this study reported involvement with research within their dietetic education (50\% master's thesis, $29 \%$ doctoral dissertation, $26 \%$ master's non-thesis, 21\% DI project, 19\% undergraduate project) (see Table 3); however, the findings from this study indicated that they were not very involved with research based upon their RIQ scores. Though it is promising that the participants in this study were involved with research within their educational careers, the low RIQ scores indicated that these individuals were not highly involved with research, making it difficult for them to become the leaders in research as described by Hynak-Hankinson et al. (1997) and Whelan and Markless (2012). There are likely many contributing factors to this, but an important area that deserves attention is the possibility of requiring DI Directors and other dietetic educators to complete an original research project to ensure they have experience with all of the necessary steps of the research process. Of course, ACEND has changed the dietetic curriculum over the years, which means some DI Directors may have completed the current requirements, including CRD 1.5. However, as shown in this study, the types of projects aligned with this competency may not be sufficient. Additionally, some DI Directors have likely completed full research projects through their thesis or dissertation work. Nonetheless, the current requirements for the position of DI Director do not include research experience despite research being described as core competency for DI programs (Accreditation Council for Education in Nutrition and Dietetics, 2016c). Utilizing the theory of experiential learning as the framework for this recommendation, requiring DI Directors to have meaningful experience with research will help to close the proposed 
research-competency gap as shown in Figure 3.

Furthermore, restrictions on the type of graduate degree may be warranted, especially when the master's degree is required to sit for the national registration exam. Specifically, a research-based degree might be beneficial to help ensure DI Directors have this structured experience with research prior to becoming educators. Though it is not guaranteed, it is likely that the experience would be meaningful, which would ideally perpetuate the proposed cycle in Figure 3. In addition to completing a project, these types of programs may have coursework, such as research methods and statistics, which would presumably further increase research competence. A research-based degree may not be feasible for every DI Director due to financial considerations, location, or other reasons. Thus, an alternative for these individuals could be required to complete some additional training, which will be discussed next.

Opportunities for additional training. The findings from this study indicate that DI Directors benefit from additional training with research. As noted by Dougherty et al. (2015), many resources are available to aid dietitians with research, but they are often "underused and should be advertised more clearly to members" of the Academy of Nutrition and Dietetics (p. 1006). The extent to which these resources are utilized by DI Directors is not known. However, if the results of this study are any indication, with only $6 \%$ utilizing the Academy's Online Research Toolkit for their students, it is likely that the benefits of these resources are not being maximized.

Dietitians, including DI Directors, are required to complete continuing professional education (CPE) hours in order to maintain their credential (Academy of Nutrition and Dietetics, 2016b). Each dietitian is able to customize their professional portfolio plan 
according to their professional interest. Though there are a few requirements to these plans, there is no requirement regarding research. Mandatory CPEs related to research would serve to provide some opportunities for training in this area for DI Directors and other educators. These mandatory research-focused CPEs would be particularly beneficial for those with minimal experience with research as well as experienced researchers who have not been involved with research in recent years. Importantly, if these mandatory research CPEs could be counted as hours toward maintaining their credentials, it should not increase the workload of these busy educators.

Completion of required modules or toolkits could certainly supplement the lack of research experience; however, actual and meaningful experience with research cannot be overshadowed. Several participants in this study felt that completion of a few components of the research process sufficed for the implementation of CRD 1.5; thus, it is essential for these individuals to have an accurate understanding of how to conduct research. DI Directors have multiple responsibilities, so adding on a requirement to complete an independent project may be difficult. As such, previous research has noted that collaboration with experienced researchers seems to be the most effective and preferred method to gain research experience and competence (Eck et al., 1998; Gardner et al., 2002; Hays \& Peterson, 2003; Slawson et al., 2000; Whelan et al., 2007b). Therefore, DI Directors could collaborate with other faculty members, preceptors, or outside individuals on research projects. DI Directors who are currently involved with research could get CPEs for leading these collaborations, rather than completing the aforementioned mandatory CPEs. One example of how to initiate these collaborations would be the creation of a network that could match experienced researchers to DI Directors and other educators in 
need of research experience. In addition to increasing the research involvement of DI Directors and dietetic educators, it would also contribute to the body of research within dietetics, as many of these projects would be focused on some aspect of the profession.

Summary. It is critical to ensure that dietetic educators are equipped with the required research knowledge and research skills to develop and implement research curriculums that will foster research competence within their students. Based upon the findings from this study, it seems that DI Directors play a significant role in closing the research-competency gap within dietetics. However, it is evident that these individuals are not very involved with research. Strategies that were recommended to help close the research-competency gap include reevaluating the educational requirements of DI Directors and providing opportunities for additional research experience. Though DI Directors should have experience with all required aspects of the DI curriculum, research experience is especially critical since research is described as the "backbone" of the dietetics profession (Sims \& Simko, 1988; Smitherman \& Wyse, 1987).

\section{Limitations}

Survey research tends to be "strong on external validity or generalizability" because it is designed to "gather the same information from a large number of respondents with the goal of being able to summarize their responses quantitatively" (Vogt, 2007, p. 307). However, this type of research is not without limitations (Creswell, 2009; Vogt, 2007). Accordingly, several limitations were present in this study.

First, the overall response rate of $63.5 \%$ indicates that nearly a third of the potential population did not participate in the study. As with any survey research, response bias can be an issue (Creswell, 2009). It is possible that DI Directors who were 
involved with research were more likely to participate in this study. Additionally, the high rate of participants who did not complete the survey $(n=56)$ suggests that the length of the survey may have been a factor in obtaining usable data. Thus, the results can only be generalized to the DI Directors who participated in this study.

Another limitation to this study was the exclusive use of DI Directors. Though there are additional avenues for completion of the educational pathway to become a registered dietitian, the DI is the most common. Also, even though DI Directors are the gatekeepers to the DI curriculum, it is likely that other constituents, such as faculty members or preceptors, were involved with competency CRD 1.5. However, since no study on this topic has focused on this population, the contributions of these findings were considered to outweigh the potential limitations.

The design of the study also posed some limitations. This study had a quantitative focus, as the purpose was to examine the relationship between the research involvement of DI Directors and their interpretation and implementation of competency CRD 1.5 for DI programs. Though the survey contained a few open-ended questions, the majority of the data were quantitative. The comments on the open-ended questions provided additional insight into the questions, but it is possible that a deeper understanding of the research involvement of DI Directors as well as their interpretation and implementation of competency CRD 1.5 may be gained through a more qualitative approach.

Finally, the study was limited to the concepts of interpretation and implementation as measured by the tool developed for the present study. The questions designed to measure interpretation and implementation were reviewed by the expert panel; however, as described in Chapter III, some issues were noted with the manner in 
which participants answered these questions. Research involvement was measured by the validated RIQ; however, since it is a relatively new instrument, no similar studies have been conducted making comparisons difficult.

Despite these limitations, this study sought to help fill a void in the literature regarding the influence of DI Directors' experience with research as well as how their involvement affects the manner in which they manage their DI program as it relates to competency CRD 1.5. This study provided a novel perspective on the influence of the DI Director on competency CRD 1.5 within DI programs. However, additional research is warranted in this area.

\section{Recommendations for Future Research}

The findings from this study suggest that the DI Directors who participated in this study have a role in the research-competency gap that has been reported in the literature. This study was the first to examine the research involvement of DI Directors as well as the relationship between their research involvement and their interpretation and implementation of competency CRD 1.5 for DI programs. As such, additional research is needed to further explore this important topic.

Future research should include more qualitative measures to better understand the interpretation and implementation of competency CRD 1.5. The present study focused on the quantification of these variables with the goal of generalizing the results. A qualitative approach can help identify "meaning, not the frequency” (Merriam, 2009, p. 13). Individual interviews or focus groups could provide an avenue to gain a deeper understanding of the manner in which DI Directors interpret and implement competency CRD 1.5 as well as their experiences with research. Additionally, document analysis of 
projects and assignments that are aligned with competency CRD 1.5 would serve to obtain a more authentic perspective of the implementation of competency CRD 1.5 within DI programs.

The purpose of this study was to look exclusively at the influence of DI Directors, who are the gatekeepers of the DI curriculum. However, future research could explore the role of other constituents who are involved with competency CRD 1.5. DI Directors are ultimately responsible for the alignment of meaningful experiences for each competency, but it is unlikely that the process is done in isolation. Furthermore, though some work has been done in this area, additional research is needed to identify barriers to research involvement for DI Directors and the other constituents in order to provide appropriate environments and experiences that will lead to research competence.

Finally, future research should focus on student outcomes. DI Directors were identified as the population for this study because these individuals play a critical role in the development and implementation of the DI curriculum. However, the aim of this study was to explore one potential contributor to the well-documented gap of research competence between education and practice. Successful completion of the learning experiences that are aligned with competency CRD 1.5 should translate to research competence for DI students. Ideally, this will strengthen the profession because it will help bridge the research-competency gap between education and practice.

\section{Summary}

Research is considered to be at the foundation of the profession of dietetics (Cassell, 1990; Manore \& Myers, 2003), and it is a core competency for DI programs (Accreditation Council for Education in Nutrition and Dietetics, 2016c). However, there 
is a substantial body of literature demonstrating the lack of research involvement among dietitians and dietetic educators (Byham-Gray et al., 2006; Eck et al., 1998; Gardner et al., 2002; Guyer et al., 1993; Schiller, 1988; Schiller et al., 1988; Slawson et al., 2000; Whelan \& Markless, 2012). The present study aimed to help bridge the researchcompetency gap between education and practice by investigating the influence of DI Directors' involvement with research and the manner in which DI Directors interpreted and implemented competency CRD 1.5 within DI programs.

Many factors likely contribute to this gap, including the influence of DI Directors. These individuals play a significant role in the development of the research competence of future dietitians because they are directly involved in the DI curriculum, which centers on the principles of experiential learning theory. No previous studies on this topic have exclusively examined this population; however, dietetic educators have been described as being "ideally positioned to be research leaders" (Whelan \& Markless, 2012, p. 1027), and as stakeholders who can influence the future of the profession by "conducting research, teaching research to dietetic students, and investigating the effectiveness of education" (Hynak-Hankinson et al., 1997, p. S106). Therefore, per the theory of experiential learning, dietetic educators, including DI Directors, must have meaningful experiences with research in order to have the necessary research competence to lead this endeavor.

The results from this study provided a novel perspective to the researchcompetency gap between dietetic education and practice. DI Directors who participated in this study demonstrated low research involvement as measured by the RIQ. Additionally, the research involvement of participants influenced the manner in which 
they interpreted and implemented competency CRD 1.5, which undoubtedly influences the research competence of their students. This highlights the significant role DI Directors have in either the perpetuation or extinction of the current cycle of dietitians who are not involved with research despite research being embedded into the dietetic curriculum. The findings from this study can be used to better prepare DI Directors and other dietetic educators as well as to inform curricular decisions to better align education and practice within the profession of dietetics. 


\section{REFERENCES}

Academy of Nutrition and Dietetics. (2016a). The Academy's Research Philosophy. Retrieved from Academy of Nutrition and Dietetics' member website: http://www.eatrightpro.org/resource/research/evidence-basedresources/philosophy-and-framework/the-academys-research-philosophy

Academy of Nutrition and Dietetics. (2016b). What is a Registered Dietitian Nutritionist? Retrieved from Academy of Nutrition and Dietetics website: http://www.eatrightpro.org/resources/about-us/what-is-an-rdn-and-dtr/what-is-aregistered-dietitian-nutritionist

Academy of Nutrition and Dietetics. (2016c). Who We Are. Retrieved from Academy of Nutrition and Dietetics website: http://www.eatrightpro.org/resources/aboutus/academy-vision-and-mission/who-we-are

Academy Quality Management Committee and Scope of Practice Subcommittee of the Quality Management Committee. (2013). Academy of Nutrition and Dietetics: Revised 2012 standards of practice in nutrition care and standards of professional performance for registered dietitians. Journal of the Academy of Nutrition and Dietetics, 113, S29-S45.

Accreditation Council for Education in Nutrition and Dietetics. (2015). Dietetic Internships. Retrieved from Accreditation Council for Education in Nutrition and Dietetics website: http://www.eatrightacend.org/ACEND/content.aspx ?id=10760

Accreditation Council for Education in Nutrition and Dietetics. (2016a). Accreditation Council for Education in Nutrition and Dietetics: Policy and Procedure Manual. Retrieved from Accreditation Council for Education in Nutrition and Dietetics website: http://www.eatright.org/ACEND/

Accreditation Council for Education in Nutrition and Dietetics. (2016b). ACEND Accreditation Standards for Didactic Programs in Nutrition \& Dietetics: Leading to Supervised Practice. Retrieved from Accreditation Council for Education in Nutrition and Dietetics website: http://www.eatrightacend.org/ACEND/

Accreditation Council for Education in Nutrition and Dietetics. (2016c). ACEND Accreditation Standards for Internship Programs in Nutrition \& Dietetics: Leading to the RD Credential. Retrieved from Accreditation Council for Education in Nutrition and Dietetics website: http://www.eatrightacend.org/ACEND/ 
Aldas, T., Crispo, V., Johnson, N., \& Price, T. A. (2010). Learning by doing: The Wagner plan from classroom to career. Peer Review, 12, 24-28.

Anchondo, I. M., Campbell, C., \& Zoellner, J. (2014). Academy of Nutrition and Dietetics 2011 survey on member research activities, needs, and perceptions. Journal of the Academy of Nutrition and Dietetics, 114, 803-810.

Astin, A. W., \& Sax, L. J. (1998). How undergraduates are affected by service participation. Journal of College Student Development, 39, 251-263.

Barr, A. B., Walters, M. A., \& Hagan, D. W. (2002). The value of experiential education in dietetics. Journal of the American Dietetic Association, 102, 1458-1460.

Baskind, F. R., Shank, B. W., \& Ferraro, E., K. (2001). Accountability for professional practice: Assessment in social work education. In C. Palomba \& T. Banta (Eds.), Assessing student competence in accredited disciplines (pp. 95-120). Sterling, VA: Stylus.

Batalden, P., Leach, D., Swing, S., Dreyfus, H., \& Dreyfus, H. (2002). General competencies and accreditation in graduate medical education. Health Affairs, 21, 103-111.

Benner, P. (2004). Using the Dreyfus model of skill acquisition to describe and interpret skill acquisition and clinical judgment in nursing practice and education. Bulletin of Science Technology \& Society, 24, 188-199.

Bennett, S., Hoffmann, T., \& Arkins, M. (2011). A multi-professional evidence-based practice course improved allied health students' confidence and knowledge. Journal of Evaluation in Clinical Practice, 17, 635-639.

Brehm, B. J., Rourke, K. M., \& Cassell, C. (1999). Enhancing didactic education through participation in a clinical research project. Journal of the American Dietetic Association, 99, 1090-1093.

Brittingham, B. (2009). Accreditation in the United States: How did we get to where we are? New Directions for Higher Education, 145, 7-27.

Byham-Gray, L. (2004). Dietitians' perceptions, attitudes, and knowledge of evidencebased practice and involvement in research activities (Doctoral dissertation). Retrieved from ProQuest Dissertations and Theses database (UMI No. 3110992).

Byham-Gray, L. (2005). A review of the "body" and the "backbone" for the dietetics profession. Topics in Clinical Nutrition, 20, 2-15.

Byham-Gray, L. D., Gilbride, J. A., Dixon, B., \& Stage, F. K. (2006). Predictors for research involvement among registered dietitians. Journal of the American Dietetic Association, 106, 2008-2015. 
Carraccio, C., Englander, R., Adams, D., Giudice, E., \& Olsen, A. G. (2010). Is there a gap between program directors' expectations and residents' performance? Comparing predictions with outcomes for competence in patient care. Academic Medicine, 85, 1152-1156.

Cassell, J. (1990). Carry the flame: The history of the American Dietetic Association. Chicago, IL: The American Dietetic Association.

Castellanos, V.H., Myers, E.F., \& Shanklin, C.W. (2004). The ADA's research priorities contribute to a bright future for dietetics professionals. Journal of the American Dietetic Association, 104, 678-681.

Chabot, J. M., \& Holben, D. H. (2003). Integrating service-learning into dietetics and nutrition education. Topics in Clinical Nutrition, 18, 177-184.

Chambers, D. W., Gilmore, C. J., O’Sullivan Maillet, J., \& Mitchell, B. E. (1996). Another look at competency-based education in dietetics. Journal of the American Dietetic Association, 96, 614-617.

Chrencik, E., Xu, R., Neal, T., \& Steiber, A. (2008). Renal dietitians'self-perceptions on research participation: A pilot study. Journal of Renal Nutrition, 18, 389-392.

Clark, R. W., Threeton, M. D., \& Ewing, J. C. (2010). The potential of experimental learning models and practices in career and technical education \& career and technical teacher education. Journal of Career and Technical Education, 25, 4662.

Code of Ethics Task Force. (2009). American Dietetic Association/Commission on Dietetic Registration code of ethics for the profession of dietetics and process for consideration of ethics issues. Journal of the American Dietetic Association, 109, 1461-1467.

Cohen, A. M., \& Kisker, C. B. (2010). The shaping of American higher education: Emergence and growth of the contemporary system ( $2^{\text {nd }}$ ed.). San Francisco, CA: Jossey-Bass.

Commission on Accreditation for Dietetics Education. (2010). 2009 Annual Report. Retrieved from Academy of Nutrition and Dietetics website: http://www.eatright.org/CADE/content.aspx?id=6442451290

Commission on Dietetic Registration (2016a). Registered Dietitian (RD) and Registered Dietitian Nutritionist (RDN) by Demographics. Retrieved from Commission on Dietetic Registration website: https://www.cdrnet.org/registrystatistics?id=1825\&actionxm=ByDemographics 
Commission on Dietetic Registration (2016b). Registration Examination for Dietitians: Handbookfor Candidates. Retrieved from Commission on Dietetic Registration website: https://www.cdrnet.org/vault/2459/web/files/CDRRDHandbook20151.pdf

Committee on Education. (1927). Outline for standard course for student dietitians in hospitals. Journal of the American Dietetic Association, 3, 183-186.

Corbett, F. R. (1910). Essentials in the training of the dietitian. Journal of Home Economics, 2, 499-505.

Creswell, J. W. (2009). Research design: Qualitative, quantitative, and mixed methods approaches $\left(3^{\text {rd }}\right.$ ed.). Thousand Oaks, CA: Sage.

Desbrow, B., Leveritt, M., Palmer, M., \& Hughes, R. (2014). Evaluation of a curriculum initiative designed to enhance the research training of dietetics graduates. Nutrition and Dietetics, 71, 57-63.

Dewey, J. (1938). Experience \& education. New York, NY: Touchstone.

Dougherty, C. M., Burrowes, J. D., \& Hand, R. K. (2015). Why registered dietitian nutritionists are not doing research-perceptions, barriers, and participation in research from the Academy's dietetics practice-based research network needs assessment survey. Journal of the Academy of Nutrition and Dietetics, 115, 10011007.

Dreyfus, S. E. (2004). The five-stage model of adult skill acquisition. Bulletin of Science Technology \& Society, 24, 177-181.

Eck, L. H., Slawson, D. L., Williams, R., Smith, K., Harmon-Clayton, K., \& Oliver, D. (1998). A model for making outcomes research standard practice in clinical dietetics. Journal of the American Dietetic Association, 98, 451-457.

Ewell, P. T. (2008). U.S. accreditation and the future of quality assurance. Washington, DC: Council for Higher Education Accreditation.

Eyler, J. (2009). The power of experiential education. Liberal Education, 95, 24-31.

Fitz, P., \& Winkler, M. F. (1989). Education, research, and practice: Bridging the gap. Journal of the American Dietetic Association, 89, 1676-1679.

Frank, J. R., Snell, L. S., ten Cate, O., Holmboe, E. S., Carraccio, C., Swing, S.R., \& Harris, H. A. (2010). Competency-based medical education: Theory to practice. Medical Teacher, 32, 638-645. 
Furman, N., \& Sibthorp, J. (2013). Leveraging experiential learning techniques for transfer. New Directions for Adult and Continuing Education, 137, 17-25.

Gabel, K. A. \& Pond-Smith, D. (1995). Coordinated program directors: Activities and perceptions about research, tenure, and promotion. Journal of the American Dietetic Association, 95, 1156-1157.

Gardner, J. K., Rall, L. C., \& Peterson, C. A (2002). Lack of multidisciplinary collaboration is a barrier to outcomes research. Journal of the American Dietetic Association, 102, 65-71.

Gates, G. E., Kris-Etherton, P. M., \& Greene, G. (1990). Nutrition care planning: Comparison of the skills of dietitians, interns, and students. Journal of the American Dietetic Association, 90, 1393-1397.

Gates, G., \& Sandoval, W. (1998). Teaching multiskilling in dietetics education. Journal of the American Dietetic Association, 98, 278-284.

Gavigan, L. (2010). Connecting the classroom with real-world experiences through summer internships. Peer Review, 12, 15-19.

Gilboy, M. B. R., Harris, J., \& Lazarow, H. L. (2010). Public policy in undergraduate dietetics education: Challenges and recommendations. Topics in Clinical Nutrition, 25, 109-117.

Gilbride, J. A., \& Byham-Gray, L. (2008). Bridging research into practice. In E. R. Monsen \& L. Van Horn (Eds.), Research: Successful Approaches (pp. 441-451). Chicago, IL: American Dietetic Association.

Gilmore, C. J., Maillet, J. O., \& Mitchell, B. E. (1997). Determining educational preparation based on job competencies of entry-level dietetics practitioners. Journal of the American Dietetic Association, 97, 306-316.

Gravetter, F. J., \& Wallnau, L. B. (2009). Statistics for the behavioral sciences (8th ed.). Belmont, CA: Wadsworth Cengage Learning.

Green, A. J., \& Holloway, D. G. (2006). Student nurses' experience of experiential teaching and learning: Towards a phenomenological understanding. Journal of Vocational Education \& Training, 48, 69-84.

Green, G., \& Ballard, G. H. (2010). No substitute for experience: Transforming teacher preparation with experiential and adult learning practices. SRATE Journal, 20, 1220.

Green, S. B., \& Salkind, N. J. (2008). Using SPSS for Windows and Macintosh: Analyzing and understanding data. Upper Saddle River, NJ: Pearson. 
Gregoire, M. B., Lafferty, L. J., \& Dowling, R. A. (2006). Teaching foodservice management: A critical component in dietetics education. Topics in Clinical Nutrition, 21, 182-189.

Gregoire, M. B., Sames, K., Dowling, R. A., \& Lafferty, L. J. (2005). Are registered dietitians adequately prepared to be hospital foodservice directors? Journal of the American Dietetic Association, 105, 1215-1221.

Guyer, L. K., Roht, R. R., Probart, C. K., \& Bobroff, L. B. (1993). Broadening the scope of dietetic practice through research. Topics in Clinical Nutrition, 8, 26-32.

Hand, R. K. (2014). Research in nutrition and dietetics: What can the Academy do for you? Journal of the Academy of Nutrition and Dietetics, 114, 131-135.

Harrison, J. A., Brady, A. M., \& Kulinskaya, E. (2001). The involvement, understanding and attitudes of dietitians towards research and audit. Journal Human Nutrition and Dietetics, 14, 319-330.

Hays, J. E., \& Peterson, C. A. (2003). Use of an outcomes research collaborative training curriculum to enhance entry-level dietitians' and established professionals' selfreported understanding of research. Journal of the American Dietetic Association, $103,77-84$.

Hooker, R. S., Williams, J. H., Papneja, J., Sen, N. \& Hogan, P. (2012). Dietetics supply and demand. Journal of the Academy of Nutrition and Dietetics, 112, S75-S91.

Howard, A. J., Ferguson, M., Wilkinson, P., \& Campbell, K. L. (2013). Involvement in research activities and factors influencing research capacity among dietitians. Journal of Human Nutrition and Dietetics, 26, 180-187.

Huba, M. E. \& Freed, J. E. (2000). Learner-centered assessments on college campuses: Shifting the focus from teaching to learning. Needham Heights, MA: Allyn and Bacon.

Hynak-Hankinson, M. T., Martin, S., \& Wirth, J. (1997). Research competencies in the dietetics curricula. Journal of the American Dietetic Association, 97, S102-S106.

Jackson, M. J., Gallis, H. A., Gilman, S. C., Grossman, M., Holzman, G. B., Marquis, D., $\&$ Trusky, S. K. (2007). The need for specialty curricula based on core competencies: A white paper of the conjoint committee on continuing medication education. Journal of Continuing Education in the Health Professions, 27, 124128.

Joplin, L. (1981). On defining experiential education. Journal of Experiential Education, 4, 17-20. 
Kicklighter, J. R., Cluskey, M. M., Hunter, A. M., Nyland, N. K., \& Spear, B. A. (2013). Council on future practice visioning report and consensus agreement for moving forward the continuum of dietetics education, credentialing, and practice. Journal of the Academy of Nutrition and Dietetics, 113(12), 1710-1732.

King, C. (2013). Comparison of educational interventions on registered dietitians' research outcome constructs. (Doctoral dissertation). Retrieved from ProQuest Dissertations and Theses databases (UMI No. 3537375).

King, C., Byham-Gray, L., 'OSullivan Maillet, J., Parrott, J. S., Splett, P., \& Roberts, M. M. (2014). Dietitians and research: Facilitating involvement: History of dietitian involvement in dietetics research in the U.S. Topics in Clinical Nutrition, 29, 227238.

Knoblock-Hahn, A. L., Scharff, D. P., \& Elliott, M. (2010). Cultural competence in dietetics education: Where are we now and where do we need to go? Topics in Clinical Nutrition, 24, 323-334.

Kolb, D. A. (1984). Experiential learning: Experience as the source of learning and development. Englewood Cliffs, NJ: Prentice-Hall.

Langholz, E. P. (1982). The President's page. Journal of the American Dietetic Association, 80, 163.

Levine, R. B., Hebert, R. S., \& Wright, S. M. (2005). Resident research and scholarly activity in internal medicine residency training programs. Journal of General Internal Medicine, 21, 155-159.

Lordly, D. (2007). Performance issues of dietetic interns: A dietetic educator's perspective. Perspectives in Practice, 688, 36-40.

Lurie, S. J., Mooney, C. J., \& Lyness, J. M. (2009). Measurement of the general competencies of the accreditation council for graduate medical education: A systematic review. Academic Medicine, 84, 301-309.

Manore, M. M., \& Myers, E. F. (2003). Research and the dietetics profession: Making a bigger impact. Journal of the American Dietetic Association,103, 108-112.

Markowitsch, J., \& Luomi-Messerer, K. (2008). Putting Dreyfus into action: The European credit transfer system. Journal of European Industrial Training, 32, 171-186.

Mazurkewicz, M., Harder, A., \& Roberts, T. G. (2012). Evidence for experiential learning in undergraduate teaching farm courses. Journal of Agricultural Education, 53, 176-189. 
Merriam, S. B. (2009). Qualitative research a guide to design and implementation. San Francisco, CA: Jossey-Bass.

Mertler, C. A., \& Vannatta, R. A. (2005). Advanced and multivariate statistical methods $\left(3^{\text {rd }}\right.$ ed.): Practical applications and interpretations. Glendale, CA: Pyrczak Publishing.

Meyer-Adams, N., Potts, M. K., Koob, J. J., Dorsey, C. J., \& Rosales, A. M. (2011). How to tackle the shift of educational assessment from learning outcomes to competencies: One program's transition. Journal of Social Work Education, 47, 489-507.

Morley-Hauchecorne, C., \& Lepatourel, J. A. (2000). Self-perceived competence of clinical dietitians to participate in research: A needs assessment. Canadian Journal of Dietetic Practice and Research, 61, 6-12.

Muffo, J. A. (2001). Assessing student competence in engineering. In C. Palomba \& T. Banta (Eds.), Assessing student competence in accredited disciplines (pp. 159176). Sterling, VA: Stylus.

Nasca, T. J., Philbert, I., Brigham, T., \& Flynn, T. (2012). The next GME accreditation system: Rationale and benefits. New England Journal of Medicine, 366, 10511056.

Nyland, N., K., Spears, M. C. \& Meyers, E. F. (1989). Activities of coordinated dietetic program directors compared by educational background. Journal of the American Dietetic Association, 89, 1822-1826.

Ogrinc, G., Headrick, L. A., Mutha, S., Coleman, M. T., O’Donnell, J., \& Miles, P. V. (2003). A framework for teaching medical students and residents about practicebased learning and improvement, synthesized from a literature review. Academic Medicine, 78, 748-756.

Palomba, C. A., \& Banta, T. W. (2001). Assessing Student Competence in Accredited Disciplines. Sterling, VA: Stylus.

Pavlinac, J. M. (2010). Know and use ADA's evidence-based practice resources. Journal of the American Dietetic Association, 110, 17.

Payne-Palacio, J., \& Canter, D. D. (1996). The profession of dietetics: A team approach. Englewood Cliffs, NJ: Prentice-Hall.

Penumetcha, M., McCarroll, C., \& Smith S. C. (2012). Use of food frequency questionnaire to fulfill the research competency requirement for dietetic students. Journal of Allied Health, 41, e21-e25. 
Peterson, C. A., Hays-Kimmons, J. E., \& Cole, J. S. (2008). Short-term effectiveness of an outcomes research training curriculum within a coordinated program. Journal of the American Dietetic Association, 108, 120-124.

Rebovich, E. J., Wodarski, L. A., Hurley, R. S., Rasor-Greenhalgh, S., \& Stombaugh, I. (1994). A university-community model for the integration of nutrition research, practice, and education. Journal of the American Dietetic Association, 94, 179182.

Reddy, P., \& Hill, R. (2002). Learning outcomes and assessment strategies for a psychology sandwich placement year. Psychology Teaching Review, 10, 102-111.

Rinke, W. J., \& Berry, M. W. (1987). Integrating research into clinical practice: A model and call for action. Journal of the American Dietetic Association, 87,159-161.

Roberts, T. G. (2006). A philosophical examination of experiential learning theory for agricultural educators. Journal of Agricultural Education, 47, 17-29.

Rogers, D. (2009). Report on the American Dietetic Association/Commission on Dietetic Registration 2008 Needs Assessment. Journal of the American Dietetic Association, 109, 1283-1293.

Schiller, M. R. (1988). Research activities and interests of dietitians. Journal of Parenteral and Enteral Nutrition, 12, 1-7.

Schiller, M. R. (1992). Research development, progress, and expansion. Nutrition in Clinical Practice, 7, S15-S17.

Schiller, M. R., Rudge, S. J., \& Ballinger, P. W. (1988). Research activities and interests of dietetic educators. Journal of the American Dietetic Association, 88, 10701075.

Shafer, K., J., \& Knous, B. L. (2001). A longitudinal study of cognitive and affective behavior in didactic program in dietetics: Implications for dietetics education. Journal of the American Dietetic Association, 101, 1051-1054.

Simons, L., Fehr, L., Blank, N., Connell, H., Georganas, D., Fernandez, D., \& Peterson, V. (2012). Lessons learned from experiential learning: What do students learn from a practicum/internship. International Journal of Teaching and Learning in Higher Education, 24, 325-334.

Sims, L. S. \& Simko, M. D. (1988). Applying research methods in nutrition and dietetics: Embodiment of the profession's backbone. Journal of the American Dietetic Association, 88, 1045-1046. 
Skipper, A., \& Lewis, N. M. (2005). A look at the educational preparation of the healthdiagnosing and treating professions: Do dietitians measure up? Journal of the American Dietetic Association, 105, 420-427.

Slawson, D. L., Clemens, L. H., \& Bol, L. (2000). Research and the clinical dietitian: Perceptions of the research process and preferred routes to obtaining research skills. Journal of the American Dietetic Association, 100, 1144-1148.

Smith, R. (2003). Expanding medical nutrition therapy: An argument for evidence-based practices. Journal of the American Dietetic Association, 103, 313-314.

Smith, T. L. (2001). Research across the curriculum (RAC): Integration of research into 3 undergraduate foods courses. Journal of the American Dietetic Association, 101, 1470-1472.

Smitherman, A. L., \& Wyse, B. N. (1987). President's Page: The backbone of our profession. Journal of the American Dietetic Association, 87, 1394-1396.

Snyder, C. (2012). Finding the "royal road" to learning to teach: Listening to novice teacher voices in order to improve the effectiveness of teacher education. Teacher Education Quarterly, 38, 33-53.

Solomon, S. S., Tom, S. C., Pichert, J., Wasserman, D. \& Powers, A. C. (2003). Impact of medical student research in the development of physician-scientists. Journal of Investigative Medicine, 51, 149-156.

Steiber, A., \& Barkoukis, H. (2006). Individualized research experience in a dietetic internship program. Topics in Clinical Nutrition, 21, 176-181.

Stichman, A. J., \& Farkas, M. A. (2005). The pedagogical use of internships in criminal justice programs: A nation-wide study. Journal of Criminal Justice Education, 16, 145-165.

Sullivan, B. J., Schiller, M. R., \& Horvath, M. C. (1990). Journal of the American Dietetic Association, 90, 1418-1422.

Taylor, M. A. (1998). Evidence-base practice: Are dietitians willing and able? Journal of human Nutrition and Dietetics, 11, 461-472.

Thomas, A., Saroyan, A., \& Dauphinee, W. D. (2011). Evidence-based practice: A review of theoretical assumptions and effectiveness of teaching and assessment interventions in health professions. Advances in Health Sciences Education, 16, 253276.

Vaughan, L. (2003). Research and the dietetics profession: Initiating undergraduate students into the culture of research. Journal of the American Dietetic Association, 103, 815-816. 
Vogt,W.P. (2007). Quantitative research methods for professionals. Boston, MA: Allyn and Bacon.

Waller, K. V., Jordan, L., Giehart, J., Brodnik, M. P., Schiller, M. R., Flanigan, K. S., . . . \& Ballinger, P. W. (1988). Research skills and the research environment: A needs assessment of allied health faculty. Journal of Allied Health, 17, 101-113.

Ward, B. (2012). Compensation and benefits survey 2011: Moderate growth in registered dietitian and dietetic technician, registered, compensation in the past 2 years. Journal of the American Dietetic Association, 112, 29-40.

Ward, B., Rogers, D., Mueller, C., Touger-Decker, R., \& Sauer, K. L. (2011). Entry-level dietetics practice today: Results from the 2010 Commission on Dietetic Registration entry-level dietetics practice audit. Journal of the American Dietetic Association, 111, 914-941.

Wenberg, B. G., Ingersoll, R. W., \& Dohner, C. W. (1969). Evaluation of dietetic interns. Journal of the American Dietetic Association, 54, 297-301.

Whelan, K., Madden, A. M, \& Thomas, J. E. (2007a). Student dietitians' attitudes towards research and audit: A comparison with registered dietitians. Journal Human Nutrition and Dietetics, 20, 121-125.

Whelan, K., Thomas, J. E., \& Madden, A. M. (2007b). Student research projects: The experiences of student dietitians, university faculty members, and collaborators. Journal of the American Dietetic Association, 107, 1567-1574.

Whelan, K., \& Markless, S. (2012). Factors that influence research involvement among registered dietitians working as university faculty: A qualitative interview study. Journal of the Academy of Nutrition and Dietetics, 102, 1021-1028.

Whelan, K., Copeland, E., Oladitan, L., Murrells, T., \& Gandy, J. (2013). Development and validation of a questionnaire to measure research involvement among registered dietitians. Journal of the Academy of Nutrition and Dietetics, 113, 563568.

Wood, O. (1993). Using role delineation data to design dietetics education curriculums. Journal of the American Dietetic Association, 93, 907-908.

Wylie-Rosett, J., Wheeler, M., Krueger, K., \& Halford, B. (1990). Opportunities for research-oriented dietitians. Journal of the American Dietetic Association, 90, 1531-1534.

Yates, M. S., Drewery, S., \& Murdoch-Eaton, D. G. (2002). Alternative learning environments: What do they contribute to professional development of medical students? Medical Teacher, 24, 609-615. 


\section{APPENDIX A}

\section{INFORMED CONSENT}

Introduction: You are being asked to participate in a research study. The purpose of this study is to assess the ACEND-required research competency within dietetic internship programs.

\section{What is involved in the study?}

- Participants will complete an anonymous survey, which will take approximately 15-20 minutes.

\section{What are the risks of participating in the study?}

- There are minimal risks associated with this study.

- Participants may feel uncomfortable answering some questions, but they will have the option to skip questions or withdraw from the study at any time.

\section{What are the benefits of participating in the study?}

- We hope to gather information that may help dietetic educators make curricular decisions that better align with the overall goals of the profession.

\section{What about confidentiality?}

- All reasonable efforts will be made to keep your personal information confidential.

- No identifying information will be collected and all data will be reported as aggregates.

- Raw data will be stored in a locked office and destroyed upon completion of the study.

\section{What are the costs?}

- There are no costs for participation in this study.

\section{What are my rights?}

- Taking part in this study is voluntary. You may choose not to take part or you may

leave the study at any time.

- Your decision to participate or not to participate will have no effect on your position. 
Who should I call with questions or problems regarding this study?

- Questions about this study may be directed to the researcher, Amanda Newell, MS, RDN ( ) or the research advisor in charge of this study, Dr. Wendy Troxel (wgtroxe@ilstu.edu or 309-438-8575).

- This study has been approved by the IRB at Illinois State University and by the Committee on the Use of Human Subjects in Research (CUHSR) at Bradley University. If you have general questions about being a research participant, you may contact:

- Illinois State University's Research Ethics \& Compliance Office at 309438-2529.

- Bradley University's CUSHR office at 309-677-3877.

\section{Documentation of informed consent}

You are voluntarily making a decision to participate in this study. Participants must be at least 18 years of age. Clicking "yes" below means that you have read and understand the information presented and have decided to participate. If you think of any additional questions during the study, please contact the researchers.

Thank you! We greatly appreciate your insight!

_Yes, I have read the information above and agree to participate in this study.

_No, I do not agree to participate in this study. 


\section{APPENDIX B}

\section{SURVEY}

Please select the answer that most closely matches your perspective and opinion.

\section{Section 1}

1. What is your interpretation of ACENDs Core Competency CRD 1.5, which reads "conduct projects using appropriate research methods, ethical procedures and data analysis"? Please describe the concept in your own words and without consulting any document or (re)source.

2. Which of the following best describes your interpretation of ACENDs Core Competency CRD 1.5, which reads "conduct projects using appropriate research methods, ethical procedures and data analysis"?

- Interns must be familiar with the basic concepts of research, but do not need to be able to conduct an original research project.

- Interns must be able to conduct components of a research project, but do not have to complete an original research project. For instance, interns may complete a literature review, but may not formulate research questions or a hypothesis.

- Interns must be able to conduct a complete, original research project, which includes systematically testing research questions, a hypothesis, or a theory in order to discover new information.

3. What specific experience(s) within your DI curriculum do you have aligned with ACENDs Core Competency CRD 1.5, which reads "conduct projects using appropriate research methods, ethical procedures and data analysis"? You may need to refer to your curriculum matrix. Please be as specific as possible and please limit your answer to only those that are used to meet this specific competency. 
4. Which of the following are required component(s) for the experience(s) that are aligned with ACENDs Core Competency CRD 1.5, which reads "conduct projects using appropriate research methods, ethical procedures and data analysis"? Please limit your answer to only those that are used to meet this specific competency. (Select all that apply)

- Analysis of data

- Collection of data

○ Completion of ethics tutorials

- Completion of IRB protocol

○ Completion of the Academy's Online Research Toolkit

- Critical evaluation of research articles

- Design of research protocol

- Formulation of research questions/hypothesis

- Presentation of an original research paper/report

- Production of a literature review

- Production of an original research paper/report

O Others (please specify below)

\section{Section 2}

How much are you involved in the following activities?

\begin{tabular}{|l|l|l|l|l|l|l|}
\hline 1 & $\begin{array}{l}\text { Interpreting basic aspects of data analysis (e.g. } \\
\text { means, medians, standard deviations, t-tests, P- } \\
\text { values) when reading journal articles }\end{array}$ & $\begin{array}{l}\text { Not } \\
\text { at all }\end{array}$ & $\begin{array}{l}\text { A } \\
\text { little }\end{array}$ & $\begin{array}{l}\text { Quite } \\
\text { a bit }\end{array}$ & $\begin{array}{l}\text { A } \\
\text { lot }\end{array}$ & $\begin{array}{l}\text { A great } \\
\text { deal }\end{array}$ \\
\hline 2 & $\begin{array}{l}\text { External presentation (e.g. national/international } \\
\text { conferences or publications in peer-reviewed } \\
\text { journals) of results from research projects that you } \\
\text { have led. }\end{array}$ & $\begin{array}{l}\text { Not } \\
\text { at all }\end{array}$ & $\begin{array}{l}\text { A } \\
\text { little }\end{array}$ & $\begin{array}{l}\text { Quite } \\
\text { a bit }\end{array}$ & $\begin{array}{l}\text { A } \\
\text { lot }\end{array}$ & $\begin{array}{l}\text { A great } \\
\text { deal }\end{array}$ \\
\hline 3 & $\begin{array}{l}\text { Participating in research as part of a collaborative } \\
\text { team. }\end{array}$ & $\begin{array}{l}\text { Not } \\
\text { at all }\end{array}$ & $\begin{array}{l}\text { A } \\
\text { little }\end{array}$ & $\begin{array}{l}\text { Quite } \\
\text { a bit }\end{array}$ & $\begin{array}{l}\text { A } \\
\text { lot }\end{array}$ & $\begin{array}{l}\text { A great } \\
\text { deal }\end{array}$ \\
\hline
\end{tabular}




\begin{tabular}{|c|c|c|c|c|c|c|}
\hline 4 & $\begin{array}{l}\text { Using the literature to identify what research } \\
\text { studies still need to be conducted within general } \\
\text { areas. }\end{array}$ & $\begin{array}{l}\text { Not } \\
\text { at all }\end{array}$ & $\begin{array}{l}\text { A } \\
\text { little }\end{array}$ & $\begin{array}{l}\text { Quite } \\
\text { a bit }\end{array}$ & $\begin{array}{l}\text { A } \\
\text { lot }\end{array}$ & $\begin{array}{l}\text { A great } \\
\text { deal }\end{array}$ \\
\hline 5 & $\begin{array}{l}\text { Developing the research budget and subsequently } \\
\text { managing funding, staffing and time management } \\
\text { issues for a research project. }\end{array}$ & $\begin{array}{l}\text { Not } \\
\text { at all }\end{array}$ & $\begin{array}{l}\text { A } \\
\text { little }\end{array}$ & $\begin{array}{l}\text { Quite } \\
\text { a bit }\end{array}$ & $\begin{array}{l}\text { A } \\
\text { lot }\end{array}$ & $\begin{array}{l}\text { A great } \\
\text { deal }\end{array}$ \\
\hline 6 & $\begin{array}{l}\text { Educating colleagues in research methodology } \\
\text { and methods (This does not include supervising a } \\
\text { BS/MS student project). }\end{array}$ & $\begin{array}{l}\text { Not } \\
\text { at all }\end{array}$ & $\begin{array}{l}\text { A } \\
\text { little }\end{array}$ & $\begin{array}{l}\text { Quite } \\
\text { a bit }\end{array}$ & $\begin{array}{l}\text { A } \\
\text { lot }\end{array}$ & $\begin{array}{l}\text { A great } \\
\text { deal }\end{array}$ \\
\hline 7 & $\begin{array}{l}\text { Appreciating the ethical framework in which } \\
\text { research should be conducted. }\end{array}$ & $\begin{array}{l}\text { Not } \\
\text { at all }\end{array}$ & $\begin{array}{l}\text { A } \\
\text { little }\end{array}$ & $\begin{array}{l}\text { Quite } \\
\text { a bit }\end{array}$ & $\begin{array}{l}\text { A } \\
\text { lot }\end{array}$ & $\begin{array}{l}\text { A great } \\
\text { deal }\end{array}$ \\
\hline 8 & $\begin{array}{l}\text { Extensively involved in reviewing the research of } \\
\text { others (e.g. peer review of manuscripts for } \\
\text { journals and reviewing grant applications). }\end{array}$ & $\begin{array}{l}\text { Not } \\
\text { at all }\end{array}$ & $\begin{array}{l}\text { A } \\
\text { little }\end{array}$ & $\begin{array}{l}\text { Quite } \\
\text { a bit }\end{array}$ & $\begin{array}{l}\text { A } \\
\text { lot }\end{array}$ & $\begin{array}{l}\text { A great } \\
\text { deal }\end{array}$ \\
\hline 9 & $\begin{array}{l}\text { Applying for approval from research ethics and } \\
\text { R\&D departments, and managing projects in line } \\
\text { with research governance frameworks. }\end{array}$ & $\begin{array}{l}\text { Not } \\
\text { at all }\end{array}$ & $\begin{array}{l}\text { A } \\
\text { little }\end{array}$ & $\begin{array}{l}\text { Quite } \\
\text { a bit }\end{array}$ & $\begin{array}{l}\text { A } \\
\text { lot }\end{array}$ & $\begin{array}{l}\text { A great } \\
\text { deal }\end{array}$ \\
\hline 10 & $\begin{array}{l}\text { Understanding and interpreting advanced data } \\
\text { analysis (e.g. correlation, meta-analysis, } \\
\text { qualitative data analysis) when reading journal } \\
\text { articles. }\end{array}$ & $\begin{array}{l}\text { Not } \\
\text { at all }\end{array}$ & $\begin{array}{l}\text { A } \\
\text { little }\end{array}$ & $\begin{array}{l}\text { Quite } \\
\text { a bit }\end{array}$ & $\begin{array}{l}\text { A } \\
\text { lot }\end{array}$ & $\begin{array}{l}\text { A great } \\
\text { deal }\end{array}$ \\
\hline 11 & $\begin{array}{l}\text { Participating in research under the supervision or } \\
\text { mentorship of colleagues. }\end{array}$ & $\begin{array}{l}\text { Not } \\
\text { at all }\end{array}$ & $\begin{array}{l}\text { A } \\
\text { little }\end{array}$ & $\begin{array}{l}\text { Quite } \\
\text { a bit }\end{array}$ & $\begin{array}{l}\text { A } \\
\text { lot }\end{array}$ & $\begin{array}{l}\text { A great } \\
\text { deal }\end{array}$ \\
\hline 12 & $\begin{array}{l}\text { Critically appraising aspects of research methods } \\
\text { when reading journal articles. This includes } \\
\text { understanding the appropriate use of different } \\
\text { study designs (e.g. randomized controlled trial, } \\
\text { case-control study, focus group etc.) }\end{array}$ & $\begin{array}{l}\text { Not } \\
\text { at all }\end{array}$ & $\begin{array}{l}\text { A } \\
\text { little }\end{array}$ & $\begin{array}{l}\text { Quite } \\
\text { a bit }\end{array}$ & $\begin{array}{l}\text { A } \\
\text { lot }\end{array}$ & $\begin{array}{l}\text { A great } \\
\text { deal }\end{array}$ \\
\hline 13 & $\begin{array}{l}\text { Undertaking comprehensive literature searches } \\
\text { using electronic databases (e.g. Medline) in order } \\
\text { to inform your practice. }\end{array}$ & $\begin{array}{l}\text { Not } \\
\text { at all }\end{array}$ & $\begin{array}{l}\text { A } \\
\text { little }\end{array}$ & $\begin{array}{l}\text { Quite } \\
\text { a bit }\end{array}$ & $\begin{array}{l}\text { A } \\
\text { lot }\end{array}$ & $\begin{array}{l}\text { A great } \\
\text { deal }\end{array}$ \\
\hline 14 & $\begin{array}{l}\text { Developing and leading programs of research (i.e. } \\
\text { a planned series of projects designed to answer } \\
\text { research questions within a particular area). }\end{array}$ & $\begin{array}{l}\text { Not } \\
\text { at all }\end{array}$ & $\begin{array}{l}\text { A } \\
\text { little }\end{array}$ & $\begin{array}{l}\text { Quite } \\
\text { a bit }\end{array}$ & $\begin{array}{l}\text { A } \\
\text { lot }\end{array}$ & $\begin{array}{l}\text { A great } \\
\text { deal }\end{array}$ \\
\hline 15 & $\begin{array}{l}\text { Leading the development and design of a research } \\
\text { protocol following an appropriate literature } \\
\text { review, including identifying appropriate research } \\
\text { methods and statistical analyses. }\end{array}$ & $\begin{array}{l}\text { Not } \\
\text { at all }\end{array}$ & $\begin{array}{l}\text { A } \\
\text { little }\end{array}$ & $\begin{array}{l}\text { Quite } \\
\text { a bit }\end{array}$ & $\begin{array}{l}\text { A } \\
\text { lot }\end{array}$ & $\begin{array}{l}\text { A great } \\
\text { deal }\end{array}$ \\
\hline 16 & $\begin{array}{l}\text { Internal presentation (e.g. to other healthcare } \\
\text { professionals or scientists) of results from } \\
\text { research projects in which you have been } \\
\text { involved. }\end{array}$ & $\begin{array}{l}\text { Not } \\
\text { at all }\end{array}$ & $\begin{array}{l}\text { A } \\
\text { little }\end{array}$ & $\begin{array}{l}\text { Quite } \\
\text { a bit }\end{array}$ & $\begin{array}{l}\text { A } \\
\text { lot }\end{array}$ & $\begin{array}{l}\text { A great } \\
\text { deal }\end{array}$ \\
\hline 17 & $\begin{array}{l}\text { Independently formulating research questions or } \\
\text { hypotheses within your area of practice. }\end{array}$ & $\begin{array}{l}\text { Not } \\
\text { at all }\end{array}$ & $\begin{array}{l}\text { A } \\
\text { little }\end{array}$ & $\begin{array}{l}\text { Quite } \\
\text { a bit }\end{array}$ & $\begin{array}{l}\text { A } \\
\text { lot }\end{array}$ & $\begin{array}{l}\text { A great } \\
\text { deal }\end{array}$ \\
\hline 18 & $\begin{array}{l}\text { Supervising and mentoring colleagues to } \\
\text { undertake research (This does not include } \\
\text { supervising a BS/MS student project, but could } \\
\text { include supervising a PhD project) }\end{array}$ & $\begin{array}{l}\text { Not } \\
\text { at all }\end{array}$ & $\begin{array}{l}\text { A } \\
\text { little }\end{array}$ & $\begin{array}{l}\text { Quite } \\
\text { a bit }\end{array}$ & $\begin{array}{l}\text { A } \\
\text { lot }\end{array}$ & $\begin{array}{l}\text { A great } \\
\text { deal }\end{array}$ \\
\hline
\end{tabular}




\begin{tabular}{|c|c|c|c|c|c|c|}
\hline 19 & $\begin{array}{l}\text { Influencing the research of others through active } \\
\text { participation in research-related committees or } \\
\text { external organizations (e.g. Research Ethics } \\
\text { Committee, Research Council). }\end{array}$ & $\begin{array}{l}\text { Not } \\
\text { at all }\end{array}$ & $\begin{array}{l}\text { A } \\
\text { little }\end{array}$ & $\begin{array}{l}\text { Quite } \\
\text { a bit }\end{array}$ & $\begin{array}{l}\text { A } \\
\text { lot }\end{array}$ & $\begin{array}{l}\text { A great } \\
\text { deal }\end{array}$ \\
\hline 20 & $\begin{array}{l}\text { Undertaking research as a major component of } \\
\text { your current job description. }\end{array}$ & $\begin{array}{l}\text { Not } \\
\text { at all }\end{array}$ & $\begin{array}{l}\text { A } \\
\text { little }\end{array}$ & $\begin{array}{l}\text { Quite } \\
\text { a bit }\end{array}$ & $\begin{array}{l}\text { A } \\
\text { lot }\end{array}$ & $\begin{array}{l}\text { A great } \\
\text { deal }\end{array}$ \\
\hline 21 & $\begin{array}{l}\text { Using the literature and your experience to } \\
\text { identify what research studies still need to be } \\
\text { conducted within your area of interest. }\end{array}$ & $\begin{array}{l}\text { Not } \\
\text { at all }\end{array}$ & $\begin{array}{l}\text { A } \\
\text { little }\end{array}$ & $\begin{array}{l}\text { Quite } \\
\text { a bit }\end{array}$ & $\begin{array}{l}\text { A } \\
\text { lot }\end{array}$ & $\begin{array}{l}\text { A great } \\
\text { deal }\end{array}$ \\
\hline 22 & $\begin{array}{l}\text { Participating in the review of the research of } \\
\text { others (e.g. peer review of manuscripts for a } \\
\text { journal). }\end{array}$ & $\begin{array}{l}\text { Not } \\
\text { at all }\end{array}$ & $\begin{array}{l}\text { A } \\
\text { little }\end{array}$ & $\begin{array}{l}\text { Quite } \\
\text { a bit }\end{array}$ & $\begin{array}{l}\text { A } \\
\text { lot }\end{array}$ & $\begin{array}{l}\text { A great } \\
\text { deal }\end{array}$ \\
\hline 23 & $\begin{array}{l}\text { External presentation (e.g. at conferences or in a } \\
\text { journal article) of results from research projects in } \\
\text { which you have been involved. }\end{array}$ & $\begin{array}{l}\text { Not } \\
\text { at all }\end{array}$ & $\begin{array}{l}\text { A } \\
\text { little }\end{array}$ & $\begin{array}{l}\text { Quite } \\
\text { a bit }\end{array}$ & $\begin{array}{l}\text { A } \\
\text { lot }\end{array}$ & $\begin{array}{l}\text { A great } \\
\text { deal }\end{array}$ \\
\hline 24 & $\begin{array}{l}\text { Using the findings from journal articles/original } \\
\text { research studies when making decisions within } \\
\text { your area of practice. }\end{array}$ & $\begin{array}{l}\text { Not } \\
\text { at all }\end{array}$ & $\begin{array}{l}\text { A } \\
\text { little }\end{array}$ & $\begin{array}{l}\text { Quite } \\
\text { a bit }\end{array}$ & $\begin{array}{l}\text { A } \\
\text { lot }\end{array}$ & $\begin{array}{l}\text { A great } \\
\text { deal }\end{array}$ \\
\hline
\end{tabular}

\section{Section 3}

\section{Sex}

○ Female

- Male

- Choose not to respond

2. Age
○ Less than 25 years old
- 25-35 years old
○ 36-45 years old
○ 46-55 years old
- 56-65 years old
- Greater than 65 years old

\section{Race or ethnicity}
- African American
- Asian or Pacific Islander
- Asian Indian or South Asian
- Biracial/Multiracial
- Caucasian
- Latino
- Native American
- Another racial identity 
4. Highest level of education

- Master's degree

- Working towards doctoral degree

○ $\mathrm{PhD}$

O EdD

$\circ$ Other

5. Have you had any formal education (i.e. undergraduate, graduate, dietetic internship) in how to conduct research? Examples might include research/statistics courses, ethics/IRB training, or completion of a graded research project.

O Yes

○ No

Please describe below.

6. Have you completed a master's thesis?
○ Yes
○ No
In progress

7. Have you completed a doctoral dissertation?
○ Yes
○ No
$\bigcirc$ In progress

8. Have you had any additional training besides your formal education (i.e. undergraduate, graduate, dietetic internship) in how to conduct research? Examples of additional training might include taking additional research/statistics courses, working closely with a research expert, attending continuing education sessions on research, or utilizing resources from the Academy of Nutrition and Dietetics or from other professional organizations. If you select yes, please describe your additional training in the box below.

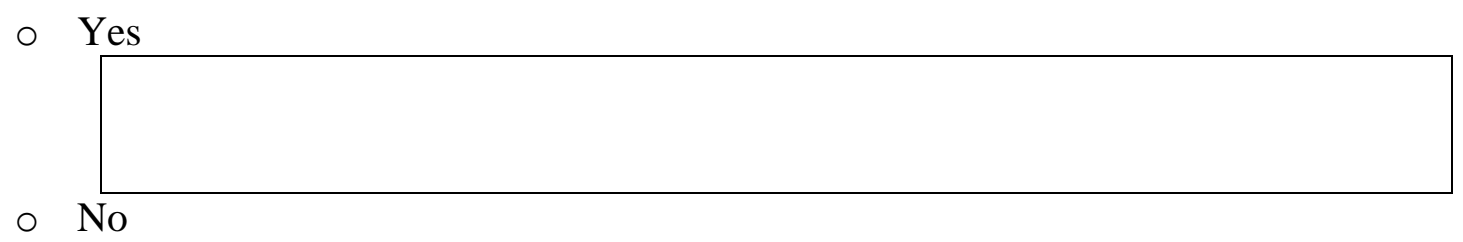

9. Have you been an author or co-author on a published, research-based article?

$\begin{array}{ll}\circ & \text { Yes } \\ \circ & \text { No }\end{array}$ 
10. Please select at what point you have worked on a research project. (Select all that apply)

- Undergraduate research project

- Dietetic internship research project

- Master's non-thesis research project

- Master's thesis

- Doctoral dissertation

- Professional research project for job

- Other research experience

- No research experience

11. How often do you spend time reading professional journals?
- Never
O Once a year
- Once every 6 months
- Once every 3 months
- Once a month
- Bimonthly
○ Weekly
○ Daily

12. When was the last time you read a peer-reviewed research article?
- Over 6 months ago
- 2-6 months ago
○ 1 month ago
- 2 weeks ago
○ Last week
○ This week

13. How many years have you been a dietitian?
○ 3-5 years
○ 6-10 years
○ 11-15 years
o 16-20 years
- 21-25 years
○ More than 25 years

14. How long have you been a dietetic internship director?
○ 0 -2 years
○ 3-5 years
○ 6-10 years
○ 11-15 years
○ 16-20 years
○ 21-25 years
○ More than 25 years 
15. How many research projects have you worked on within a group?
○ 0
○ $1-5$
○ 6-10
○ 11-20
- More than 20

16. How many research projects have you been solely responsible for?
$\circ 0$
○ $1-5$
○ 6-10
○ $11-20$
- More than 20

17. Are you involved in research in your current position? If you select yes, please describe your role below.

$\circ \quad$ Yes
. $\mathrm{No}$

18. Were you involved in research in any of your past positions? If you select yes, please describe your role below.

○ Yes

$\circ$ No

19. How confident do you feel about your own research skills?

\begin{tabular}{|l|c|c|c|c|}
\hline & $\begin{array}{c}\text { Not confident } \\
\text { at all }\end{array}$ & $\begin{array}{c}\text { Not very } \\
\text { confident }\end{array}$ & $\begin{array}{c}\text { Somewhat } \\
\text { confident }\end{array}$ & $\begin{array}{c}\text { Very } \\
\text { confident }\end{array}$ \\
\hline $\begin{array}{l}\text { How } \\
\text { confident } \\
\text { do you feel } \\
\text { about your } \\
\text { own } \\
\text { research } \\
\text { skills }\end{array}$ & 0 & 0 & 0 & $\bigcirc$ \\
\hline
\end{tabular}


20. What type of institution is your dietetic internship program housed in?

○ Governmental agency

○ Hospital

$\circ$ Industry

- University

○ University-based hospital

o Other

21. What type of program is your dietetic internship?

- Supervised practice only

- Some master's credit only

- Master's degree only

- Both master's and non-master's tracks

○ Other

22. Does your dietetic internship program offer distance learning?

- Yes, it is exclusively a distance program.

- Yes, we have a distance program and a traditional on-site program.

- No

Thank you so much for your input! We really appreciate it. Please feel free to contact Amanda Newell, MS, RDN, for any additional questions 


\section{APPENDIX C \\ RECRUITMENT EMAIL}

Sent $7 / 30 / 15$

Dear Dietetic Internship Director,

You are being invited to participate in a research study that assesses the ACENDrequired research competency within dietetic internship programs. This study is being conducted by Amanda Newell, MS, RDN, Dietetic Internship Director at Bradley University, who is a Ph.D. candidate in the Higher Education Administration program in the Department of Educational Administration and Foundations at Illinois State University, under the supervision of Dr. Wendy Troxel, Associate Professor.

Participation in this study entails the voluntary completion of an anonymous survey, which will take approximately 15-20 minutes. This electronic survey was developed using Qualtrics Survey Software. The link for the survey is below.

\section{http://bradley.az1.qualtrics.com/SE/?SID=SV_8xncBDqPENJQx9j}

The targeted population for this study is dietetic internship directors, so if you are no longer the program director, please forward this email to the new director, if possible.

This study has been approved by the IRB at Illinois State University and by the Committee on the Use of Human Subjects in Research (CUHSR) at Bradley University. If you have general questions about being a research participant, you may contact:

- Illinois State University's Research Ethics \& Compliance Office at 309-438-2529

- Bradley University's CUSHR office at 309-677-3877

Please feel free to contact the researchers with questions about this study.

- Amanda Newell, MS, RDN at or

- Dr. Wendy Troxel at wgtroxe@ilstu.edu or 309-438-8575

We appreciate your responses, and we hope to gather information that may help dietetic educators make curricular decisions that better align with the overall goals of the profession. Thank you for participating.

Sincerely,

Amanda Newell 


\section{APPENDIX D}

\section{REMINDER EMAIL}

Sent $8 / 6 / 15$ and $8 / 31$ and $9 / 8 / 15$

Dear Dietetic Internship Director,

Last week you were invited to participate in a research study that assesses the ACENDrequired research competency within dietetic internship programs.

If you have completed the survey, thank you!

If you have not had a chance to take the survey yet, we would greatly appreciate your input. Participation in this study entails the voluntary completion of an anonymous survey, which will take approximately 15 minutes. This electronic survey was developed using Qualtrics Survey Software. The link for the survey is below.

\section{http://bradley.az1.qualtrics.com/SE/?SID=SV_8xncBDqPENJQx9j}

The targeted population for this study is dietetic internship directors, so if you are no longer the program director, please forward this email to the new director, if possible.

This study has been approved by the IRB at Illinois State University and by the Committee on the Use of Human Subjects in Research (CUHSR) at Bradley University. If you have general questions about being a research participant, you may contact:

- Illinois State University's Research Ethics \& Compliance Office at 309-438-2529

- Bradley University's CUHSR office at 309-677-3877

Please feel free to contact the researchers with questions about this study.

- Amanda Newell, MS, RDN at

- Dr. Wendy Troxel at wgtroxe@ilstu.edu or 309-438-8575

We appreciate your responses, and we hope to gather information that may help dietetic educators make curricular decisions that better align with the overall goals of the profession. Thank you for participating.

Sincerely,

Amanda Newell, MS, RDN 